\title{
COLLOIDAL STABILITY AND AGGREGATION OF LIGNOCELLULOSIC MATERIALS IN AQUEOUS SUSPENSION: A REVIEW
}

\author{
Martin A. Hubbe and Orlando J. Rojas \\ Aqueous dispersions of lignocellulosic materials are used in such fields \\ as papermaking, pharmaceuticals, and preparation of cellulose-based \\ composites. The present review article considers published literature \\ dealing with the ability of cellulosic particle dispersions (fiber, fines, \\ nanorods, etc.) to either remain well dispersed or to agglomerate in \\ response to changes in the composition of the supporting electrolyte \\ solution. In many respects, the colloidal stability and coagulation of \\ lignocellulosics can be understood in terms of well-known concepts, \\ including effects due to osmotic pressure arising from overlapping \\ electrostatic double layers at the charged surfaces. Details of the \\ morphology and surface properties of lignocellulosic materials give rise \\ to a variety of colloidal behaviors that make them unique. Adjustments in \\ aqueous conditions, including the $\mathrm{pH}$, salt ions (type and valence), \\ polymers (charged or uncharged), and surfactants can be used to control \\ the dispersion stability of cellulose, lignin, or wood-extractive materials to \\ serve a variety of applications.
}

Keywords: Cellulose; Lignocellulose; Dispersions; Suspensions; Coagulation; Flocculation; Colloidal Stability; Zeta potential; Polyelectrolytes; Electrolyte concentration; Dispersions; Lignin; Hemicellulose; Extractives

Contact information: Department of Forest Biomaterials, College of Natural Resources, North Carolina State University, Campus Box 8005, Raleigh, NC 27695-8005; hubbe@ncsu.edu; orlando_rojas@ncsu.edu

\section{INTRODUCTION}

The term "colloidal stability" refers to the state of dispersion of finely divided materials, emulsions, foams, and a variety of other systems in which the behavior is dominated by interfacial and surface forces. An aqueous dispersion of fibers or small particles can be defined as stable if the individual elements mainly remain separated from each other over a given observation time. Otherwise, the dispersion can become destabilized by a number of effects, including the addition of salts or specifically adsorbing polymers or surface active substances. The state of dispersion can be predicted in some situations by evaluating the collective effect of various types of interactions. The subject is especially complex in the case of lignocellulosic materials, due to their complex composition and structure. This article attempts to summarize and discuss reported work related to the colloidal stability and agglomeration of relevant aqueous dispersions, including cellulosic fibers, fibrils on fiber surfaces, water-swollen portions of cellulosic materials, microcrystalline cellulose, and cellulosic nanofibers. Since these materials vary widely in terms of their dimensions, it is worth mentioning that as a general rule of thumb, short-range attraction and repulsion forces in suspensions become 
dominant over gravity and inertia when at least one dimension of the dispersed phase is smaller than about $1 \mu \mathrm{m}$ (Hunter 2001; Hiemenz and Rajagopalan 1997). Though cellulosic fibers themselves usually exceed this size range, the other objects mentioned in the preceding list do not.

Already in the 1940s scientists in the Netherlands and in Russia had developed a quite serviceable theory to account for the rates at which colloidal particles in aqueous solution can be expected to undergo sticking collisions, forming agglomerates, and eventually precipitating out of suspension (Derjaguin and Landau 1941; Verwey and Overbeek 1948). This so-called DLVO theory is based on the net effect of two classes of forces. On the one hand, van der Waals forces, which can be considered as forces of attraction under the conditions to be considered in this article (in some cases they can be repulsive), result primarily from a correlation among permanent, induced, and transient electronic dipoles in facing surfaces, associated with the whirling movements of electrons in their orbitals. The van der Waals forces are treated as additive with electrostatic forces, which result from the interplay between net excess populations of ions that accumulate adjacent to charged surfaces, i.e. "ionic double layers." Such electrostatic forces usually contribute to repulsion between like-charged objects in aqueous suspension. These concepts have served as a foundation underlying most attempts at understanding the colloidal behavior of cellulose, lignin, and related materials.

The outermost molecules on the dispersed phase can be expected to play a dominant role in determining the nature and strength of colloidal forces, which also will depend on the distance between the surfaces. Because hydrogen bonds play such a prominent role relative to the structure and properties of cellulose, it is reasonable to expect hydrogen bonding to affect the relative proportions of different chemical moieties that are exposed at the surface. Ordinarily it might be expected that the presence of polar, hydrogen-bonding $\mathrm{OH}$ groups would impart a water-loving character to a surface. However, as elucidated by Mann and Marrinan (1958), a majority of cellulose's OH groups participate in intra-molecular and inter-chain hydrogen bonding, leaving only a minority that may be available for interactions with an aqueous medium or surrounding materials (Kadla and Gilbert 2000). Thus, despite the presence of three $\mathrm{OH}$ groups per glucopyranose unit in the cellulose chain, cellulose can be expected to show properties that are intermediate between fully hydrophilic and hydrophobic (Biermann et al. 2001). In addition, the relatively hydrophilic polysaccharide components of wood and other cellulosic materials often are at least partly covered up by relatively lower surface energy substances, i.e. lignin and extractives. Conversely, dissociation of carboxylic acid groups associated with hemicellulose, certain extractives, and other components of cellulosic surfaces contributes to negative surface charges. Because of their strong interaction with water, ionic groups at a fiber surface are expected to contribute strongly to its hydrophilic character.

\section{Surface Morphology of Cellulose Materials}

Morphology can profoundly affect colloidal interactions between surfaces. Theories of colloidal interactions, in their most basic form, usually start by assuming that the facing surfaces have idealized, perfect shapes, i.e. two facing smooth slabs, a pair of perfect cylinders, a sphere approaching or being pulled from a planar surface, etc. (see,

Hubbe and Rojas (2008). "Colloidal stability of cellulosics," BioResources 3(4), 1419-1491. 1420 
for instance, Hogg et al. 1966; Israelachvili 1992; Hiemenz and Rajagopalan 1997). For example, the left-hand frame of Fig. 1 depicts one of the idealized situations that is often used to calculate colloidal forces. Although recently it has been possible to prepare both regenerated and native cellulosic surfaces that are fairly smooth on a nanometer scale (Edgar and Gray 2003; Tammelin et al. 2005; Sczech and Riegler 2006; Ahola et al. 2008a; Kontturi et al. 2006), most naturally occurring lignocellulosic materials have surfaces that are rough, porous, and often fibrillated. For instance, the refining of cellulosic fibers, in preparation for their use in the manufacture of paper, can be expected to unravel and partially delaminate the outer layers of a fiber, resulting in fibrils that can extend outwards toward the solution phase (Clark 1985; Neuman et al. 1993; see righthand frame of Fig. 1). Due to the complex structure of most cellulosic surfaces, it even can be difficult to define where the solution phase ends and the solid phase begins. The sizes of fibrils at cellulosic surfaces can range from micrometer dimensions down to macromolecular chains and small bundles of such chains (Neuman et al. 1993; Pelton 1993). Pang and Gray (1998) used atomic force microscopy to show that the conformation of nano-sized fibrils at fiber surfaces from fiber surfaces is controlled by colloidal forces. Thus, the degree of extension of the nano-fibrils outwards from the cellulosic surface decreased with increasing salt concentration (Rutland et al. 1997).
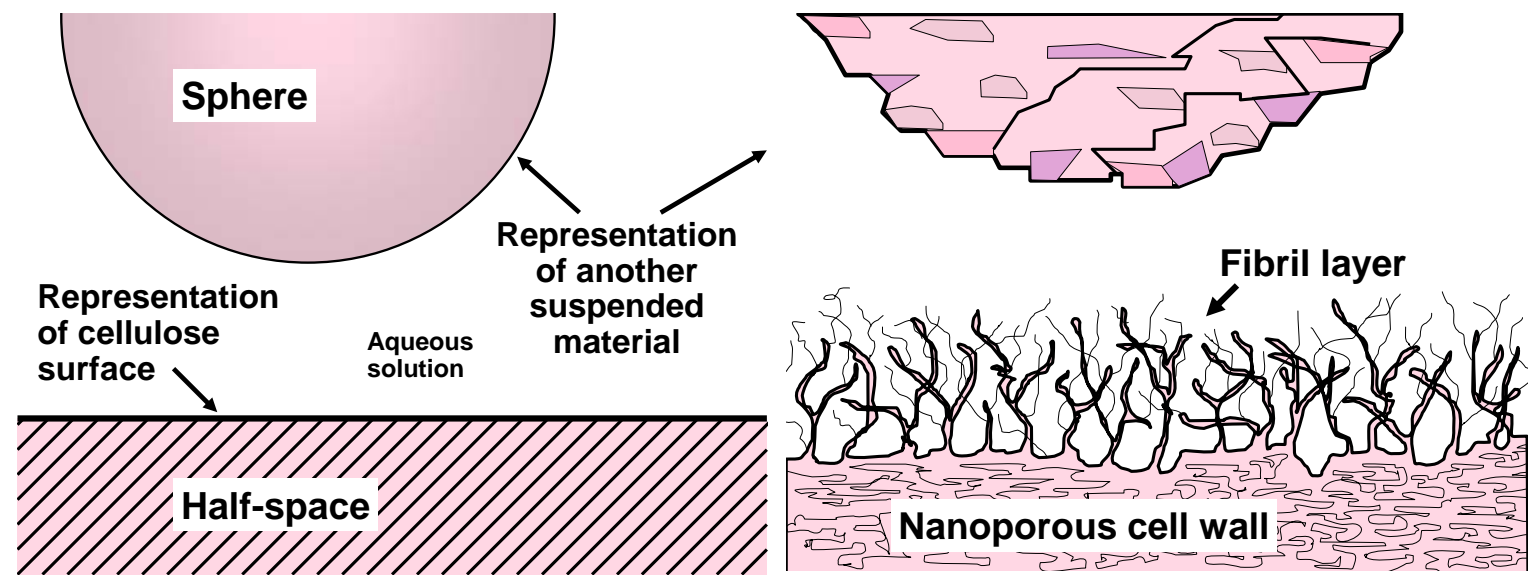

Fig. 1. Representations of (left) an idealized geometry that can be used to estimate short-range interaction forces involving surfaces in aqueous solution, and (right) a reminder that the actual situation is likely to involve porous and rough materials which, in the case of cellulosic surfaces, may involve fibrils and nanofibrils extending towards the solution phase.

Another factor that makes it difficult to actually calculate colloidal forces at wetted cellulose surfaces is porosity. Cellulosic pulp fibers, when they are wet, are highly porous. Typical pore sizes range from about $1 \mathrm{~nm}$ to about $50 \mathrm{~nm}$, depending on the type of pulp, its preparation, the method of analysis, and how the data are interpreted (Stone and Scallan 1968; Deodhar and Luner 1980; Berthold and Salmén 1997; Alince 2002; Andreasson et al. 2003; Zemljic et al. 2008). As will be discussed later, the presence of nano-sized pores helps to explain the tendency of cellulosic materials to swell in water, and also the dependency of such swelling on $\mathrm{pH}$, electrolyte concentration, and other factors (Grignon and Scallan 1980; Scallan 1983; Scallan and Tigerström 1992;

Hubbe and Rojas (2008). "Colloidal stability of cellulosics," BioResources 3(4), 1419-1491. 1421 
Lindström 1992; Salmén and Berthold 1997; Fält and Wågberg 2003; Freudenberg et al. 2007).

Another complication is that the surface area per unit mass (specific surface area) of cellulosic fibers (including tracheids, fibers, and cell elements) is often smaller than the specific surface area of fine particles in the suspension. Due to their relatively high specific surface area (Marton and Marton 1976; Marton 1980a,b; Seth 2003), cellulosic fine materials can be expected to play an important role in colloidal interactions of cellulose-based suspensions.

\section{Chemical Nature of Cellulosic Surfaces}

Cellulose-related surfaces (comparing fibers, tracheids, cell elements, fines, etc.) often have different proportions of cellulose, hemicellulose, lignin, and extractives (Tiberg et al. 2001; Duchesne et al. 2003). The lignin content of natural woody fibers generally is higher towards their outer surface, reaching a maximum in the middle lamella region between the fibers (Fujita and Harada 2000). As demonstrated by Micic et al. (2003), there is reason to think that the organization of lignin and cellulose within natural products is partly a consequence of the molecular attributes and their phase behavior.

\section{Surface composition vs. pulping conditions}

The surface chemical composition of fibers can be expected to change dramatically in response to different pulping methods. At one extreme, lignin-rich fiber surfaces can be expected to result from certain thermomechanical (TMP) pulping conditions. Temperatures during the TMP process often exceed the glass transition point of lignin, which can be as low as 80 to $115^{\circ} \mathrm{C}$ under the wet, pressurized conditions of refining (Back and Salmén 1982; Salmén et al. 1985). As a consequence, the fibers typically separate from each other within the lignin-rich phase, which results in a relatively noncompliant, hydrophobic crust on the fiber surfaces after cooling. The surfaces of highyield pulps tend to be enriched with respect to lignin and extractives (Kleen et al. 2003; Koljonen et al. 2004). Methods for comparing the relative coverage of pulp fibers by extractives and lignin, mainly relying on X-ray photoelectron spectroscopy, have been critically compared (Fardim et al. 2006). Various consequences of natural resins and their decomposition products in various wood pulps have been reviewed (Back and Allen 2000).

At the other extreme, chemical pulping methods, such as the kraft process (Smook 1992), usually are designed to remove lignin from wood and to avoid solubilizing the polysaccharide component. As a consequence, one can expect a higher proportion of hydrophilic components at the resulting fiber surfaces (Suurnäkki et al. 1996), as well as more compliant surfaces in the wet state. However, the degree of selectivity of different pulping and bleaching agents varies over a wide range, and significant amounts of lignin and extractives still may be present on the fiber surfaces in some cases. Stenius and Laine (1994) used X-ray photoelectron spectroscopy (XPS) to demonstrate progressive reductions in surface lignin during kraft pulping. Sjöberg et al. (2004) observed that bleaching treatments had their greatest effects on the surface layers of fibers, preferentially removing lignin from fiber surfaces. Fardim and Duran (2005) carried out

Hubbe and Rojas (2008). "Colloidal stability of cellulosics," BioResources 3(4), 1419-1491. 1422 
related work, using infra-red spectroscopy and analysis of wetting behavior, showing the consequences of surface composition on surface free energy. Shen and Parker (1999) compared different pulping sequences; the kraft process yielded higher surface levels of lignin and extractives, compared to equal delignification degrees achieved by soda pulping or by neutral sulfite semichemical (NSSC) pulping. Laine et al. (2004) showed that different bleaching strategies tend to impart differing levels of negative charge to fibers, and such differences can be highly correlated to the demand for cationic additives, including hydrophobic sizing agents used in the papermaking process.

\section{Surface composition vs. de-waxing and de-resination}

Preparation methods also can be expected to affect the surface composition of non-wood cellulosic materials. Cotton in its natural state consists mainly of cellulose. However, as shown by Ribitsch et al. (2001), cotton's surface can be made much more hydrophilic by removal of waxy material. Possible methods to clean cotton's surface include rinsing in boiling $\mathrm{NaOH}$ solution, enzyme treatment, solvent extraction, and oxidative bleaching (Stana-Kleinschek and Ribitsch 1998).

\section{OH groups at the wetted fiber surface}

The bound $\mathrm{OH}$ group can be regarded as being the most predominant functional group at the surfaces of pure cellulosic materials. As noted already, even in the presence of water, a majority of such groups already can be expected to be involved in hydrogen bonding to adjacent groups either within the same molecule or in adjacent chains. Molecular dynamics simulations (Bergenstrahle et al. 2008) predict that contact with a water phase will result in only a limited change in the proportions of inter-molecular, intra-molecular, and outwardly directed hydrogen bonding, which is further limited to just the outermost layer of cellulose molecules (Heiner et al. 1998; Heiner and Teleman 1997). Experimental evidence of such interactions is shown in NMR work by Newman and Davidson (2004). Recent work by Kocherbitov et al. (2008) shows that the adsorption of water onto cellulose is dominated by placement of water molecules between rather than onto cellulosic fibrillar surfaces. This finding reinforces the importance of the three-dimensional nature of cellulose and the tendency of water to affect the bulk properties of the material.

Compared to water that is further away from the cellulose surface, the interaction between cellulose and the first molecular layer of water is stronger. Evidence suggests that the term "cellulose hydrate" may be appropriate (see Joubert et al. 1959; Gert 1996). For instance, Kocherbitov et al. (2008) showed that the interaction between the initial water and dry cellulose is strongly exothermic. Joubert et al. (1959) suggested the term "hydrate" because the first $12 \%$ of water imbibed by a cellulose film did not affect its contact angle with water. A further reason for thinking of cellulose as a hydrate is that it is seldom truly dry; under moderate conditions of humidity, cellulosic fibers can be expected to contain about 6 to $8 \%$ moisture, by mass. This is roughly equivalent to one water molecule per glucopyranose unit. Watanabe et al. (2006) applied principal component analysis to near-infra-red spectroscopy data; they showed that the first 3-7\% of "adsorbed" water, based on the mass of solid, immediately becomes involved with development of the hydrogen bonded structure of cellulose. Furthermore, when cellulose

Hubbe and Rojas (2008). "Colloidal stability of cellulosics," BioResources 3(4), 1419-1491. 1423 
fibers are suspended in water, some of the water closest to the surface does not have a freezing point (Deodhar and Luner 1980; Weise et al. 1996). The effect is sufficiently pronounced that it can be used to estimate the predominant pore size of nanoporous materials (Park et al. 2006; Hubbe et al. 2007a). Indeed, nuclear magnetic resonance results ( $\mathrm{Li}$ et al. 1992) suggest that the water molecules closest to cellulose have a reorientation rate that is about 25 times slower than that of bulk water. According to Bellissent-Funel (2002), interfacial water adjacent to a hydrophilic surface can resemble super-cooled bulk water, which is characterized by unusually long-range correlations between the locations of neighboring molecules.

\section{Ionic Groups: Surface vs. Total Charge}

Unmodified cellulose surfaces usually can be described as weakly acidic in the Lowry-Brønsted sense (Pearson 1969). This means that if the $\mathrm{pH}$ of an aqueous solution is high enough, the cellulosic material can release protons and acquire a net negative charge. Carboxylic acid groups having various dissociation constants can be due to the presence of hemicelluloses, extractives, lignin and its byproducts, and various products of oxidation, especially in the case of bleached cellulosic products. Purified cellulose has a much lower acid content compared to other typical cellulosic material (Herrington and Petzold 1992; Lloyd and Horne 1993). Polysaccharide-bound hydroxyl groups, though they do not significantly release protons in the $\mathrm{pH}$ range up to about 12 , still may allow the surface of relatively pure cellulose to be classified as acidic (Simoncic et al. 2008).

Charged groups at the "surfaces" of cellulosic materials in aqueous solution appear to be located in three-dimensional regions, rather than in planar surface layers (Chen et al. 2004). Evidence in support of this assertion comes, for instance, from discontinuities in potentiometric titration curves (Fernandez Diniz 1995). This author showed that fibers still contained a substantial amount of titratable charge even after their surfaces had been derivatized to convert the carboxylic acid groups to a neutral species. Further supporting evidence comes from the fact that the measured streaming potential of cellulosic fibers, to which a suitable amount of high-mass, high-charge cationic polymer has been added, can be changed from positive to negative by addition of salt (Hubbe et al. 2007a). The effect has been attributed to the fact that, in the absence of salt, double layers do not have sufficient space in which to form within the cell walls of fibers, whereas the double layer thickness can be greatly decreased by salt addition. At increased ionic strength, the surfaces within the nanopore structure of cellulosic fibers can be expected to make a significant contribution to the measured streaming potential. Such a contribution to the signal can have striking results in cases where the molecular size of charged additives is too large to allow significant penetration into the cell wall during the time allowed for testing.

Depending on the conditions of processing, it is possible to prepare cellulosic fibers having a higher proportion of charged groups on their outer surfaces. For instance, Barzyk et al. (1997) carboxymethylated cellulose fibers under non-swelling conditions. In the case of fibers that had been dried from a water suspension, subsequent tests showed that the resulting charged groups tended to be located towards the outer surfaces. These results imply that closure of pores in the cellulose during ordinary drying inhibited access by the reagent. By contrast, treatment of fibers that had been dried from a solvent

Hubbe and Rojas (2008). "Colloidal stability of cellulosics," BioResources 3(4), 1419-1491. 1424 
suspension, preventing closure of the pores in the cell wall, resulted in a more uniform distribution of charge throughout the cell walls of the fibers.

\section{Charge of the outer surface}

The extent of ionization at wetted cellulosic surfaces can be evaluated in various ways, and understandably, the results often depend on the method that has been selected (Hubbe 2000a; Fardim and Holmbom 2005). For instance, polyelectrolytes can be used to titrate colloidal charge, especially under circumstances that justify an assumption of one-to-one stoichiometry of polyelectrolyte charged groups with surface-bound ionized groups. Briefly stated, such one-to-one stoichiometry can be approached in systems where the ionic strength is low, where the surface charge density is sufficiently high to allow a strong affinity with an oppositely charged polyelectrolyte, and where the definition of "surface" is defined by the penetration ability of the polyelectrolyte being used in the analysis. As suggested by Fig. 2, polyelectrolytes of high charge density usually are used in this type of analysis in order to favor strong, essentially irreversible complexation with outer surface groups. In typical industrial samples of cellulosic materials in aqueous suspension the titrant is assumed not only to interact with surfacebound ionic groups, but also with colloidal materials, dissolved polyelectrolytes, charged surfactants, and colloidal-sized particles. Mocchiutti and Zanuttini (2005) have provided an elegant formula by which to avoid over-estimating fiber surface charge. Overestimation is expected to become increasingly likely as titration progresses, due to a tendency for polyelectrolytes to adsorb with more loops and tails extending out from the surface as one approaches the limit of the maximum adsorbed amount.
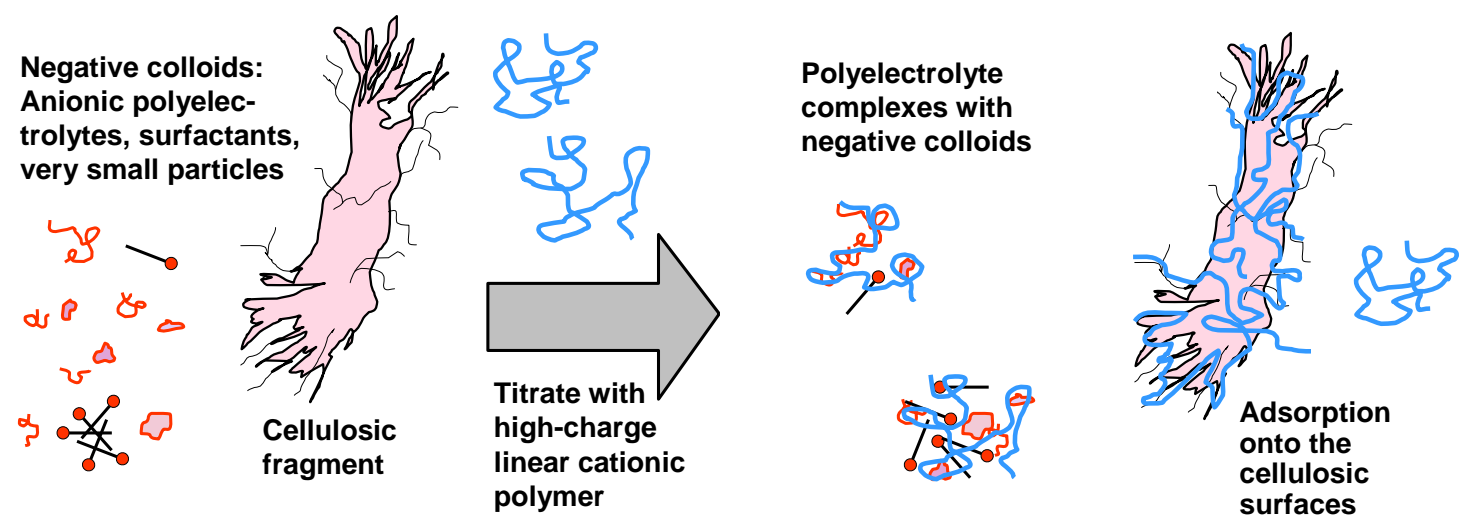

Fig. 2. Schematic representation polyelectrolyte titration of aqueous sample that contains not only cellulosic surfaces, but also negatively charged colloidal matter, such as anionic surfactant molecules, polyelectrolytes, and very small particles

Higher amounts of adsorbed polyelectrolyte often coincide with decreasing molecular mass in the case of porous substrates (Hostetler and Swanson 1974; Wågberg et al. 1989; Wågberg and Ödberg 1989; Gruber et al. 1996; Alince and van de Ven 1997; Horvath et al. 2006). Such results have been interpreted by saying that the smaller molecules are better able to penetrate materials having a range of pore size. Wågberg et 
al. (1989) used such differences to determine an effective "surface charge," based on titrations with poly-diallyldimethylammonium chloride (poly-DADMAC) having a mass of about a million Daltons. By contrast an effective "total charge" has been defined by the results of titration with a much lower-mass cationic polyelectrolyte. The results of titrations with a suitably low-molecular-mass cationic polyelectrolyte agreed with results of charge determinations based on acid-base titrations (Wågberg and Ödberg 1989). Such results suggest that sufficiently low-mass cationic polyelectrolytes can diffuse into essentially all of the pore spaces within cellulosic fibers.

\section{Polyelectrolyte titration with streaming current endpoint}

For practical applications, one of the most popular methods for determining the endpoint of a polyelectrolyte titration involves a loosely-fitted plastic piston reciprocating within a plastic cylinder (Gerdes 1966), i.e. the streaming current titration method. To carry out such an analysis, one has to make the implicit assumption that the plastic surfaces adsorb colloidal material from the solution to which they are exposed and that the net charge of the plastic surfaces in the annular region indicates the sign of colloidal charge of the system as a whole. This method has been widely used for evaluation of the charge demand of paper machine systems (Kenaga et al. 1967; Lafaye and Jacquelin 1968; Davison and Cates 1975; Beck et al. 1987; Lindström 1991; Bley 1992; Bley and Kästner 1992; Ojala 1993; Patton and Lee 1993; Baumgartner and Bley 1994; Carrasco et al. 1996; Petzold et al. 1997; Bischoff 1997; Thiele and Kopp 1997; Phipps 1999; Mutje et al. 2001; Chen et al. 2001; Pruszynski and Jakubowksi 2002; Rice and Roeraade 2003; Koljonen et al 2004; Hubbe and Chen 2004; Yoon 2007). Jaycock (1995) criticized the streaming current method due to (a) reasonable doubts that the plastic surface charge necessarily matches that of the colloidal system to which it is exposed, (b) the likelihood that results are affected by remnants of adsorbed polyelectrolytes from a previous test, and (c) the non-ideality of the flow conditions within the annulus. However, as a practical tool, the streaming current titration method has gained wide acceptance.

\section{Color endpoint}

An alternative way to detect the endpoint of a polyelectrolyte titration involves a charge-induced shift in the hue of a suitable dye, such as toluidine blue (Terayama 1952; Halabisky 1977; Hubbe 1979; Springer and Taggart 1986; Schempp 1988; St. John and Gallagher 1992; Stenius and Laine 1994). The color shift does not proceed to a significant extent until an excess of the polyelectrolyte that is opposite in charge to the dye is present in the solution. The procedure rests on an assumption that the interaction between the dye and one of the polyelectrolytes is significantly weaker than the interaction between two oppositely charge polyelectrolytes used in the analysis. Difficulties with the procedure can be expected in the presence of colored materials, increasing salt concentrations, and aluminum compounds (Hubbe 1979; St. John and Gallagher 1992). However, results of such titrations have been used successfully for many years for optimization of paper machine system charge. 


\section{Other ways to quantify charge of cellulosic surfaces}

Alternatively, the surface charge can be estimated by the adsorption of charged dye molecules, based on an assumed one-to-one charge interaction (Oertel et al. 1991; Fardim and Holmbom 2003, 2005). van de Ven et al. (2007) showed that the charge character of fiber suspensions can be evaluated by direct adsorption of toluidine blue dye. High-yield pulp surfaces appear to adsorb dye both due to their hydrophobic character (related to lignin and extractives content) and due to their negative charge. Kraft pulps appear to adsorb the dye through a simple ion-exchange mechanism, consistent with the idea of using the dye for titrations of surface charge. Mathews et al. (2004) carried this approach a step further, using the stained appearance of single fibers, after exposure to a dye solution, as an indication of their surface charge density. Tanaka et al. (2000) showed that it even is possible to use a colored derivative of poly-DADMAC as a means of quickly determining how much of the polymer can be taken up by cellulosic material in suspension. Colorimetric analysis of the filtrate, relative to a blank determination, was used to estimate adsorbed charge

Jacob and Berg (1993) demonstrated a highly unique strategy for endpoint detection during polyelectrolyte titrations, showing that wettability can be used as an indication of the degree of neutralization. The logic behind this approach is that surfaces having a net ionic charge can be expected to have a stronger interaction with water, compared to a charged surface to which an equal and opposite amount of polyelectrolyte charge has been added.

\section{Potentiometric titrations}

Titrations with strong acid or strong base can be used for analysis of charge in cases where essentially all of the surface-bound ionizable groups consist of weak acids or weak bases. In principle, one can evaluate the amount of strong acid or base that becomes consumed in converting, say, a weak acid to its conjugate base, or vice-versa. Because the $\mathrm{OH}^{-}$and $\mathrm{H}_{3} \mathrm{O}^{+}$ions are very small and highly mobile in an aqueous solution, it is reasonable to expect significant contributions from ionizable groups deep within very small pores. Titrations can be carried out either by observing the $\mathrm{pH}$ or by observing conductivity changes, usually during the addition of $\mathrm{NaOH}$ (Katz et al. 1984).

Potentiometric titrations of cellulosic fibers in suspension have demonstrated the presence of weak acidic groups (Herrington and Midmore 1984a-c; Beck et al. 1987; Budd and Herrington 1989; Herrington and Petzold 1992; Laine et al. 1994; Stenius and Laine 1994; Fernandez Diniz 1995; Laine 1997; Räsänen and Stenius 1997; Bygrave and Englezos 1998; Räsänen et al. 2001; Lindgren et al. 2000, 2002). Laine and coworkers showed that titration data for kraft pulp could be best fitted by assuming the existence of two types of carboxyl groups (Laine et al. 1997; Stenius and Laine 1994). The stronger of these two acid functions, having a fitted pKa value of 3.4, was attributed to the uronic acid groups of xylan hemicellulose. Somewhat weaker acids, having a fitted pKa value of about 5.5, were attributed to lignin-bound carboxylic acid species. More recent studies have achieved similar results (Lindgren et al. 2001, 2002). 


\section{DISPERSION FORCES}

Regardless of ionic charge, there exist substantial short-range interactive forces between all forms of matter, arising from the seemingly random motions of electrons (Visser 1972, 1995; Bowen and Jenner 1995). van der Waals (1910) found early evidence for such forces, consisting of deviations from the ideal gas law. Thus, even the noble gases, which lack chemical reactivity, are attracted to each other, making it possible to condense them into liquids at sufficiently low temperature. The dispersion component of the van der Waals forces is of particular importance to interactions between colloidal particles in suspension.

As a first approximation, the van der Waals interactions between two macroscopic particles or bodies can be calculated by adding (using integration) the interactions between all molecular pairs between the two bodies (Hamaker 1937). The result of such integration shows that the distance dependence of the van der Waals force between macroscopic surfaces is much weaker than that between molecules, i.e., the interaction is more long-ranged. Furthermore, the numerical integration used to compute the strength of interaction between solids, due to the dispersion contributions, requires the detailed geometry of the facing surfaces to be known. This geometry usually is assumed as an equivalent "sphere-plane" or "two planes" model of interaction. Other factors determining the strength of dispersion forces are the distances of separation, the nature of the suspending medium, if any, and a constant $A$, which is known as the Hamaker constant, which depends on the electrical polarizabilities of the materials in question.

To give an example, Eq. (1) estimates the dispersion component of force for the "sphere-plane" model of interaction (Visser 1972),

$$
F_{\text {disp }}=(A / 6) R\left\{\left(1 / x^{2}\right)+1 /(x+2 R)^{2}-1 /[x(x+2 R)]\right\}
$$

where $R$ is to be regarded usually as an effective radius, representing the interaction between non-ideal surfaces, and $x$ is the minimum distance between the sphere and the plane.

The Hamaker method explained above is conceptually easy but unfortunately not very accurate. There are several reasons for the inaccuracy: The method neglects manybody interactions, entropic contributions, and other factors. It is also not very easy to accurately account for the presence of the medium separating the two interacting particles.

All these effects are considered in an alternative treatment due to Lifshitz et al. (see Dzyaloshinskii et al. 1961). Here the interacting particles and the intervening medium are treated as continuous phases, and the interaction is viewed as originating from interference between fluctuating electromagnetic fields extending beyond the surfaces of the particles. The expressions for the interaction energy between bodies of a specific shape have the same functional form as in the Hamaker treatment, but the equivalent to the Hamaker constant $A$ is a function of the frequency-dependent bulk dielectric properties of the continuous phases. Rather accurate approximate equations to the Lifshitz expression are often used for calculating the Hamaker constant (see Israelachvili 1992; Fröberg et al. 1999).

Hubbe and Rojas (2008). "Colloidal stability of cellulosics," BioResources 3(4), 1419-1491. 1428 
An implicit assumption so far is that the Hamaker constant is not affected by the separation between the particles, i.e., the distance over which the electric fields have to travel between the interacting surfaces. However, this is not correct at large antiparticle separations. In this case the time needed for the electric field emanating from one body to travel to the other body and to be reflected back again becomes comparable to the period of the fluctuations that generate the field. Thus the phase correlation between the fields emanating from the two bodies will be diminished, and the interaction will be weakened. This phenomenon, called retardation, becomes important at separations larger than about $5 \mathrm{~nm}$, and can be taken care of within the framework of the Lifshitz theory, e.g., as described by Mahanty and Ninham (1976).

Relative to their importance, surprisingly little research has been devoted to the evaluation of dispersion forces involving cellulosic materials. Most notably, Bergström et al. (1999) evaluated the Hamaker constant for cellulose. They based their estimates on macroscopic observations of the dispersion of light, using ellipsometry. The Hamaker constant for regenerated cellulose phases interacting with each other in air was determined to be $58 \times 10^{-21} \mathrm{~J}$. When immersed in an aqueous phase, the corresponding Hamaker constant was reduced to $8.0 \times 10^{-21} \mathrm{~J}$. Related work for ethylcellulose films was carried out by Oh and Luner (1999).

Another approach for determining the strength of dispersion force contributions to interactions at surfaces involves evaluation of contact angles of test liquids. For instance Tze et al. (2006) used such an approach to find out how the dispersion component of interactive forces was affected by various chemical derivatizations of the cellulose surface. Notably, various silane-related treatments decreased the dispersion component of surface free energy from a $\gamma_{d}$ value of $24.3 \mathrm{~mJ} / \mathrm{m}^{2}\left(\mathrm{mNm}^{-1}\right)$ to a range between 15.6 and $17.8 \mathrm{~mJ} / \mathrm{m}^{2}$. A cellulose surface that had been grafted with styrene-maleic anhydride (SMA), also had a $\gamma_{d}$ value of $15.6 \mathrm{~mJ} / \mathrm{m}^{2}$.

As noted by Pelton (1993), the fibrillated surfaces of many cellulosic surfaces can be expected to pose profound challenges when one attempts to calculate the contributions of dispersion forces. The predicted attractive forces that one obtains, when using a conventional sphere-plane or two-planes model of the contact region between a pair of cellulosic surfaces, etc., are far too high, relative to practical observations. Coagulation of cellulosic suspensions by means of charge reduction or by adding relatively high concentrations of monomeric ions is known to yield relatively weak structures that are easily redispersed by hydrodynamic shear. Pelton attributed this discrepancy between the calculations and the observations by proposing that hydrated fibrillar elements, including structures down to the macromolecular level, extend outwards from typical cellulosic materials, so that it does not make any sense to carry out calculations based on a model of planar surfaces. In fact, the first reported measurements of interactions between cellulose surfaces were interpreted with reference to "dangling tails" of cellulose fibrils extending out from the surface (Neuman et al. 1993).

Another issue that deserves more attention in the future is the effect of the waterswollen and nanoporous nature of wetted cellulosic materials on dispersion force interactions. For example, the measurements by Neuman noted above was only partly successful because of the large swelling of their cellulose surfaces, thus giving rise to long-range steric forces. As a first approximation it makes sense to employ a linear 
combination of the Hamaker constants for cellulose and for water, depending on the relative amounts of each of these substances at the outermost surfaces of the interacting phases.

\section{IONIC DOUBLE LAYERS}

As was noted earlier, the unmodified surfaces of cellulosic materials can be expected to develop a net negative charge when exposed to aqueous solution in the absence of strongly adsorbing cationic species. It is well known that such charged surfaces will attract an equal amount of oppositely charged "counter-ions," which will be present in the solution adjacent to the surface. These counter-ions are in excess of what would be expected in the bulk aqueous solution.

The relative distances of the excess ions, on average, from a charged surface have been the subject of extensive investigation and modeling. To a first approximation it is useful to divide the distribution into two parts, a condensed part and a diffuse part (Verwey and Overbeek 1948; Hiemenz and Rajagopalan 1997). Ions present in the condensed part of the double layer are regarded is being in physical contact with the surface, consistent with their ionic radius. The time-averaged location of counter-ions in the diffuse part of the double layer is governed by interplay between electrostatic attraction and the tendency of such ions to diffuse in all directions due to their thermal energy. The results of this interplay can be described as an "atmosphere" of excess charge, in which the concentration of excess charge falls off exponentially with distance from the surface.

In the diffuse layer the ions are only affected by electrostatic forces, and in this region it is straightforward, using a mean field approach such as the Poisson Boltzmann (PB) model, to calculate the concentration of counter-ions as a function of distance from the surface. The degree of extension of the diffuse layer out from the surface will depend on the surface charge density, the bulk ion concentrations, and valencies of the ions present. A central quantity in this respect is the Debye length $\kappa^{-1}$, which describes the rate with which the mean potential decays away from the surface. The Debye-length decreases with increasing ionic strength, but it is independent of the surface charge density and surface potential. The Debye length $\kappa^{-1}$ can be calculated from the following equation,

$$
\frac{1}{\kappa}=\left(\frac{\varepsilon \varepsilon_{0} k_{B} T}{\sum_{i}\left(z_{i} e\right)^{2} n_{i}}\right)
$$

where $z_{i}$ is the valence of the ion " $i$ ", $n_{i}$ is its concentration (bulk number density) in consistent units, $e$ is the elementary electron charge, $\varepsilon_{0}$ is the permittivity of vacuum, $\varepsilon$ is the dielectric constant of the medium, $k_{T}$ is Botzmann's constant, and $T$ is the absolute temperature.

Electrostatic double-layer forces between two surfaces immersed in aqueous solution arise when the two surfaces come close enough for their diffuse layers to start to

Hubbe and Rojas (2008). "Colloidal stability of cellulosics," BioResources 3(4), 1419-1491. 1430 
overlap, giving rise to an osmotic pressure. The resulting force can be calculated only in the case of relatively simple, known geometries. For instance Eq. (3) gives the approximate electrostatic force between a sphere of radius $R$ and a plane surface at a distance $x$ having respectively low electrical potentials $\psi$, under the assumption that the potentials do not change during the interaction (Hogg et al. 1966).

$$
F_{\text {elec }}=-\pi R \varepsilon \kappa \operatorname{cosech}\left\{(\kappa x)\left[2 \psi_{1} \psi_{2}-\left(\psi_{1}^{2}+\psi_{2}^{2}\right) \exp (-\kappa x)\right]\right\}
$$

In this expression $\varepsilon$ is the dielectric constant, and $\kappa$ is the Debye-Hückel reciprocal length parameter. The reader is referred to the review by Fröberg et al. (1999) for more detailed and extensive explanations.

\section{Zeta Potential}

As mentioned before, the electrostatic forces between surfaces suspended in aqueous solution arise due to the overlap of ionic double layers at adjacent surfaces. As a first step in estimating the magnitudes and dependencies of these forces it is common practice to evaluate the zeta potential $\zeta$. The zeta potential can be described as the electrical potential at a hypothetical "slip plane" adjacent to a charged surface. The slip plane represents the demarcation between ions that act as if they are part of the solid surface, versus those which act as if they are part of the bulk aqueous phase. Methods for evaluating zeta potential and related parameters have been summarized elsewhere (Biefer and Mason 1954; Sennett and Olivier 1965; Britt and Unbehend 1974; Lindström 1996; Hunter 1981; Poppel 1992).

\section{Electrophoretic mobility}

From a theoretical and practical standpoint (Jaycock 1985; Schempp 1988; Strazdins 1995) microelectrophoresis is the best-established method of determining the zeta potential of cellulosic materials that are smaller than about $100 \mu \mathrm{m}$. In its classical form, a microelectrophoresis test is carried out in a capillary cell. A direct-current voltage is applied by means of electrodes in two chambers connected to the capillary. For non-conducting particles the speed of migration in the applied field is proportional to the average electrical potential at the hydrodynamic slip plane, i.e. the zeta potential.

The purpose of using a capillary cell is to suppress eddies of flow. However, in order to properly evaluate zeta potential, it is necessary to focus a microscope and visualize particles in at a specific location within the capillary that is known as the stationary layer. The reason for this procedure is that application of a voltage across a length of a glass or quartz capillary generally results in an electro-osmotic effect; counter-ions in the diffuse part of the double layers adjacent to the glass or quartz surfaces are attracted by the applied electric field, and the motion of such ions causes a net motion of the surrounding liquid adjacent to the capillary wall. In a properly sealed microelectrophoresis apparatus the resulting counter-flow of fluid can be accurately predicted, and it is relatively easy to calculate the locations where the net effect of electro-osmotic flow will be zero. Problems of eddy flow also can be overcome by use of automated laser-optical measurement systems; in such systems the period of application of the electric field is kept sufficiently brief that eddy flows do not have time to develop.

Hubbe and Rojas (2008). "Colloidal stability of cellulosics," BioResources 3(4), 1419-1491. 1431 
As noted by Strazdins (1995), application of the micro-electrophoresis method for analysis and control of fiber suspensions used in papermaking rests upon an assumption that fine particles obtained by screening of fiber suspension (i.e. "white water) is representative of the charge behavior of all of the surfaces in the suspension. Though it is reasonable to expect some deviations from this assumption, depending on the circumstances, the results of micro-electrophoresis tests often correlate well with dewatering rates, fine-particle retention, and other parameters of interest to papermakers (Davison and Cates 1975; Strazdins 1977, 1989, 1994, 1995).

By means of laser-Doppler technology it has been feasible to obtain detailed distributions of zeta potential in populations of particles. Results of studies using this approach have had important implications for the manufacture of paper (Sanders and Schaefer 1989, 1992, 1994, 1995; Sanders 1994). For instance, such results have revealed bi-modal and poly-modal distributions of zeta potential among populations of suspended particles. Prolonged hydrodynamic shearing, along with the passage of time, tend to gradually make the suspended particles more uniform with respect to zeta potential (Sanders 1994). This effect has been attributed to gradual redistribution of colloidal materials onto the surfaces of the suspended particles, which can include both cellulosic fine particles and calcium carbonate, along with various ionic and polymeric additives to the papermaking process.

\section{Streaming potential}

Streaming potential tests have had a long history of applications for study of cellulosic materials (Briggs 1928; Neale 1946; Goring and Mason 1950a,b; Biefer and Mason 1954; Ghosh and Pal 1961; Chang and Robertson 1967a,b; Hoffmann et al. 1975; Sack 1976; Penniman 1992; Hand et al. 1993; Rohloff and Höschle 1993; Sack et al. 1993; Sanders and Schaefer 1994; Jacobasch et al. 1995; Jaycock 1995; Stana-Kleinschek et al. 1995; Miyanishi 1995a,b; Miyanishi and Montegi 1996; Miyanishi and Shigeru 1997; Thiele and Kopp 1997; Ribitsch et al. 2001; Wang and Hubbe 2001; Hubbe and Wang 2004; Hubbe et al. 2007a). Various authors have reported progress with automated applications of streaming potential measurements for purposes of process monitoring and control (Sack 1976; Sack et al. 1993; Hand et al. 1993; Rohloff and Höschle 1993; Sanders and Schaefer 1994; Miyanishi and Shigeru 1997; Hubbe 1999; Hubbe 2001b)

The use of streaming potential tests has not yet become widespread in industrial applications. A likely explanation has been proposed (Hubbe et al. 2007a), based on the nanoporous nature of cellulosic fibers. It was found that when streaming potential tests were carried out at levels of salt typical of papermaking operations, the results were greatly affected by the charged condition of the interior spaces within the fibers. This is undesirable from a process control perspective, since the surfaces inside the nanoporous structure of fibers are not expected to have much effect on retention and drainage operations, and it is unlikely that most polymeric additives used in papermaking will be able to diffuse to a significant extent into such pores within the available time. The most striking results were obtained when testing fiber slurry samples to which cationic polyelectrolyte had been added. In certain cases even the sign of streaming potential could be reversed repeatedly just by varying the salt concentration of the suspending medium. 
An explanation for the observed effect is that, in the presence of a suitable concentration of electrolyte, the thickness of ionic double layers is sufficiently small so that double-layer effects can be observed within the nanopores. Thus, if one wants to obtain an accurate indication of just the charged condition of the outer surface of cellulosic fibers, the suspending solution should be replaced with deionized water. This procedure effectively "turns off" the contribution to the electrokinetic signal that originates within the very fine pores. Indeed, when practical tests of dewatering rates and fine-particle retention were carried out in this way (Hubbe et al. 2007a), there was good agreement between the measured streaming potential and the expected trends in retention and drainage. The most rapid dewatering was observed when the streaming potential tests in the absence of salt indicated that a sufficient amount of high-charge cationic polymer had been added to neutralize the system. Also, there was an equal retention of positive and negative probe particles when the streaming potential tests carried out in the absence of salt indicated a neutral charge on the fiber surfaces. No such agreement was obtained when the streaming potential tests were carried out in the presence of sufficient sodium sulfate to raise the electrical conductivity to $1000 \mu \mathrm{S} / \mathrm{cm}$.

Another factor that affects the results of zeta potential and streaming potential tests is the conductivity of fiber surfaces (see Scallan 1989; van de Ven 1999). Although pure cellulose can be considered to be an insulating material, the ionic double-layers associated with cellulosic surfaces can be expected to conduct electricity in the presence of an electrical field. Effects of surface conductance on the results of zeta potential tests can be expected to become increasingly significant as the ionic strength becomes low, and as the counter-ions adjacent to surfaces comprise an ever-greater proportion of the movable ions in the system.

\section{Colloidal Forces}

A discussion of colloidal forces must consider the DLVO theory of Derjaguin and Landau (1941) and Verwey and Overbeek (1948), which was briefly mentioned before. DLVO interaction forces are determined as the total, additive contributions from the van der Waals and the double layer interactions. As stated above, usually the van der Waals interactions are attractive, whereas the double-layer interactions often are repulsive. Also, the van der Waals contribution is dominant at small surface separation, while the double-layer contribution gives rise to a net force barrier at larger separations, as illustrated in Fig. 3 (left). The insert in this figure illustrates that increasing the ionic strength or lowering the surface potential results in a lower energy maximum. The righthand frame of Fig. 3 represents a system with a strong van der Waals attraction and moderate double-layer repulsion, resulting in the existence of a secondary minimum at relatively large interparticle distances. Just considering the DLVO-forces, one may obtain different force-distance profiles, including those representing kinetically stable, weakly flocculated or coagulated systems. Further, by increasing the ionic strength one may go from a kinetically stable colloidal dispersion to one that is coagulated. An explanation of these aggregation states is included below. 


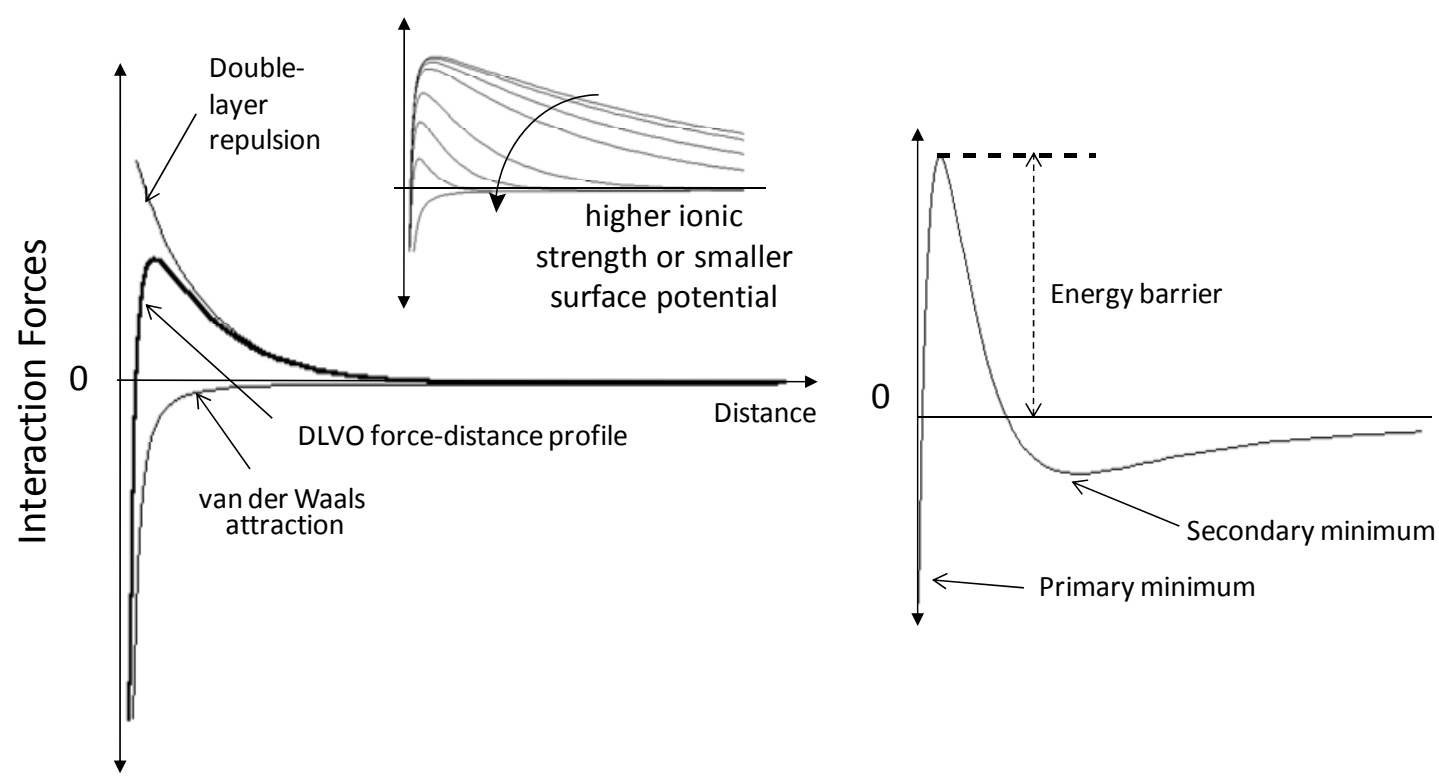

Fig. 3. Forms of typical functions of interactive free energy vs. separation distance, as determined by contributions from attractive van der Waals energy and electrostatic double layer energy contributions. Inset (left): Effect of increased electrolyte concentration on net energy of interaction. Right: Illustration of common calculated result, predicting a secondary minimum in net interactive free energy.

The reader is referred to the review of Fröberg et al. (1999), in which some calculated DLVO profiles are presented for various aqueous electrolyte concentrations and surface potentials (using non-retarded Hamaker constants). Remarkably, in simple systems DLVO calculations fit experimental data that have been made available only very recently. Most of the reported experimental systems have been developed using very smooth surfaces that allow measuring the net interactive force as a function of very small separation distances (Israelachvili and McGuiggan 1990; Holmberg et al. 1997a,b; Fröberg et al. 1999; Österberg 2000; Claesson and Rutland 2001). The ultra-smooth surfaces of freshly cleaved mica have been particularly favored by investigators for such fundamental work (see, for instance Rojas et al. 1998). To extend similar methods to studies of cellulose's colloidal interactions, a key challenge has been to prepare very smooth cellulosic films, and several approaches for the preparation of such films have been developed (Holmberg et al. 1997a,b; Rojas et al. 2000; Kontturi et al. 2006; Turon et al. 2008).

Using a surface force apparatus to measure interaction forces between regenerated cellulose surfaces, Neuman et al. (1993) observed non-DLVO forces; specifically electrosteric forces brought about by small dangling cellulose fibrils on the surfaces gave rise to steric contributions. These macromolecular chains contributed to the repulsion forces at separation distances as large as $100 \mathrm{~nm}$. More recently, Holmberg et al. (1997a) surprisingly observed no evidence of double-layer repulsion between smooth, pure cellulose surfaces at $\mathrm{pH}=6$; they concluded that the surfaces were essentially uncharged under the conditions of testing. In contrast, Poptoshev et al. (2000) observed weak electrostatic repulsion in a related experiment, and they showed that the negative charge 
of the cellulose could be neutralized with a low level of cationic polyelectrolyte addition. Österberg (2000) showed the effects of exposing very smooth cellulosic surfaces to different amounts of cationic polyelectrolytes. Net adhesive forces were observed at low levels of coverage and short exposure times, consistent with charged patch and bridging mechanisms. At higher levels of coverage and longer adsorption times the net forces tended to become repulsive, consistent with like-charge repulsion and steric stabilization.

Less quantitative, but still very revealing analyses have been achieved by atomic force microscopy (AFM) and related tests (Rojas et al. 1998; Zauscher and Klingenberg 2000a; Amelina et al. 2000; Paananen et al. 2004; Leporatti et al. 2005; Radtchenko et al. 2005; Notley et al. 2006; Notley and Norgren 2006; Stiernstedt et al. 2006a,b; Salmi et al. 2007a; Bastidas et al. 2008; Notley 2008). The term "colloidal probe microscopy" has been applied to methods in which the standard AFM stylus is replaced by a spherical probe surface. Pang and Gray (1998) observed significant repulsive forces at separation distances up to $1700 \mathrm{~nm}$ between fibrillated cellulose and an AFM probe, depending on the level of refining. These distances are much higher than would be expected based on the double-layer forces at planar surfaces. Rather, the results were consistent with interaction between cellulosic macromolecular strands extending outwards from the facing surfaces. Addition of salt decreased the separation distance at which the repulsion could be detected; this observation is consistent with suppression of double-layer repulsion by the dissolved salt, allowing the fibrils to lie down to a greater extent onto the fiber surface. Carambassis and Rutland (1999) and Rutland et al. (1997) found evidence of repulsive forces when seemingly smooth cellulosic spheres were within $20 \mathrm{~nm}$ from each other, and they attributed such forces to cellulosic chains extending outwards from the respective surfaces.

Surface force measurements via AFM or surface force apparatus (SFA) are particularly useful to understand the effect of adsorbed polymers on cellulose and other model surfaces. For example, Claesson et al. (2003) and Rojas et al. (2005) studied adsorbed layers of polyelectrolytes and focused on determining the effect of the polyelectrolyte charge density on surface topography, as well as the effect of the polyelectrolyte coating on adhesion between the polymer-coated surfaces. Their data provide evidence for formation of electrostatic bridges, particularly when highly charged polyelectrolytes were used. Further, material transport between the surfaces was observed when the polyelectrolyte was either highly charged or had a very low charge density. For intermediate charge densities they did not observe any indication of material transfer. The charge density of the adsorbing polyelectrolyte is particularly important in determining the adsorbed mass on cellulose, as observed in Fig. 4.

The adhesion between one polyelectrolyte-coated surface and one bare surface was initially higher than that between two polyelectrolyte-coated surfaces. However, due to material transfer between the two surfaces the adhesion decreased significantly with the number of times that the surfaces were driven into contact. For the polyelectrolytes of the lowest charge density the results suggested that entanglement effects contributed to the adhesive interaction. Such results can guide efforts to modify surface adhesion by polyelectrolytes, for example to enhance the performance of dry-strength additives aimed at improving fiber bonding and paper strength.

Hubbe and Rojas (2008). "Colloidal stability of cellulosics," BioResources 3(4), 1419-1491. 1435 


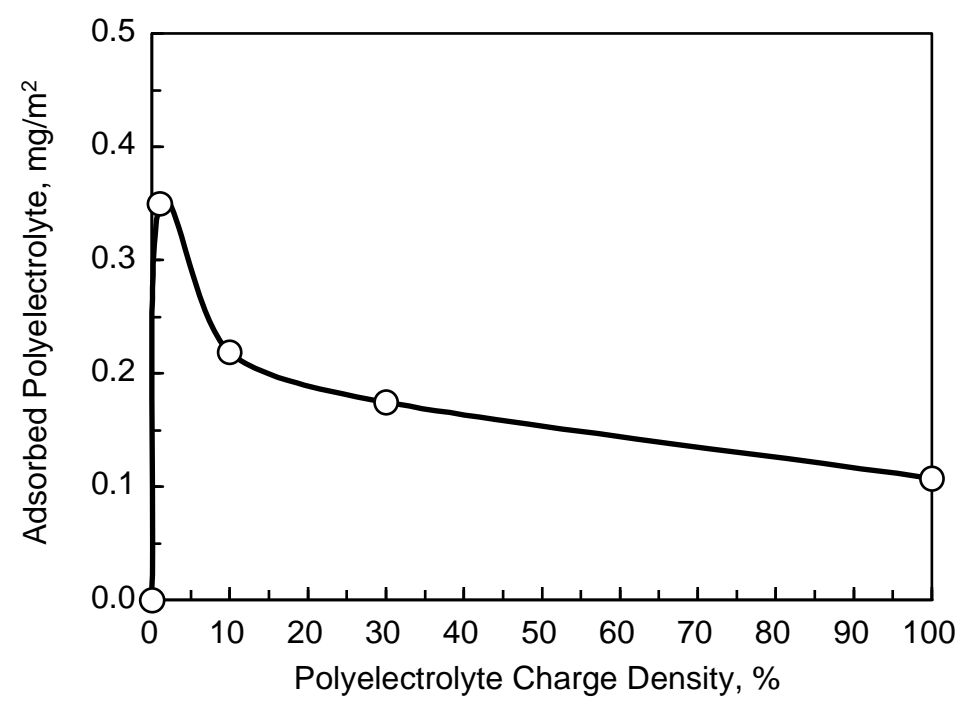

Fig. 4. Effect of polyelectrolyte charge density on the extension of adsorption on cellulose surfaces as measured by an XPS method developed by Rojas et al. (2005)

Steric forces: A non-DLVO interaction relevant in cellulose systems

High-molecular-weight polymers, which are often used in fiber processing, can affect interactive forces, thus affecting the stability of colloidal systems. Synthetic and natural polymers and their derivatives, including modified cellulose and starch, are widely used. Factors that determine the sign, range, and magnitude of polymer-induced forces include solvent-polymer interactions, surface coverage, polymer concentration, and whether the polymers adsorb reversibly or irreversibly. Forces between surfaces carrying adsorbed polymers, as commonly occur during the wet processing of cellulose fibers, can be considered by theoretical models developed by de Gennes (1987) and Fleer et al. (1993). Both systems of analysis predict that under full equilibrium conditions, i.e., when polymers are free to desorb as the surfaces approach each other, purely attractive forces are generated by homopolymers. The reason for this is that, as some polymers desorb from the surfaces, a greater fraction of the remaining polymers will attach to both surfaces and a bridging attraction will pull them towards each other. Hence, under full equilibrium conditions one does not expect steric stabilization to result from adsorption of homopolymers. The reason that homopolymers can be used as steric stabilisers is that, due to a very slow desorption, they are retained on the surface during a collision event, and the interactions are thus better described by theories for interactions between surfaces carrying irreversibly adsorbed polymers. In this case contributions are to be considered from osmotic pressure and elasticity. The osmotic contribution includes changes in ideal entropy of mixing and changes in solvation of the polymer segments. The elastic contribution can be due to a reduction of the number of possible conformations of the polymer chains at smaller surface separations. Under restricted equilibrium conditions, the second contribution always becomes increasingly repulsive as the surface separation is decreased, and it becomes dominant at sufficiently small separations. This is a more formal definition of the steric repulsive force, which is very important in the stabilization of many colloidal systems, including mineral particles in coating. 


\section{Swelling vs. charge}

The degree to which aqueous solutions diffuse into the cell walls of fibers can be evaluated by solute exclusion, centrifugation, and other methods. Solute exclusion tests (Stone and Scallan 1968; Scallan and Carles 1972; Maloney et al. 1999) require the assumption that there is no significant net attraction or repulsion between certain highmass dextran molecules and the fibers. Also it is assumed that the selected dextran molecules are too big to diffuse into the pore structure, other than the fiber lumens. It follows that some water from solution will be present within pore spaces that are not accessible to the solute molecules. Thus, the concentration of the dextran in the bulk solution can be expected to be greater than what would be calculated simply from the total mass of water, solids, and dissolved dextran; this difference is used to calculate the volume of inaccessible pores in the system.

A related quantity, the water retention value (WRV), is defined by the results of centrifugation tests (Thode and Ingmanson 1959; Jayme and Büttel 1968; Anon. 1981; Maloney et al. 1999; Ahrens et al. 1999). To perform such tests, researchers prepare damp plugs of their sample and run the centrifuge for a specified time and acceleration. After weighing the centrifuged damp cellulosic samples, the material is dried and weighed again. The WRV equals the ratio of water to dry mass in the centrifuged sample. According to the original interpretation, the centrifugal force is assumed mainly to remove water from between fibers, as well as from the fiber lumens. However, systematic deviations can be expected between results of solute exclusion and WRV results (Scallan and Carles 1972). In particular, work by Ström and Kunnas (1991) implies that WRV test results can be markedly affected by water that is associated with surface fibrillation, and also by chemical additives that affect surface-bound water, in addition to water in the cell wall structures.

Significant decreases in swelling have been observed when water-swollen cellulosic samples were treated with high-charge cationic polyelectrolytes (Swerin et al. 1990; Ström and Kunnas 1991; Notley 2008). Such results suggest that the chemical treatment causes the fibrils to lie down on the fiber surfaces and possibly to line up to a greater degree so that less water is held between and among the fibrils. In addition, the effective sizes of nanopores in the cell wall structure appear to change as a function of how the fiber plugs are prepared, the acceleration intensity, the duration of centrifugation, etc.

In general, higher negative zeta potential, which often is indicative of a higher density of anionic carboxylate groups at a cellulosic surface, has been correlated to higher degrees of swelling (Ribitsch et al. 2001). Less swelling has been observed in cellulosic samples containing hydrophobic substituent groups (Bletzinger 1943). In simple terms it is reasonable to expect that interactions with water ought to be weakened as the proportion of $\mathrm{OH}$ groups becomes smaller. However, such effects should not necessarily be assumed to be monotonic with increasing degree of substitution. Work by Ehrnrooth et al. (1977) showed that the first five percent of acetylation of cellulose hydroxyl groups actually can enhance the swelling of cellulose in water, and this effect was attributed to an interruption in the regularity of macromolecular structure. Such disruption, in small amounts, might decrease the proportion of surface-bound $\mathrm{OH}$ groups that are involved in the inter- and intra-molecular hydrogen bonding of cellulose.

Hubbe and Rojas (2008). "Colloidal stability of cellulosics," BioResources 3(4), 1419-1491. 1437 


\section{Swelling, salt, and the Donnan equilibrium}

To account for swelling, Scallan (1983) proposed that fibers be considered as a cross-linked polyelectrolyte gel (Northrop and Kunitz 1926; Grignon and Scallan 1980; Scallan 1983; Alince and van de Ven 1997). The term "polyelectrolyte" is justified by the fact that cellulosic material can contain a significant level of ionizable groups. The term "gel" is appropriate because although cellulose can swell, its complete dissolution is resisted by the presence of crystalline regions. Using the analogy of a sponge, the cellulosic material is assumed to stretch in an elastic manner as water is drawn into the pores by osmotic pressure. A correlation has been observed between the negative charge density and the amount of water taken up by fibers (Scallan 1983; Lindström and Carlsson 1982; Lindström 1992; Scallan and Tigerström 1992; Laine and Stenius 1997; Salmén and Berthold 1997; Ribitsch et al. 2001; Baltazar-Y-Jimenez and Bismarck 2007). The addition of salt ions generally has been shown to decrease the swelling of cellulosic materials in aqueous systems (Fält and Wågberg 2003; Tammelin et al. 2005).

Scallan and Tigerström (1992) showed, by use of Donnan equilibrium theory, that the degree of swelling can be used to estimate the magnitude of elastic forces within cellulosic fibers. As is true for polyelectrolyte gels in general, the charged groups within a fiber cell wall are fixed in location (Scallan and Tigerström 1992; Freudenberg et al. 2007). Water will tend to penetrate into a charged gel material, especially if the ionic content of the water phase is low. Such an in-flow of water builds up a net pressure, which is resisted by the elastic forces within the swellable material. Stiff fibers, such as those containing substantial amounts of lignin, are expected to have greater forces resisting expansion. However, if the higher-yield fibers also have a higher density of acidic groups, their greater stiffness will need to compete against the effect of higher osmotic pressure. In the absence of salt the osmotic pressure, tending to cause swelling of a charged gel, can be predicted from

$$
\pi=R T(1+z) \alpha c_{p} / M_{p}
$$

where $R$ is the gas constant, $T$ is absolute temperature, $z$ is the number of chargeable groups per polymer, $\alpha$ is the fraction of those groups in their ionized state, $c_{p}$ is the mass concentration of the polymer, and $M_{p}$ is the molecular mass of the polymer (see Hiemenz and Rajagopalan 1997).

The dependencies of swelling of cellulosic materials on such factors as salt concentration and $\mathrm{pH}$ have been found to be in good agreement with theory (Grignon and Scallan 1980). The relative increase in swelling, compared to an equivalent, uncharged gel structure, could be fit to the equation

$$
\left(V-V_{o}\right) /\left(V_{c}+V_{o}\right)=R T(n / V) / K,
$$

where $V$ is the swollen specific volume, $V_{o}$ is the specific volume in the absence of charged groups (for instance, at very low $\mathrm{pH}$ in the case of carboxyl groups), $V_{c}$ is the specific volume of cellulose (or other solid), $n$ is the concentration of the ionic species responsible for the swelling, and $K$ is the effective elastic modulus of the material

Hubbe and Rojas (2008). "Colloidal stability of cellulosics," BioResources 3(4), 1419-1491. 1438 
(Scallan and Tigerström 1992). Laine et al. (2003a) employed Eq. (5) to distinguish the effects of surface swelling vs. bulk swelling of cell walls.

To obtain good fits to Eqs. (4) and (5) it was necessary, especially when no salt was added, to assume values of the fractional dissociation $\alpha$ that were much lower, at a given $\mathrm{pH}$, compared to what would be expected for carboxyl groups in bulk solution. This effect was explained in terms of Donnan equilibrium theory, which predicts a shift in the local $\mathrm{pH}$ within very small pores, relative to the $\mathrm{pH}$ at in the bulk phase adjacent to the fibers. The effect also can be regarded as a shift in the $\mathrm{p} K_{a}$ values of the carboxyl groups within fiber cell walls (Freudenberg et al. 2007).

Decreased thickness of double layers also can be used as a way to explain decreased swelling of fibers, especially when salt ion levels are increased from the $0.1 \%$ range to higher concentrations. It makes sense that the electrostatic repulsion forces tending to expand the sizes of pores within cellulose ought to become less effective when the double layer thickness becomes small relative to the pore size. What is less often reported is that the swelling of cellulosic fibers can decrease when the salt concentrations are reduced to very low levels (Li and Dai 2004). In other words the swelling of fibers can go through a maximum with increasing salt concentration. The decreased swelling in the absence of salt ions is consistent with the estimated 2-50 $\mathrm{nm}$ size of typical pores within the cell walls of wet pulp fibers (Stone and Scallan 1968; Deodhar and Luner 1980; Berthold and Salmén 1997; Alince 2002; Andreasson et al. 2003). As described elsewhere (Hubbe et al. 2007a), the calculated thickness of double layers in the absence of salt ions is too large for the double layer to fit within such nanopore spaces. Figure 5 illustrates the contrasting situation of a system in which charged groups and counter-ions exist within the tiny pores within cell walls $(5$, left), vs. suppression of dissociation and double layers when no salt is present (5, right). As the concentration of monomeric ions is increased from nil to about $1 \mathrm{mM}$, corresponding to an electrical conductivity range from near zero up to hundreds of $\mu \mathrm{S} / \mathrm{cm}$, double layers will have sufficient space to be able to form and contribute efficiently to electrostatic repulsion forces.

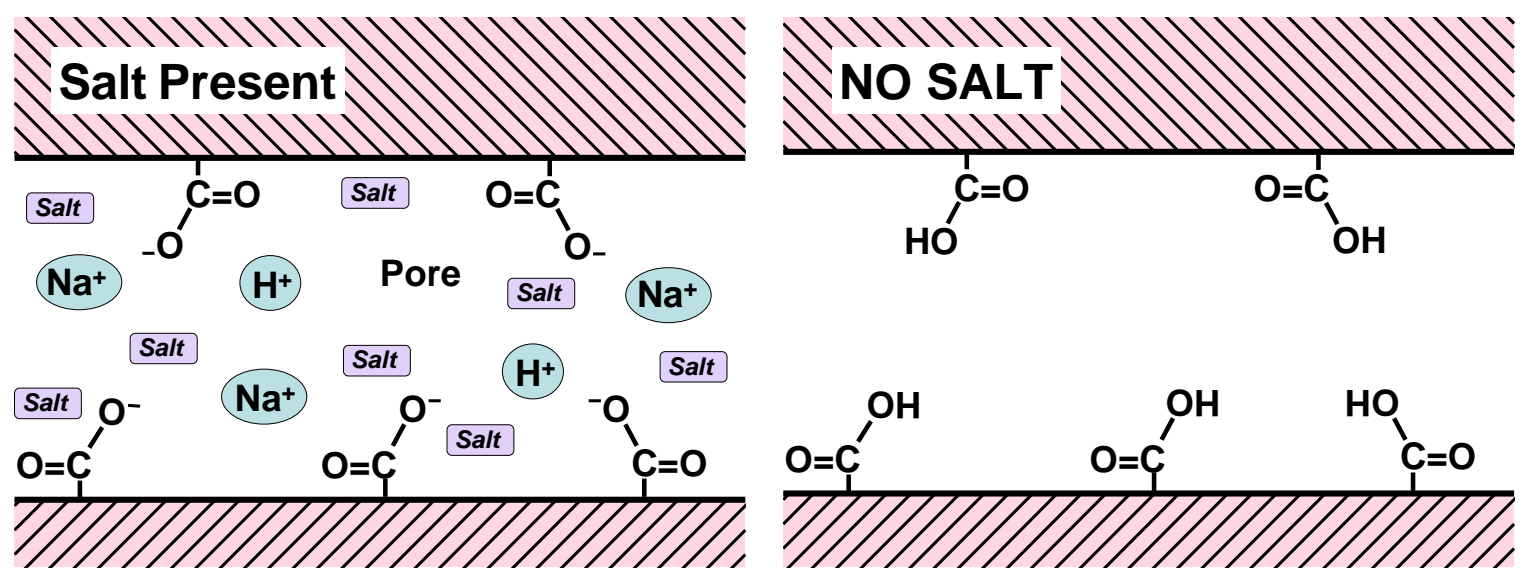

Fig. 5. Representations of (left) a nanopore within cellulosic material in the presence of salt ions in aqueous solution; note presence of dissociated weak acid groups and counter-ions, and (right) suppression of weak acid dissociation and ionic double layer effects in absence of salt ions 
Swelling effects, as just discussed, do not necessarily affect all parts of a cellulosic fiber equally. The structure of a kraft fiber tends to be looser in the surface region of a cell wall (Laine et al. 2003a). Thus, the surface layers, including cellulosic fibrils at the fiber surface, can be expected to imbibe more water in comparison to an equal mass of material from elsewhere in the fiber. Such effects can be further enhanced by surface-selective treatment to increase the negative charge of fiber surfaces, e.g. by carboxymethylation. Conversely, neutralization of charges at the fiber surface, for instance by treatment with a high-charge cationic polyelectrolyte, can be expected to decrease the swelling (Ahola et al. 2008a,b).

\section{COAGULATION AND STABILITY}

The word "coagulation" is commonly used to describe events involving small particles, droplets, or bubbles of one type of material dispersed in a liquid phase. Coagulation is said to have occurred if, during the time of observation, the dispersed phase undergoes sticking collisions, resulting in agglomerated solids or droplets, the matting down of fibrils at a surface, etc. The terms coagulation and flocculation are often used interchangeably. Sometimes the term coagulation is used to imply the formation of compact aggregates by charge-related effects, leading to a macroscopic separation of phases. The term flocculation is used to describe the formation of a loose or open network that may or may not separate macroscopically.

A "stable" colloidal dispersion means that even if the particles collide with each other to a significant extent during the time of observation, most of them remain individually suspended or otherwise in an expanded form in the medium. Coagulation can be triggered by increasing the electrolyte concentration to a value greater than or equal to the critical coagulation concentration (CCC). The value of the CCC depends on the experimental conditions, e.g. the surface charge characteristics, particle sizes, method of mixing, time of mixing, etc.

Although the emphasis here will be on the characteristic colloidal behaviors of cellulosic materials, such behaviors in many respects mirror those of other substances for which the theories have been more fully developed (Hiemenz and Rajagopalan 1997). The DLVO theory has been used to predict trends in the rates of coagulation between charged particles in aqueous suspension. In DLVO force profiles, as explained before, the distance-dependencies of the attractive and repulsive components of force tend to be quite different from each other. In typical situations, the attractive component of force becomes dominant if and when the particle surfaces actually come into contact.

\section{Kinetics of Coagulation}

Even in the absence of flow, it is well known that very small particles undergo ceaseless, erratic motion. The motion is associated with the thermal energy of each particle, equal to $1 / 2 k T$ of average kinetic energy in each of the three Cartesian coordinates. Because of such motions, even if there is a net repulsion between particles at intermediate distances, there is always a finite chance that diffusion will succeed in overcoming the barrier of interactive energy that stands in the way of coagulation (see the

Hubbe and Rojas (2008). "Colloidal stability of cellulosics," BioResources 3(4), 1419-1491. 1440 
"energy barrier illustrated in Fig. 3, right and also in Fig. 6). In the case of smooth spheres of arbitrary size, the surfaces of which have variously relatively low values of electrical potential, equations given by Hogg et al. (1966) have been found adequate to estimate rates of coagulation in terms of the DLVO theory.
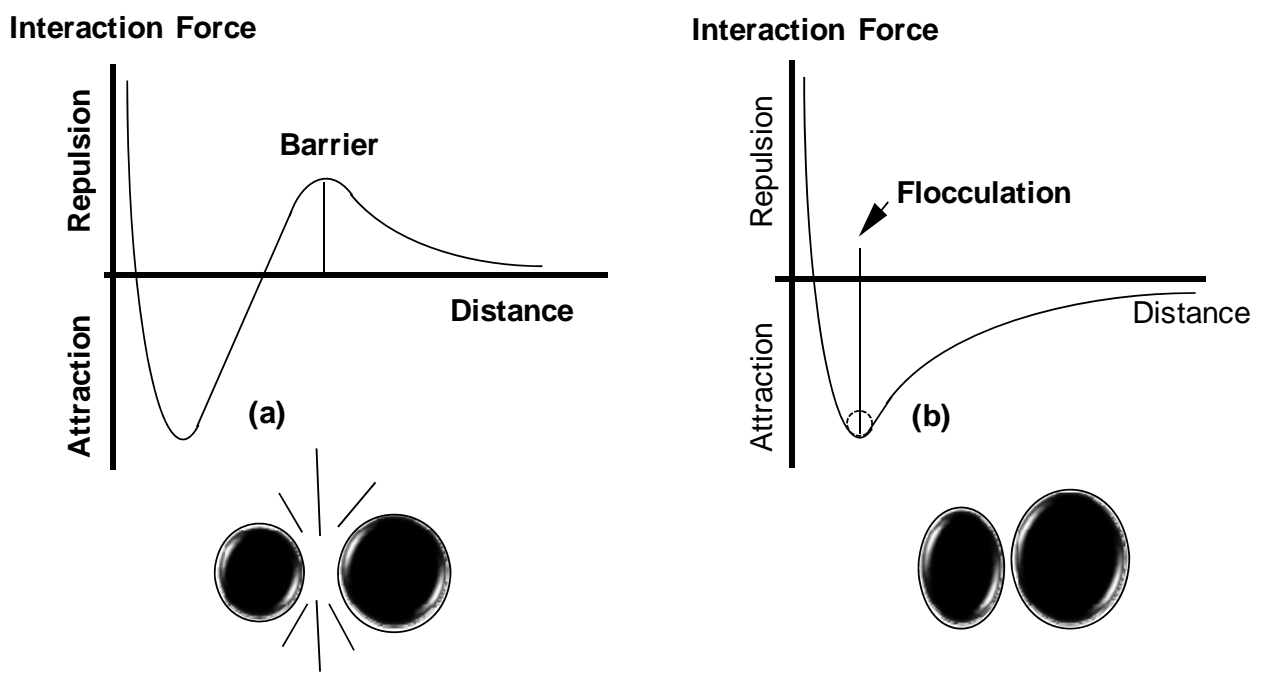

Fig. 6. Schematic diagrams of net interactive force between surfaces as a function of separation distance. Left: A typical shape of such a curve in presence of electrostatic repulsion in aqueous solution. Right: Shape of curve expected if the electrostatic repulsion becomes insignificant.

Relatively few investigators have attempted to directly test the implications of the DLVO theory in the case of cellulosic particles in aqueous suspension (Kratohvil et al. 1969; Walkush and Williams 1974; Donnan et al. 1981). Kratohvil et al. (1969) found, consistent with theory, that the stability of microcrystalline cellulose (MCC) suspensions increased with increasing $\mathrm{pH}$, which resulted in increasingly negative surfaces. However, not all of the observations agreed with the DLVO predictions. The stability of MCC suspensions was found to be much more sensitive to the concentrations of cations, compared to what would be expected from the theory. Much better agreement has been found, for instance, for silver halide and hydrous oxide particles (Matijević et al. 1953; Bleier and Matijević 1976). It would seem reasonable that at least part of the lack of fit with DLVO theory is due to the complex surface morphology of typical cellulosic materials, as noted earlier. Still, Walkush and Williams (1974) found good agreement of cellulose suspension coagulation with the well-known Shulze-Hardy rule, which predicts the dependency on counter-ion valence of the minimum electrolyte concentration capable of bringing about coagulation, i.e. the critical coagulation concentration. Thus, as in the case of other colloidal suspensions, a high valence of the oppositely charged ions in an added electrolyte gives a low critical coagulation concentration.

\section{Rapid coagulation and stability ratio}

The rate of aggregation is in general determined by the frequency of collisions and the probability of cohesion during collision. It is customary to refer to "perikinetic aggregation" when the collisions are caused by Brownian motion. On the other hand 
aggregation is termed "orthokinetic" when it is caused by hydrodynamic motions (e.g. convection or sedimentation). A parameter $W$, called the colloid stability ratio (Hogg et al. 1966), can be defined as the ratio of the observed time required for a certain degree of coagulation, when compared to the time for an equivalent suspension to coagulate in the absence of repulsive forces between the particles (diffusion-controlled collision rate that corresponds to "rapid" coagulation). For instance, a sufficiently high concentration of salt can be added so that the effects of electrostatic repulsion become negligible, and essentially every random collision between suspended particles becomes a sticking collision. Alternatively, a strongly-adsorbing ionic species may be added to neutralize the surface charge.

These concepts also apply to heterogeneous systems. Kleimann et al. (2006) and Ravnjak et al. (2007) observed cases involving deposition of positively charged particles onto cellulose. Though in both cases the results initially were consistent with nearly $100 \%$ of sticking collisions, the deposition rates ultimately were found to be controlled by the available space on the cellulosic surfaces. Kamiti and van de Ven (1995) studied the rates of deposition and detachment of calcium carbonate particles onto a flat cellulose substrate subjected to stagnation-point impinging flow. They found that the results obeyed the expectations based on charge interactions following treatment by high-charge moderate-mass cationic polymer. However, the results did not follow DLVO rule expectations in cases where a very-high-mass cationic polyelectrolyte had been added. Halab-Kessira and Ricard (1996) likewise showed reasonable trends when testing stabilization ratios in the case of calcium carbonate particle deposition onto cellulose that had been treated with a cationic polymer. Wang and Chase (2004) found reasonable agreement with trends predicted by the DLVO equation when applied to $\mathrm{TiO}_{2}$ particle deposition onto cellulose under different conditions of $\mathrm{pH}$ and salt concentration.

An early study by Haslam and Steele (1936) was the first to document a rather striking and characteristic feature of colloidal particle deposition onto fibrillated cellulosic fibers. That is, rather than depositing onto the main surface of the fiber, there was a strong tendency for particles to become attached to fibrils extending from the fiber surfaces. Such an effect was independently reported more recently (Siffert and Metzger 1991). Two kinds of explanations can be given. On the one hand, if both surfaces have the same sign of charge, the predicted forces of repulsion between a small particle and a very thin fibril is expected to be much less than for the same particle to approach the broad surface of the fiber, especially if the surfaces are otherwise assumed to be identical. As a consequence, depending on the details, chain-like agglomeration may be favored over gross agglomeration. In addition, hydrodynamic effects can be expected to decrease the likelihood of flow-induced collisions between a particle and the broad surface of a fiber, compared to a fibril (van de Ven and Mason 1981).

Detachment forces can be used as a sensitive way to probe the mechanisms by which double layers respond to changes in the distances between surfaces. Most theoretical studies of coagulation rates start by assuming that the electrical potential of the surfaces remains constant as the surfaces move relative to one another. For instance, Eq. (3), is based on a "constant potential" assumption. But other assumptions are possible, including "constant charge" (Wiese and Healy 1970) and a model in which there is a continual re-equilibrium and adjustment of local charges and potentials as the

Hubbe and Rojas (2008). "Colloidal stability of cellulosics," BioResources 3(4), 1419-1491. 1442 
surfaces move relative to each other (Chan et al. 1976). As shown by Hubbe (1987a), the choice between the "constant potential" and the "constant charge" model can have a big effect on the outcome of calculations dealing with forces required to detach particles from cellulose film or glass. Results for detachment of a variety of oxide spheres, over a range of $\mathrm{pH}$ and ionic strength values, generally fell within the range between predictions based on the assumptions of constant potential and constant charge.

\section{Sediment density}

The structure of coagulated or sedimented matter can provide additional information about interactive forces. A relatively dense sediment structure can be expected in cases where the settling particles are able to slide over each other's surfaces. Conversely, if the surfaces stick firmly at the points of initial contact, then a more bulky, space-filling structure can be expected.

Measurements of sediment specific volume have been exploited in various studies related to cellulosic materials (Kline 1967; Alince and Robertson 1974; Gruber et al. 1997; Hubbe et al. 2007c). For instance, Alince and Robertson (1974) treated microcrystalline cellulose (MCC) suspensions with different amounts of either low-mass or high-mass polyethyleneimine (PEI). Results with the low-mass coagulant were consistent with a charge neutralization mechanism of coagulation. The maximum coagulation and bulkiest sediment corresponded to a PEI dosage just sufficient to neutralize the net surface charge. Poor agreement with the charge neutralization mechanism was observed initially when MCC was first treated with high-mass PEI; however, the results became much closer to those with the low-mass PEI if the coagulated suspensions were strongly agitated to break up the initial agglomerates. These observations suggest that the high-mass PEI at first agglomerated the MCC by a non-equilibrium mechanism, i.e. charged patches or polymer bridges, but that the combined influences of strong agitation and the passage of time tended to distribute the surface charges more uniformly over the exposed surfaces.

\section{Flow effects}

As has been well explained in earlier articles (Alince et al. 1991; Alince and van de Ven 1993; Kamiti and van de Ven 1995; Swerin and Ödberg 1997; Hubbe 2007), hydrodynamic factors can have a dominant effect on collisions among particles in suspensions of cellulosic materials, leading to rates of coagulation much higher than what would be predicted in the absence of flow. Factors affecting flow-induced (orthokinetic) coagulation rates include particle sizes, shapes, numbers per unit volume, shear rates, forces of interaction (including hydrodynamic lubrication effects), and whether the flow is predominantly laminar or turbulent. Readers are directed to the cited literature for discussion of these issues.

The flow properties of suspensions also can be used as an indication of interactive forces among cellulosic fibers or nanofibers (Bennington et al. 1990; Swerin et al. 1992; Swerin and Ödberg 1993; Hubbe 2000b; de Souza Lima and Borsali 2002; Kang and Paulapuro 2006; Yaginuma and Kimiji 2006). Research has established concepts such as the yield stress of a fiber suspension (Bennington et al. 1990) and the elastic and inelastic components of resistance to deformation of fiber flocs, especially following their

Hubbe and Rojas (2008). "Colloidal stability of cellulosics," BioResources 3(4), 1419-1491. 1443 
treatment with cationic polyelectrolytes. In general, higher resistance to deformation and flow of suspensions has been observed in cases where inter-particle repulsions were reduced by addition of cationic adsorbates, salt, or by reducing the $\mathrm{pH}$ in the range 6 to 2.5 .

\section{Effects of pH on Coagulation}

A reported increase in apparent viscosity of a cellulosic fiber suspension with decreasing $\mathrm{pH}$ (Yaginuma and Kimiji 2006) has been attributed to protonation of carboxylate groups at the fiber surfaces, thus tending to neutralize the negative surface charge. In fact, many studies have shown that $\mathrm{pH}$ is one of the key variables affecting coagulation of lignocellulosic materials in suspension (Kratohvil et al. 1969; Jaycock and Pearson 1976a,b; Leiviskä et al. 2005; Yaginuma and Kimiji 2006). In general, processes that yield a higher negative titratable surface charge at a given $\mathrm{pH}$ can be expected to provide higher negative values of zeta potential and greater colloidal stability in the absence of multivalent cationic additives (Goulet and Stratton 1990). As has been noted, the relative density of carboxylate groups can be affected by different kinds of pulping, bleaching, and related processes (Goulet and Stratton 1990; Laine 1997).

Effects related to $\mathrm{pH}$ generally can be attributed to changes in the dissociation of weak acid and basic groups. Thus, changes in the charge of cellulosic surfaces with changing $\mathrm{pH}$ usually can be predicted based on one or more dissociation constants. Equilibrium reactions of surface-bound carboxyl groups can be described by the following type of equation,

$$
\mathrm{RCOOH}=\mathrm{RCOO}^{-}+\mathrm{H}^{+}
$$

where $\mathrm{R}$ can represent various materials at the cellulosic surface. The dissociation constant corresponding to Eq. (1) is given by the expression

$$
K_{a}=\left[\mathrm{RCOO}^{-}\right]\left[\mathrm{H}^{+}\right] /[\mathrm{RCOOH}]
$$

Using an analogy the definition of $\mathrm{pH}$, the $\mathrm{p} K_{a}$ of a weak acid can be defined as the negative logarithm (base ten) of the acid dissociation constant. A convenient feature of this definition is the fact that the values of $\mathrm{pH}$ and $\mathrm{p} K_{a}$ are equal when the concentrations of the two species $\mathrm{RCOOH}$ and $\mathrm{RCOO}^{-}$also are equal.

A correction to Eq. (7) is required for those weak acid groups that are located below the fiber surface. To a first approximation, the electrical potential of the environment in the interior of a fiber in aqueous solution is shifted relative to the bulk by an amount equal to the double-layer potential at the fiber surface. To account for this, the corrected value of $K_{a}$ for the interior groups can be estimated from

$$
K_{a}{ }^{\prime}=K_{a} \exp [-z F \psi / R T],
$$

where $z$ is the valence, $F$ is the Faraday constant, $\psi$ is the difference in electrical potential from the bulk to the interior of the fiber, $R$ is the gas constant, and $T$ is the absolute temperature.

Hubbe and Rojas (2008). "Colloidal stability of cellulosics," BioResources 3(4), 1419-1491. 1444 
Several investigators have concluded, based on data from potentiometric titrations with $\mathrm{NaOH}$, that two main classes of carboxylate groups are commonly found at cellulosic fiber surfaces (Stenius and Laine 1994; Laine et al. 1996; Laine 1997; Lindgren et al. 2002). According to Stenius and Laine (1994) one set of carboxyl groups has a $\mathrm{p} K_{a}$ value of about 3.6, and the other set has a $\mathrm{p} K_{a}$ near to 5.7. The stronger acidic groups have been attributed to the uronic acid component of hemicelluloses, and the weaker acidic groups have been attributed to carboxyl groups on lignin (Laine 1997). Lokhande and Salvi (1978) employed a similar analysis in the case of fibers that had been treated with a cationic agent, resulting in a $\mathrm{p} K_{a}$ value as high as 7.

\section{Salt Effects on Coagulation}

The concentrations of different salt ions in aqueous solution can be expected to have various effects on the electrical properties, and consequently on the colloidal stability of cellulosic surfaces. Monovalent ions, even if they have no particular affinity for the surface, can be expected to affect the degree of dissociation of surface-bound weak acid groups, as a function of $\mathrm{pH}$. The mechanism works as follows: When weak acid groups are bound at fixed locations, the dissociation of one group may affect the electronic environment of other groups nearby (Athley et al. 2001). Whether there are significant effects on the dissociation of those neighboring groups depends not only on their distance from the first group, but also on the salt concentration. When the salt concentration is very low, the calculated thickness of the ionic double layer will be correspondingly large, and one can expect a shift in the corresponding dissociation constants to $\mathrm{pH}$ values higher than one would expect in the case of an isolated carboxyl group of the same type. But when the salt concentration increases, the results of potentiometric titrations can be expected to approach closer and closer to the original predictions for isolated, chemically equivalent acid groups.

Another consequence of increasing salt concentration is that absolute values of zeta potential tend to decrease (Lindström and Söremark 1975; Hunter 2001; Wang and Hubbe 2002). The usual explanation for this effect is based on the concept of a hydrodynamic slip plane, as introduced in the section entitled "Zeta Potential". Thus, the effect has been attributed to a greater proportion of the double layer lying inside of the hydrodynamic slip plane. Since zeta potential values are often used for calculations of the electrostatic components of force, for instance when using Eq. (3), it is reasonable to expect that electrostatic forces will be decreased.

In addition to the possible effect of salt on the electrical potential terms used in calculating forces, salt concentration also enters into the calculation in the term $\kappa$, which was defined in Eq. (2). Once again, the predicted effect of increasing salt concentration is to decrease the relative thickness of ionic double layers, thereby decreasing the electrostatic component of force between solids at a given distance from each other.

\section{Specific ion interactions}

The words "specific adsorption" imply that solubilized ionic species adsorb at a cellulosic surface to a higher extent than would be predicted just on the basis of their concentration, sign of charge, and valence. Rather, certain ions are able to form complexes of differing stability with surface-bound ionic groups. Figure 7 presents an

Hubbe and Rojas (2008). "Colloidal stability of cellulosics," BioResources 3(4), 1419-1491. 1445 
idealized view of this concept, in which the label " $\mathrm{Al}^{3+}$ " is used to represent ions that are able to form relatively stable complexes with surface-bound groups. Indeed it has been proposed that carboxylate groups can act as ligands coordinated with hydrated aluminum ions.

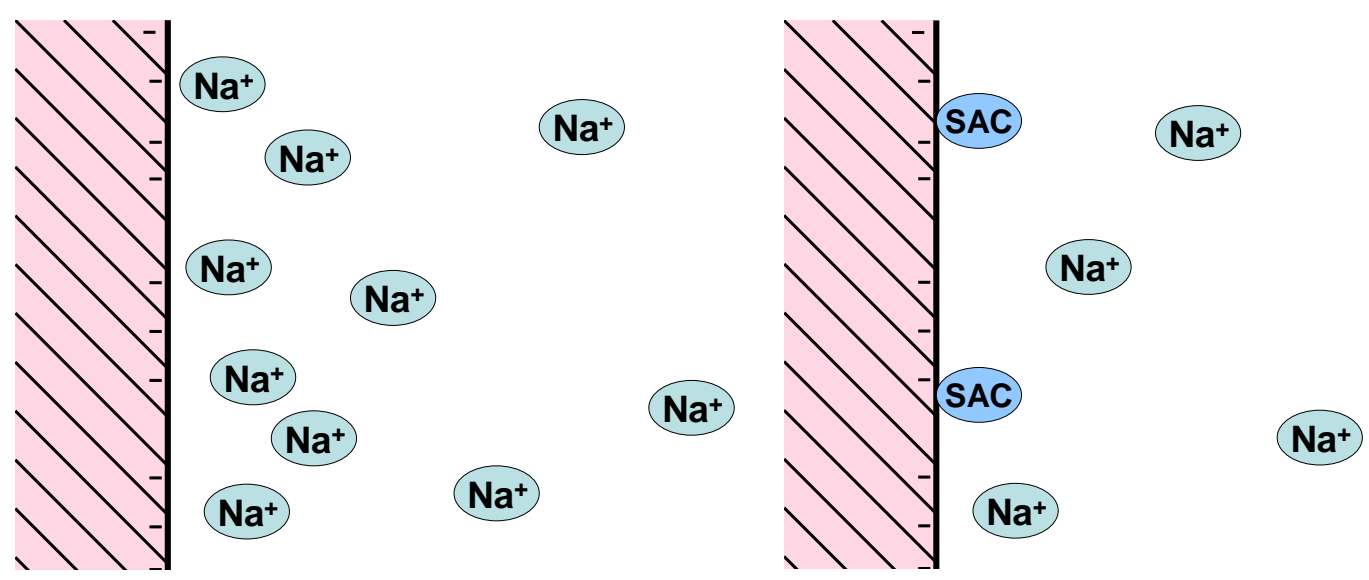

Fig. 7. Representations of (left) a cellulosic surface in the presence of monovalent salt ions; only the counter-ions are shown, and (right) specific adsorption (in the condensed part of a double layer) by, for instance, certain multivalent aluminum cations, e.g. $\mathrm{Al}_{\mathrm{a}}(\mathrm{OH})_{\mathrm{b}}{ }^{(3 \mathrm{a}-\mathrm{b})^{+}}$Note: "SAC" means "specifically adsorbed cation".

The relatively strong adsorption of certain ionic species of partially hydroxylated aluminum has many practical implications. Ionic species form through progressive interaction of $\mathrm{OH}^{-}$groups with the $\mathrm{Al}^{3+}$ hydrated ion (Bottero and Fiessinger 1989; Bottéro et al. 1989; Bi et al. 2004). Certain of these ionic species associated with values of $\mathrm{n}$ between about 1.5 and 2 in the equation

$$
\mathrm{Al}^{3+}+n \mathrm{OH}^{-}=\mathrm{Al}(\mathrm{OH})_{n}^{(3-n)^{+}}
$$

have been found to be especially effective in bringing about coagulation in suspensions of negatively charged matter (Bottéro et al. 1980; Donnan et al. 1981; Arnson and Stratton 1983; Strazdins 1989; Exall and vanLoon 2003). These effects have been attributed to the combination of large size and high valence of the partially hydroxylated aluminum oligomers. High valence and oligomeric character both appear to contribute to strong complexation with an oppositely charged surface.

Ödberg et al. (1995) carried out a detailed analysis on how the value of $n$ in equation (9) affected the ease with which adsorbed aluminum species could be transferred from the surfaces of cellulosic fibers to freshly added kaolin clay particles. In general they found that transfer of aluminum from cellulose to clay surfaces was insensitive to the value of $n$. Subsequent work by Öhman et al. (1997) showed a gradually increasing adsorption tendency onto cellulose fibers with increasing value of $n$ up to about 2.9, followed by a sharp rise in adsorbed amount up to $n=3$. Zero electrophoretic mobility was not reached until a value of $n=3.2$ to 3.3 at a $\mathrm{pH}$ of about 9.5. The latter value is consistent with the iso-electric $\mathrm{pH}$ of aluminum hydrous oxide materials (Parks 1965; Brace and Matijević 1973). 


\section{Surfactants and Coagulation}

Even when they are present as relatively minor constituents, surface-active substances can have dramatic effects in such processes as detergency, wetting, emulsification, and fabric softening. In the case of non-ionic surfactants, work by Torn et al. (2005) showed that at relatively low concentrations both tails and headgroups are likely to participate in adsorption to cellulosic surfaces. At higher concentrations one can expect lateral interactions between hydrophobic chains, leading to micelle-like structures at the cellulose-aqueous interface.

In the case of charged surfactants, small added amounts can cause large changes in the charged nature of cellulosic surfaces (Reischl et al. 2006). Cationic surfactants can be expected to have a particularly strong adsorption from aqueous solution onto cellulosic surfaces (Touchette and Jenness 1960; Grancaric et al. 1997; Paria et al. 2004). Relatively strong adsorption is expected due to the combined influence of attraction between opposite charges and the surface-active nature of the adsorbate. Penford et al. (2007) took the unusual approach of depositing a monomolecular film of a surface-active material onto a flat cellulose film, using the Langmuir-Blodgett method. Although the surfactant film remained as a monolayer when transferred to a cellulose surface, some "surface aggregates" were observed in the case of a higher-negative-charge, more hydrophilic silica surface (Penford et al. 2007; Alila et al. 2007). Alila et al. (2005, 2007) found that the adsorbed amount was increased if the cellulose film surface had been oxidized to increase its negative charge density. Habibi et al. (2007) used a related approach to prepare Langmuir-Blodgett films of nanocrystalline cellulose within a twodimensional matrix of a cationic surfactant. Biswas and Chattoraj (1997) showed that the adsorption of cationic surfactant at the cellulose-water interface also was affected by the presence of urea. In particular, the adsorbed amount of the surfactant may decrease when its bulk concentration exceeds the critical micelle concentration. Grancaric et al. (2005) showed how the adsorption of cationic surfactant can be expected to affect the zeta potential of cotton, thus affecting the coagulation tendency.

Anionic surfactants also adsorb at cellulose-aqueous interfaces, but to a lesser extent. Work by Paria et al. (2005) has shown that such adsorption is affected by the presence of cations in solution. Adsorption of anionic surfactant increased with increasing monovalent and divalent cation concentrations, whereas no such effects were observed in tests with a nonionic surfactant.

Relative to their interactions with cellulosic surfaces it is reasonable to consider dye molecules as playing a role similar to that of surfactants. The kinds of dyestuffs most commonly used in the manufacture of paper consist of highly conjugated, hydrophobic multi-ring structures, often containing sulfonate groups to aid in their solubility and to provide a mechanism for their firm attachment to the substrate. Espinosa-Jimenez and Gonzalez-Caballero (1991) showed that adsorption of such a dye onto cellulose increased the negative value of streaming potential. However, adsorption increased as the number of sulfonate groups on the dye molecules decreased; this effect is consistent with the decreasing solubility of such dyes in the aqueous phase. Multivalent cationic additives are frequently used as mordants for anionic dye molecules, and such strategies can be especially important with increasing solubility and anionic charge of the dyestuff. Iamazaki and Atvars (2007) studied the adsorption of fluorescent whitening agent

Hubbe and Rojas (2008). "Colloidal stability of cellulosics," BioResources 3(4), 1419-1491. 1447 
(FWA), which, in terms of its adsorption behavior can be considered to be an anionic direct dye. Addition of cationic surfactant below its critical micelle concentration (CMC) was found to increase the adsorption of the FWA, whereas in the case of anionic surfactant the adsorption of FWA increased above the CMC. These effects were attributed to surfactant aggregation.

\section{POLYELECTROLYTE-INDUCED EFFECTS}

Charged, water-soluble polymers can have profound effects on the stability and agglomeration of aqueous suspensions. Colloidal interactions involving polyelectrolytes and cellulosic surfaces have been reviewed (Werner and Jacobasch 1996; Werner et al. 1999; Pelton 1999).

\section{Adsorption}

Adsorption of the macromolecules is a necessary step in many kinds of processes that affect colloidal stability. In a broad sense, the adsorption of polyelectrolytes at cellulosic interfaces can be expected to obey thermodynamic principles (Wågberg and Ödberg 1989; van de Steeg et al. 1992; Fleer et al. 1993; Lindström 1996; Pelton 1999; Wågberg 2000). Compared to monomeric ions, the entropy content of a given mass of dissolved polymer is quite low. Each repeating unit, due to its connection to adjacent units, has considerable constraints on its freedom of movement at any moment in time. As a consequence, the system can lose only a modest amount of entropy that is attributable to transfer of a dissolved polymer from the bulk solution to the surface. Meanwhile, any monomeric species that may be displaced from a surface, due to polymer adsorption, can make a positive contribution to the entropy change. These considerations imply that polyelectrolyte adsorption can take place even in some cases where it would not have been predicted based on charge considerations alone.

"High affinity" adsorption (Wågberg 2000) of cationic polyelectrolytes onto cellulosic surfaces can be expected, since in that case an enthalpic term, due to chargecharge attraction, is added to the entropic term just discussed. Strong electrostatic interactions between cellulosic surfaces and polyelectrolytes can be expected due to a multiplicity of potential points of adsorption. Indeed, many authors have reported that various effects become stronger with increasing molecular mass of the polyelectrolyte (Unbehend 1976; Salmi et al. 2007a). Two distinguishing characteristics of high affinity adsorption are (a) the equilibrium concentration of the adsorbate in the bulk of solution remains near zero until the surface has become saturated, and (b) the adsorbate can be slow to leave the surface even if the bulk solution is replaced by polymer-free solution.

The adsorption affinity depends heavily on the ionic strength, especially if it is driven by electrostatic interactions. Four factors that accompany the screening of electrostatic forces by addition of salts can be cited (Rojas et al. 1998, 2001): (i) decrease of surface-polyelectrolyte attraction, (ii) increase of competition between the polyelectrolyte and the monovalent cations for adsorption at surface sites, (iii) decrease in free energy cost in creating a charged interface, and (iv) decrease in intra- and inter-chain repulsion. Factor (iv) facilitates an increased adsorption (screening-enhanced adsorption),

Hubbe and Rojas (2008). "Colloidal stability of cellulosics," BioResources 3(4), 1419-1491. 1448 
as observed in some systems, whereas factors (i) and (ii) promote a reduced adsorption. Related situations have theoretically been considered (Hesselink 1977; Wiegel 1977). A simple rule is that the extent of adsorption is reduced by electrolyte screening whenever the distance between charges on the surface is sufficiently smaller than that along the polyelectrolyte chain, or, in other words, when the ratio of the surface charge to the polyelectrolyte cationicity is sufficiently large.

Especially interesting adsorption results have been obtained in cases where the polyelectrolyte has the same sign as the net charge of the cellulosic substrate. Laine et al. (2000) achieved nearly quantitative adsorption of negatively charged carboxymethyl cellulose (CMC) on cellulose, but it was necessary to use high temperature, long adsorption time, and a sufficiently high salt concentration to suppress electrostatic repulsion forces. The authors proposed that the CMC acts as a "bifunctional" material, and that the uncharged segments provide a strong tendency for chain-like hydrogen bonding to cellulosic surfaces. Adsorption of CMC can be important for the development of increased bonding strength between cellulosic fibers (Laine et al. 2002). Further work showed that by pre-drying the fibers, it was possible to close up many of the small pores in the fibers, thereby restricting the CMC adsorption mainly to the outer surfaces (Laine et al. 2003a). Such externally adsorbed CMC was found to have a greater relative effect in increasing the bonding strength of paper (Laine et al. 2003b).

From the standpoint of colloidal stability some of the most important questions are whether the polyelectrolyte adsorbs with tails and loops extending outwards into the solution (see Fig. 8), whether and how fast it adopts a relatively flat adsorbed conformation, and whether or now long it stays on the outer surface. Lindström and Söremark (1976) showed that adsorption of cationic polyacrylamide increased with decreasing cationic charge density. These results are consistent with a charge-controlled adsorption mechanism. It follows that uncharged segments of the hydrophilic polyelectrolyte probably extend outwards from the cellulosic surface.

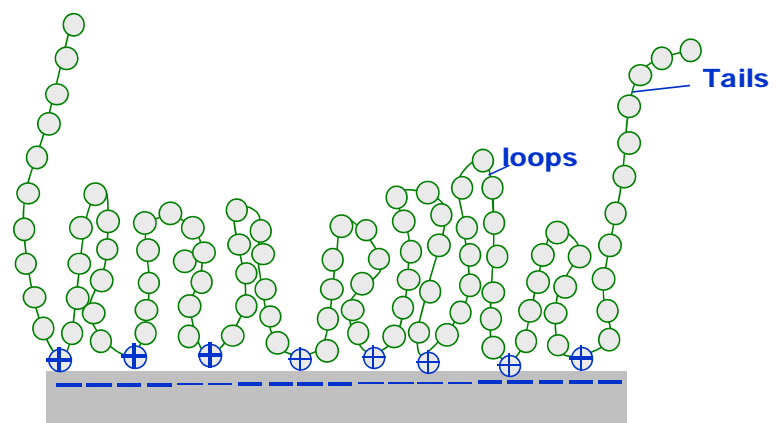

Fig. 8. Schematic illustration of a low-charge-density linear cationic polyelectrolyte adsorbing onto a negatively charge substrate (low ionic strength assumed)

Compared to Fig. 8, strikingly different images related to the conformation of adsorbed linear cationic polyelectrolytes on cellulosic surfaces were obtained in a series of studies involving transmission electron microscopy (TEM). After treatment of papermaking furnish with selected chemical additives, very small samples of the resulting mixtures were captured on wire loops, and then the thin films of water were transferred to TEM grids (Nanko and Pan 2003a,b; McNeal et al. 2005). Flow of water during drainage

Hubbe and Rojas (2008). "Colloidal stability of cellulosics," BioResources 3(4), 1419-1491. 1449 
of the films on the TEM grids tended to stretch and align the polyelectrolytes. Also, the high-mass acrylamide copolymers appeared to form strands as a result of local twisting of groups of polyelectrolyte chains (Nanko and Pan 2003b).

van de Steeg et al. (1993 a-c) studied the adsorption of cationic starches onto cellulosic surfaces as a function of the salt content of the aqueous solution. They showed that adsorption onto microcrystalline cellulose dropped to zero as the concentration of $\mathrm{NaCl}$ reached about 0.01 molar. The decrease in adsorption was attributed to screening of electrostatic effects due to the presence of salt. Related work by Bobacka et al. (1998) showed a less precipitous drop in cationic starch adsorption in the case of thermomechanical pulp (TMP) fibers, though the effect still was very significant in the industrially important conductivity range of $1000 \mu \mathrm{S} / \mathrm{cm}$ and above. The greater ability of the TMP fibers to adsorb cationic starch at relatively high electrical conductivity can be attributed to the higher negative charge density of such fiber surfaces. Shirazi et al. (2003) observed an increase in adsorption of cationic starch with increasing ionic strength, followed by a decline; these effects were attributed to a competition between adsorption/desorption of clusters of starch molecules and individual starch molecules.

Wågberg and Kolar (1996) observed that when anionic colloids are present, the complexation of cationic polymers with the colloids can become the dominant interaction, and adsorption of the cationic polyelectrolyte onto the cellulosic surfaces becomes inefficient. Likewise, if a cellulosic fiber suspension contains a lot of fines, adsorption onto the fines fraction can become important relative to the adsorption onto the long fiber fraction (Marton and Marton 1976; Marton 1980b; Wågberg and Kolar 1996). Whipple and Matesh (2002) used fluorescence spectroscopy to reveal details about polyelectrolyte adsorption phenomena in the challenging environment of a papermaking fiber slurry, which can contain substantial amounts of anionic colloidal substances. Preferential adsorption was observed onto mineral surfaces, which tend to have higher specific surface area and higher negative charge density than the cellulosic surfaces present in such mixtures.

\section{Cellulose charge alteration by polyelectrolyte adsorption}

As shown in the classic work by Varoqui (1982), the adsorption of neutral, watersoluble polymer onto cellulose can be expected to either raise or lower the measured value of zeta potential. Of these two possibilities, it is more usual to expect a decrease in the absolute value of zeta potential. This is expected if polymer tails and loops extending outwards from the surface cause the effective position of the hydrodynamic shear plane to shift outward from the surface. An opposite effect can be argued, however, if the presence of the polymer changes the dielectric constant near to the cellulosic surface, causing the double layer thickness to increase significantly.

Drastic changes in electrokinetic potential, including charge reversal, have been observed following adsorption of polyelectrolytes onto cellulosic surfaces (see, for instance, Miyanishi and Montegi 1996; Wågberg et al. 2002). It many cases the zeta potentials following polyelectrolyte adsorption appear to be almost independent of the original zeta potential of the substrate. Such observations imply that polyelectrolytes, when added in sufficient amount, usually cover the whole accessible cellulosic surface. It is especially reasonable to expect polyelectrolytes to dominate the charge character-

Hubbe and Rojas (2008). "Colloidal stability of cellulosics," BioResources 3(4), 1419-1491. 1450 
istics of the outer surfaces of a substrate if the adsorbed conformation is threedimensional, with loops and tails projecting from the surface (Varoqui 1982).

When attempting to apply the concepts just described, a simple approach is to assume a completely uniform distribution of charge on the cellulosic and other surfaces in a suspension of interest after adsorption of polyelectrolytes. Disregarding, for the moment, whether this assumption is strictly true, one of the implications is that electrostatic repulsion forces should approach zero as the measured electrokinetic potential approaches zero. This hypothesis also agrees with the well-demonstrated practice of adding high-charge, moderate-mass cationic polymers to promote fine-particle retention and more rapid release of water during the paper forming process. Maximum agglomeration of polyelectrolyte-treated cellulosic particle suspensions has been found to approximately correspond to a condition of charge neutrality (Sandell and Luner 1974). Also, various studies have shown maxima in both retention of fines and in dewatering rates when the zeta potential was near to zero (Horn and Melzer 1975; Strazdins 1994; Bhardwaj et al. 2005; Hubbe et al. 2007a).

\section{Cellulose porosity and charge decay after polyelectrolyte treatment}

Petlicki and van de Ven (1994) examined the adsorption of high vs. low molecular mass polyethyleneimine (PEI) onto and into cellulose fibers. Based on an examination of the kinetics of adsorption these authors concluded that only in the case of the low-mass PEI was there significant penetration of the polyelectrolyte into the cell walls. Various investigators have observed that larger amounts of a relatively low-mass, highly charged cationic polyelectrolyte were required to satisfy the negative surface charge of cellulosic fiber suspensions, compared to a higher-mass polyelectrolyte (Horn and Melzer 1977; Ojala 1993; Horvath et al. 2006). Likewise, van de Steeg et al. (1993b) observed higher adsorption of cationic amylose, a relatively small macromolecule, compared to cationic amylopectin, a larger, highly branched macromolecule. Such results suggest that the lower-mass polyelectrolyte is better able to penetrate into pores at the fiber surface. Wågberg et al. (1989) used such differences in their definitions of "surface charge" and "total charge," based on titrations with a high-mass vs. a low-mass cationic polyelectrolyte, respectively. Alince and van de Ven (1997) showed that it is possible to estimate the pore size of cellulosic materials by observing the molecular mass dependency of adsorbed amounts of high-charge cationic polyelectrolytes. van de Ven (2000) proposed a "sticky sieve" model to account for adsorption of cationic polyelectrolytes onto and into cellulosic substrates. It was proposed that cationic polyelectrolytes are initially attracted to exterior surfaces, but that some of them are admitted into small pores, depending on the relative sizes of polyelectrolyte, as well as the pore diameters.

Several research teams have quantified "charge decay" phenomena following treatment of cellulosic surfaces by cationic polyelectrolytes (Strazdins 1972; Penniman 1992; Koethe and Scott 1993; Miyanishi 1995b; Farley 1997; Wang and Hubbe 2002; Yoon 2007; Hubbe et al. 2007a). Though such phenomena might be considered to be just a further demonstration that lower-mass cationic polyelectrolytes are able to diffuse into small pores, it appears that more than one mechanism contributes to the results. For instance, one way to explain a decay in zeta potential or streaming potential, following

Hubbe and Rojas (2008). "Colloidal stability of cellulosics," BioResources 3(4), 1419-1491. 1451 
treatment of suspended cellulosic fibers with cationic polymer, is to assume that as soon as cationic polymers diffuse into pores below the fiber surface, they no longer contribute to charge phenomena. Such an assumption has been disproven, at least in part, by recent work (Hubbe et al. 2007a,b). Rather, as long as the salt concentration is about $10^{-3}$ molar or higher, one can expect there to be a finite contribution to electrokinetic measurements resulting from cationic polyelectrolytes that have diffused into the nanopore structure of cellulose. Another fact that appears inconsistent with penetration as a sole explanation for charge decay phenomena is the fact that very strong instances of decay in electrokinetic potential have been observed for high-mass cationic copolymers, i.e. acrylamide-based cationic retention aid polymers. Such macromolecules are clearly too big to diffuse below the outer surfaces of cellulosic materials within the time frames of experimentation (Koethe and Scott 1993). It has been proposed, therefore, that very high-mass cationic polyelectrolytes initially adsorb as semi-random, three-dimensionally coils (Fleer et al. 1993; Wågberg 2000), giving them an exaggerated influence on the measured electrokinetic potential of the substrate, until they adopt a flatter adsorbed conformation with the passage of time (Koethe and Scott 1993).

\section{Charged Patches}

There are two main problems when applying mechanisms based on uniform charge neutralization by polyelectrolytes, as proposed in the previous subsection. First, such assumptions get increasingly hard to justify with increasing molecular mass of the polymers and as the time of mixing becomes shorter. Indeed, by use of atomic force microcopy (AFM) it has been possible to demonstrate discontinuous, patch-like adsorption of individual macromolecules onto small, negatively charge surfaces (Pfau et al. 1999; Horn 2001). Further evidence of non-uniform adsorption comes from studies of electrophoretic mobility of cellulosic suspensions that have been freshly treated by polyelectrolyte solutions. Multi-modal distributions of electrophoretic mobility have been observed in such cases (Leiviskä et al. 2005).

Second, as pointed out by Pelton (1993), the fibrillated nature of cellulosic surfaces can be expected to impede the close approach of most of the facing areas of solids in a fiber suspension. As a consequence, the London dispersion forces of various solids with cellulosic surfaces can be expected to be quite weak in comparison to other typical surfaces for which the charge neutralization mechanism of coagulation, i.e. the DLVO theory, has been well demonstrated (Verwey and Overbeek 1948; Hiemenz and Rajagopalan 1997). Thus the charge neutralization hypothesis does not explain the observed greater resistance to redispersion, when comparing the effects of high-charge cationic polyelectrolytes vs. simple charge neutralization with multivalent cations.

When attempting to understand the effects of adding a high-charge cationic polymer on the colloidal behavior of cellulosic materials in suspension, it is realistic to imagine a non-uniform distribution of charge, at least on a scale up to tens of nanometers. Thus, some investigators have proposed a "charged patch" theory to account for the resulting strong coagulation (Sandell and Luner 1974; Goossens and Luner 1976). Such a mechanism is consistent with the development of considerably higher resistance to hydrodynamic shear, compared to what can be achieved by charge neutralization or

Hubbe and Rojas (2008). "Colloidal stability of cellulosics," BioResources 3(4), 1419-1491. 1452 
screening of charge effects by monomeric salts (Hubbe 1987b; Kamiti and van de Ven 1995; Tripattharanan et al. 2004b).

Österberg (2000) demonstrated the time-dependent nature of charged patch interactions between facing cellulosic surfaces. At short exposure times the adsorption of low amounts of a high-charge cationic polyelectrolyte in aqueous solution caused strong attraction between surfaces coated by cellulose films. The attraction was strong enough to cause damage to the surfaces in an uneven pattern, as observed in the Surface Force Apparatus used for testing. However, no such adhesion was observed if plenty of time was made available for the polyelectrolytes to become more evenly distributed onto the surfaces.

The principle that strong adhesion can be achieved between polyelectrolytecovered and uncovered cellulosic surfaces also has been demonstrated in different kinds of experiments. Sczech and Riegler (2006) observed strong adhesion between cellulose beads and a planar cellulosic surface, but only if just one of the surfaces had been exposed to cationic polymer. Das and Lomas (1973) showed that strong adhesion could be achieved if a suspension of cellulosic fines was divided, just one of the portions was treated with high-charge-density cationic polyelectrolyte, and then the portions were recombined. Overall, it can be stated that cationic polymers adsorbing on the negatively charged fibers mediates an increased fiber-fiber bond (Zhang et al. 2000). However, an additional phenomenon can be used to explain strong adhesion: It has been reported that the dry strength of the paper increases with decreasing charge density of the polymer (Zhang et al. 2000), presumably due to increased polymer-polymer interpenetration and due to increased viscoelastic losses that occur during the rupture of the paper sheet under strain. Further evidence was described unambiguously in experiments by Claesson et al. (2003) and Rojas et al. (2005), who used model surfaces; forces were evaluated by AFM and Surface Force Apparatus (SFA). Adsorbed polyelectrolyte bridging is thus expected to be an important contribution, as explained in more detail in the following section.

\section{Polyelectrolyte Bridging}

The term "polymer bridging" has been used to explain the relatively strong attachments between surfaces that often can be achieved by adding high-mass polyelectrolytes to oppositely charged suspensions. If one goes back to foundational work related to this topic (La Mer and Healy 1963), the term bridging was meant to imply that the flocculating polymers had sufficiently high molecular mass so that segments could extend past any ionic double layers at the surfaces adsorb on two adjacent surfaces. Thus, it is reasonable to expect that the bridging mechanism will be favored by increasing molecular mass and relatively short equilibration time following adsorption, factors that favor an extended conformation in the adsorbed state. Relatively low charge density of a cationic polyelectrolyte also favors three-dimensional adsorption, leading to effective bridging (Rojas et al. 1998). A maximum rate of bridging flocculation is expected when approximately half of the surface areas are covered, allowing segments on an adsorbed polymer to become attached to an adjacent, uncovered surface. Figure 9 illustrates the effect of bridging vs. charge neutralization mechanisms with regards to electrophoretic mobility behavior and extent of flocculation. The resultant situation will depend on the polymer charge density and molecular mass, as depicted in the figure.

Hubbe and Rojas (2008). "Colloidal stability of cellulosics," BioResources 3(4), 1419-1491. 1453 


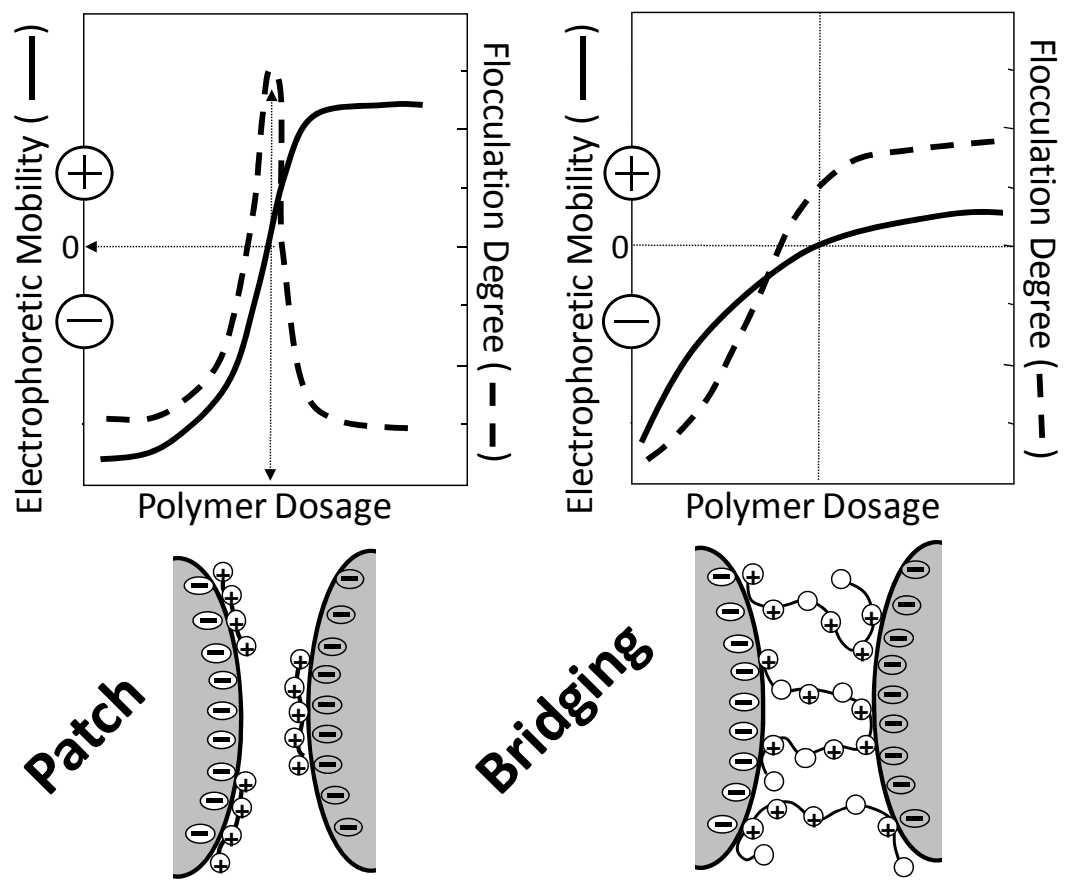

Fig. 9. Bridging vs patch flocculation: Electrophoretic mobility (solid line) and extent of flocculation (dashed)

Because the bridging mechanism was emphasized in a previous review dealing with the mechanical and chemical flocculation of cellulosic fiber suspensions (Hubbe 2007), only a brief discussion will be given here. Polymer bridging is believed to play a key role in many polyelectrolyte interactions related to paper manufacture (Sikora and Stratton 1981; Hubbe 1987b, Swerin et al. 1996b; 1997b; Tripattharanan et al. 2004a; Yoon and Park 2005; Salmi et al. 2007a). Various authors have discussed polymer bridging as a possible contributing mechanism involved in the fixation of wood resins and other negatively charged colloidal material during the papermaking process (Wågberg and Åsell 1995; Nurmi et al. 2003).

An extension of the polymer bridging concept involves flocculation after the premixing of oppositely charged polyelectrolytes. In other words, polyelectrolyte complexes (PECs) that adsorb onto cellulosic materials can be expected to affect colloidal behavior (Carr et al. 1977; Oertel et al. 1991; Buchhammer et al. 1993, 1994; Petzold et al. 1997; 1998; Gernandt et al. 2003; Gärdlund et al. 2003, 2005; Lofton et al. 2005; Hubbe et al. 2005; Maximova et al. 2005; Feng et al. 2007a,b). Petzold et al. (1998) showed, for instance, that flocculation by PECs can be advantageous in terms of creating a relatively high-density of agglomerated material, leading to more rapid sedimentation in comparison to when polyelectrolyte flocculants were used alone. Feng et al. (2007b) observed the strongest adhesion between cellulosic surfaces when the PEC contained an excess of cationic polyelectrolyte, yielding a positive surface charge capable of adsorbing strongly onto specially prepared cellulose surfaces having higher than usual negative charge. However, Salmi et al. (2007b) generally observed either net repulsion or only 
weak adhesion forces between cellulosic surfaces that had been treated with PECs. The repulsive forces were attributed to steric stabilization.

Recent work has shown that alternating polyelectrolyte layers can be applied to cellulosic material, achieving alternating changes in the sign of charge (Lvov et al. 2006; Zheng et al. 2006; Wågberg et al. 2002; Eriksson et al. 2005a,b). In principle, one might expect such treatments to affect the colloidal stability in predictable ways. However, it is regarded as very difficult to predict what will be the net effect, especially during the transitional state, when the outermost polyelectrolyte layer is not yet complete.

The flocculation effects cited up to this point all have involved charged polymers; however, nonionic polymer solutions of sufficiently high molecular mass also can be very effective flocculants when added to suspensions of cellulosic materials. Numerous studies have documented the effectiveness of polyethylene oxide (PEO) as a retention aid for the papermaking process, and only a selection of the relevant literature will be cited. The mechanism by which PEO brings about flocculation appears to involve association between macromolecular chains. Thus, incompletely dissolved PEO, in which there is substantial entanglement among the polymeric chains, tends to be a more effective flocculant, compared to well-dispersed PEO (Kratochvil et al. 1999; Bednar et al. 2004; Wu et al. 2007). In addition, PEO must be used in combination with a suitable co-factor, without which little flocculation can be achieved. Various phenolic resins have been used as cofactors (Xiao et al. 1996; Wu et al. 2007). In addition, lignin species present in various high-yield pulps, as well as unbleached kraft pulp can serve the role of cofactor to some extent. It has been proposed that the cofactors promote association among the uncharged macromolecular chains, thus creating multi-chain structures that act as flocculants in the presence of flow (Lindström and Glad-Nordmark 1984). Alternatively it has been proposed that the cofactor promotes asymmetric polymer bridging between contrasting surfaces, e.g. a cellulosic surface and a mineral surface (van de Ven and Alince 1996).

Yet another variation of the bridging theme involves use of a high-surface-area mineral additive in combination with the polymeric flocculant. For instance, Porubska et al. (2002) observed increased flocculation when a clay dispersion was used as an extra additive during flocculation of cellulosic fines by means of polyethyleneimine (PEI), a highly cationic, highly branched polyelectrolyte. Very effective dewatering effects, in addition to fine-particle retention have been achieved in papermaking applications through use of cationic polyelectrolytes added sequentially with negatively charged colloidal dispersions, i.e. microparticle or nanoparticle systems (Swerin et al. 1997a; Hubbe 2005). Such systems have been found to be highly effective despite that fact that strong electrostatic repulsion between colloidal silica particles can be expected in the absence of multivalent cationic additives (Radtchenko et al. 2005). The explanation is that the mineral particles appear to interact mainly with the cationic polyelectrolyte, and such interactions can cause a de-swelling action of the polyelectrolyte material, including any bridges that have been formed linking solid surfaces. The consequence is reduced water-holding ability by the polyelectrolytes and more streamlined paths for water to take when escaping from a mat of cellulosic materials. 


\section{Detachment forces}

To evaluate the strength of polymeric bridging phenomena, researchers have evaluated pull-off forces (Österberg 2000; Leporatti et al. 2005) and hydrodynamic shear conditions required for particle detachment (Pelton and Allen 1984; Hubbe 1984, 1987b; Petzold et al. 1997; Ibrahim et al., 2000; Willing et al. 2000, 2002).

A criterion that is often used to judge whether polymer bridging has occurred, rather than one of the other agglomeration mechanisms discussed earlier, is whether reflocculation can occur to about the same degree after the suspension has been strongly agitated, thus breaking the original cellulose-polyelectrolyte-cellulose contacts. Easy reversibility is often taken as evidence of a charge-dominated process, e.g. coagulation due to the persistence of contrasting areas of positive and negative charge on the respective surfaces. A number of studies have documented relatively irreversible flocculation in the case of very-high-mass cationic flocculants or sequential additive of a high-charge cationic polyelectrolyte and a high-mass anionic flocculant (Unbehend 1976; Alfano et al. 2000; Hubbe 2000b).

Papermakers often appear to take advantage of irreversible breakdown in polyelectrolyte bridging due to the manner in which retention aid polymers are used (Hubbe and Wang 2002). For mechanical and fluid dynamic reasons, the likelihood of detachment between relatively large objects, such as fibers, is expected to be much greater than the likelihood of detachment of small particles from other surfaces in an agitated suspension (McKenzie 1968; King and Williams 1975; Stratton 1983; Hubbe 1984, 1985b; Hubbe and Wang 2002). For this reason, hydrodynamic shear forces inherent in the paper forming process often are able to redisperse fiber flocs, thus improving the uniform appearance and other attributes of the paper product. At the same time, a significant percentage of fine particles in the suspensions may remain attached to fibers or cellulosic fine material that are large enough to be easily retained by a filtration mechanism during the paper forming process.

Solberg and Wågberg (2003a,b) documented at least one case in which reversible flocculation was observed. Notably, the flocculating polymer was a high-mass acrylamide copolymer, the kind of additive that is usually assumed to work by a bridging mechanism. A likely explanation is that the suspended matter consisted of latex particles; it may have been possible to polyelectrolyte segments to peel away from that substrate, rather than damaging the polymer chain.

It makes sense that the molecular mass of bridging polyelectrolytes ought to be reduced in the event that the joined surfaces are physically detached from each other. For instance in the papermaking process there are strong hydrodynamic shear forces that can detach solid particles or fibers from each other, depending on the strength of the adhesive forces (van de Ven and Mason 1981; Tam Doo et al. 1984; Farnood et al. 1994; Hubbe 2007). Researchers have reported evidence suggesting that the molecular mass can be reduced if shear-induced redispersion happens after the suspension has been flocculated by a cationic polyelectrolyte flocculant (Sikora and Stratton 1981; Tanaka et al. 1993).

\section{Steric stabilization}

Complete coverage of solid surfaces in an aqueous suspension by hydrophilic, long-chain molecules can be expected to stabilize the system against coagulation, even if 
the adsorbate is uncharged (Dugal and Swanson 1972; Claesson et al. 2005). The effect is attributed to the tails and loops of hydrophilic molecules that are likely to extend out into the solution phase from the surfaces. As noted by Dahlgren and Leermakers (1995), the net effect can be either attractive or repulsive, depending on the details of ionic strength, chain lengths, and surface charges. There is a strong tendency of carboxymethylcellulose (CMC) to disperse cellulosic materials (Giri et al. 2000; Laine and Lindström 2001). As shown by Beghello and Lindström (1998), CMC added to a fiber slurry can reduce the tendency for fibers to form flocs. Zauscher and Klingenberg (2000a) quantified strong repulsive forces when CMC was present during the measurement of normal forces between planar cellulose surfaces. Because CMC has a strong negative charge, the net dispersing effect probably is due to a combination of electrostatic effects and entropic effects, both of which are consistent with an expanded conformation of water-loving polymer segments extending from the surfaces.

Holmberg et al. (1997a) proposed that similar effects can occur even between untreated cellulosic surfaces in aqueous suspension, due to extended cellulose macromolecular tails at such surfaces. Various authors have reported relatively long-range repulsion between untreated cellulosic surfaces (Pang and Gray 1998; Paananen et al. 2004; Salmi et al. 2007a); it can be difficult in such cases to draw a clear distinction between mechanical effects of fibrillation and colloidal forces associated with charge repulsion or entropic effects. Indeed, it is probable that negatively charged hemicellulose segments contribute to such effects (Clark 1985; Johnsen et al. 2006; Tammelin et al. 2007). As shown by Notley et al. (2006), negatively charged sulfonate groups at treated cellulosic surfaces also can be expected to contribute to steric stabilization effects.

Depending on their strength and range of interaction, steric stabilization forces may affect rates of coagulation. The influence of the steric stabilization component is expected to be most influential at intermediate values of ionic strength, conditions under which electrostatic forces alone may be insufficient to prevent relatively rapid coagulation of suspended particles. However, with further increases in salt levels the attractive London dispersion forces may yet overpower the steric stabilization and bring about coagulation, unless the adsorbed layer of hydrophilic polymer is very thick.

\section{Friction}

A coating of steric stabilizing material on solid surfaces also can be expected to act as a kind of lubricant. The idea is that if two surfaces are held apart from each other by relatively long-range repulsive forces, then it will not be possible for significant frictional forces to develop between them. Zauscher and Klingenberg (2000b, 2001) and Song (2008) lent support to such a hypothesis by use of atomic force microscopy to measure friction at a molecular scale. Adsorption of carboxymethylcellulose onto the cellulosic surfaces caused a dramatic drop in the measured coefficient of friction. Stiernstedt et al. (2006a,b) demonstrated similar effects when cellulose surfaces were exposed to xyloglucan, a hemicellulose component.

\section{Liquid crystal phase effects}

The high aspect ratios and colloidal size of various cellulosic nanocrystals and nanofibers can give rise to some striking phase behavior. For instance, (Roman and Gray

Hubbe and Rojas (2008). "Colloidal stability of cellulosics," BioResources 3(4), 1419-1491. 1457 
(2005) and Beck-Candanedo et al. (2005) observed isotropic and chiral nematic liquidcrystalline phases in the case of highly negatively charged cellulose nanocrystals. Addition of salt or certain dye molecules caused separation of an isotropic phase.

Certain cellulosic crystals can become oriented in an electric field. Thus, Bordel et al. (2007) observed alignment of various natural cellulose particles suspended in organic solvents when a field was applied. High alignment and direction-dependent properties were observed if the field was maintained long enough to allow evaporation of the solvent. It is likely that such effects also influence the birefringent behavior of cellulosic nanocystals (Lima and Borsali 2004; Beck-Candanedo et al. 2005; Montanari et al. 2005; Petersson et al. 2007).

\section{COLLOIDAL BEHAVIOR OF OTHER WOOD-DERIVED MATERIALS}

While a great deal of published research has dealt with the colloidal properties of cellulose itself, considerable progress also has been achieved in understanding colloidal forces and coagulation of other materials having a common origin with cellulose. It should be emphasized, also, that even if one is strictly interested in the colloidal nature of cellulose, the persistence or adsorption of other wood-derived materials onto cellulosic surfaces can sometimes dominate the colloidal behavior (see, for instance, StanaKleinschek and Ribitsch 1998; Przybysz et al. 2002). Conversely, Jaycock and Pearson $(1975,1976 a, b)$ documented cases in which cellulosic colloidal materials adsorbed onto other solid surfaces and dominated the colloidal nature of the latter. Likewise Sanders (1994) showed that the zeta potential distribution of a mixture of different colloidal materials tended to become less bimodal with the passage of time, presumably due to redistribution of colloidal materials from one surface to another. Similarly, the addition of aluminum sulfate or other high-charge cationic agents to cellulosic suspensions often can re-precipitate wood resins and other materials back onto the surfaces of cellulosic fibers (McKenzie et al. 1969; Roberts et al. 1974). Recent work by Tammelin et al. (2006, 2007), Mosbye et al. (2000; 2003a,b), and Johnsen et al. (2006) addresses these issues at a fundamental level.

\section{Pitch}

The nature of wood-derived resinous materials, i.e. "pitch", has been reviewed (Back and Allen 2000). Adsorption of wood resins on cellulosic materials generally renders the surfaces less hydrophilic, and often the densities of negative charges at those surfaces also are reduced (Stana-Kleinschek and Ribitsch 1998; Koljonen et al. 2004). Danovich and Hsieh (2007) treated cotton with a variety of triglyceride fats, resulting in greatly increased resistance to water absorption. Though the word "hydrophobic" generally summarizes the surface properties, it needs to be admitted that the extractives component of cellulosic materials is extremely diverse. Rundlöf et al. (2000) went so far as to blame wood resins for the relatively poor inter-fiber bonding characteristics of certain cellulosic fine matter, since such resins can be expected to get in the way of hydrogen bonding between cellulosic fiber surfaces. Mosbye et al. (2003b) showed that

Hubbe and Rojas (2008). "Colloidal stability of cellulosics," BioResources 3(4), 1419-1491. 1458 
the tendency for colloidal extractives to precipitate back onto cellulosic surfaces was increased by low $\mathrm{pH}$ and increased salt concentrations.

The colloidal stability of wood resin droplets or particles has been attributed to the carboxylate groups of fatty acids, resin acids, and associated hemicellulose materials on their surfaces (Sundberg and Holmbom 1997; Sundberg et al. 1998). However, studies of pitch stability, agglomeration, and deposition tend to be complicated due to spontaneous reactions involving unsaturated hydrocarbon groups, gradual hydrolysis of ester groups, and complexation involving the carboxylate groups with divalent ions, such as magnesium and calcium (Hubbe et al. 2006).

\section{Hemicellulose}

Hemicelluloses generally have greater solubility in water compared to the other components of wood, so it is reasonable to regard hemicellulose mainly as a stabilizer of colloidal suspensions, rather than as a solid component (Sundberg and Holmbom 1997; Hannuksela et al. 2002; Hannuksela and Holmbom 2004; Zhou et al. 2007). The ability of hemicelluloses to confer stabilization effects (Johnsen et al. 2006; Tammelin et al. 2007) may be attributed to a combination of steric stabilization and like-charge repulsion between the surfaces. Such effects were most clearly demonstrated by selective use of peroxide bleaching, followed by pectinase enzymes (Sundberg et al. 1998). The peroxide treatment resulted in an approximate doubling of the cationic demand of the fiber slurry, an effect that was attributed to the oxidation and the partial release into solution of certain hemicellulose components. Subsequent enzymatic treatment reduced the cationic demand almost back to its starting value. The pectinase apparently hydrolyzed the anionic hemicellulose molecules to such a degree that the fragments were not large enough to interact significantly with the cationic polymer that was used for the titration of charge.

As shown by Rojas and Neuman (1999) cationic polyelectrolytes appear to be able to "substract" various solubilized polysaccharide forms from aqueous solution. Such complexation interactions were sensitive to the detailed nature of both the polysaccharide and the flocculant.

\section{Lignin}

Though chemical pulping processes generally are designed to remove lignin from cellulosic fibers, significant amounts of released lignin have been reported to precipitate back onto cellulose surfaces. For this reason it is economically important to understand the colloidal stability of lignin materials.

Foundational work by Dong et al. (1996) established that kraft lignin's surface charge is highly negative, even down to a $\mathrm{pH}$ of about 1 . The zeta potential became more negative with increasing $\mathrm{pH}$ up to 5 , then leveled off. Aluminum ions exhibited strong adsorption onto the lignin, even reversing the zeta potential in some cases, whereas the monovalent and divalent ions evaluated did not shift the iso-electric point.

Notley and Norgren (2006b) studied interactions between cellulose spheres and planar lignin surfaces. The force-distance results generally were found to be consistent with the expected electrostatic and dispersion force contributions, i.e. the DLVO theory, as discussed earlier. Maximova et al. (2004) found that dissolved lignin precipitation was

Hubbe and Rojas (2008). "Colloidal stability of cellulosics," BioResources 3(4), 1419-1491. 1459 
promoted by addition of calcium or aluminum ions. The interactions appeared to be governed by surface charge properties, and the highest levels of adsorption were associated with charge neutralization. However, except for certain treatments involving aluminum ions near to neutral $\mathrm{pH}$, most of the precipitated lignin was only loosely attached to the cellulose. Vanerek and van de Ven (2006) studied the complexation between cationic acrylamide copolymers and colloidally dispersed lignin; the phase behavior of the resulting mixtures depended on the molecular mass of the flocculant. Micic et al. (2003) studied the adsorption of a lignin model compound onto cellulose and observed a tendency for self-assembly into domains, not unlike real wood.

Cathala et al. (2003) showed, by means of size-exclusion chromatography, that different fractions of lignin can exhibit very different self-associative behavior in dimethylformamide suspension. Thus, some lignin fractions appeared to spend most of their time individually dispersed, whereas other lignin fractions had a greater tendency to form a kind of micelle.

\section{COLLOIDAL EFFECTS OF MODIFYING LIGNOCELLULOSIC SURFACES}

Intentional changes made to cellulosic surfaces can have predictable effects on the colloidal behavior of their aqueous suspensions. Processes that tend to purify cellulose are no exception. For instance, the electrokinetic properties of cotton can be changed significantly by mercerization, a process in which the cellulose is exposed to sodium hydroxide solution, followed by neutralization and rinsing (Pusic et al. 1999). Certain enzymatic treatments of cellulosic materials have been found to affect electrokinetic properties (Ribitsch et al. 2001). Laine et al. (1996) showed that certain enzymes can remove selected classes of negatively charged material from fiber surfaces, and it seems likely that such issues will receive a lot of research attention in future years. Because cellulose surface modification is a very large subject on its own, only selected examples will be cited in the present section.

\section{Mechanical Treatments}

Refining of cellulosic fibers is shown to increase their effective surface area (Baker 1995). Rohrsetzer et al. (1995) carried out an elegant analysis of this effect, using selected, narrowly dispersed colloidal particles to evaluate the surface area that is accessible to different particle sizes. The "total" surface area, defined in terms of molecular adsorption, did not depend on refining. By contrast, the "coarse" external surface area, as well as the surface area accessible to colloidal particles increased significantly with refining.

From the standpoint of colloidal interactions, one of the important impacts of increased surface area is an increased cationic demand (Strazdins 1980; Mutje et al. 2001). In other words, a greater amount of cationic titrant is required to reach a neutral zeta potential. Usually the titrant is a high-charge, linear polyelectrolyte having a molecular mass in the range of about 100,000 to 1,000,000 Daltons. Carrasco et al. (1996) also demonstrated that refining tends to release colloidal materials from cellulosic fibers, and that the released material can contribute significantly to cationic demand.

Hubbe and Rojas (2008). "Colloidal stability of cellulosics," BioResources 3(4), 1419-1491. 1460 
Because of the layered structure of cellulosic fibers, as well as the differing chemical composition of the layers (Sjöström 1993), it is reasonable to expect that the charge characteristics ought to change as one peels back successive outer layers of material by a mechanical refining process. In particular, the middle lamella and the outer surfaces of fibers, prior to pulping, can be expected to have the highest concentrations of negatively charged components, including wood extractives, lignin, and some hemicellulose. Early investigations by Jacquelin and Bourlas (1964) found a decrease in the absolute value of streaming potential with increased refining, consistent with the increased exposure of cellulose at the surface, in comparison to other materials. Mosbye et al. (2002) compared fines that were produced during different stages of refining of spruce chips; differences in hemicellulose components and net charge were quantified.

\section{Chemical Treatments Oxidation}

From a practical standpoint, some of the most convenient ways to increase the negatively charged character of cellulosic fibers involve oxidation. At a laboratory scale, such results have been achieved by periodate treatment (Alince 1975), by treatment with the 2,2,6,6-tetramethylpiperidine-1-oxy radical (TEMPO) (Isogai et al. 1997; Saito et al. 2005; Saito and Isogai 2007; Alila et al. 2007; Feng et al. 2007b; Habibi et al. 2006), or by various corona plasma treatments (Baltazar-Y-Jimenez et al. 2008).

The charged nature of cellulosic fibers also can be adjusted, to some extent, by changing the details of conventional bleaching strategies. For instance, Laine (1997) showed that bleaching sequences incorporating ozone or chlorine dioxide caused a net decrease in the negative charge of softwood kraft pulps. By contrast, a slight increase in negative charge was observed in the case of oxygen delignification. Also, bleaching sequences ending with hydrogen peroxide bleaching tended to impart more negative charge, compared to other sequences. The authors attributed the differences to whether or not each bleaching stage tended to cleave uronic acid side groups from the hemicellulose. It was proposed that much of the residual charge, after conventional bleaching sequences, is due to lignin-carbohydrate complexes. As noted by Laine and Stenius (1997), the pulp physical properties were significantly different from each other. The differences could be attributed to changes not only in the density of carboxyl groups, but also to changes in the elastic modulus of the cellulosic material, factors that affect the swelling and wet-conformability of the fibers.

\section{Derivatization}

The negative charge or fibers also can be greatly increased by chemical derivatization. Options include treatment with a substantive dye (Allan and Reif 1971), succinylation (Roberts and Tatham 1992), maleic anhydride treatment (Hubbe et al. 1999), carboxymethylation, for instance with halo-acetic acid (Nelson and Kalkipsakis 1964; Barzyk et al. 1997; Kotz et al. 1998), and treatment with an alpha-chloro sulfonic acid reagent (Hubbe et al. 2007a). Relative to the oxidative approaches mentioned in the previous paragraph, chemical derivatization can make it possible to achieve much higher levels of negative zeta potential. Though enhanced colloidal stability would be expected, none of the cited studies considered this issue. 
Cationic derivatives of cellulose have held particular fascination, since such materials can be expected to interact strongly with negatively charged particles and polyelectrolytes (Jacobasch et al. 1995; Werner et al. 1999; Kumar and Teli 2007). Halab-Kessira and Ricard (1996) used poly(2-acryloxyethyltrimethylammonium chloride as a derivatizing agent, and the product showed greatly enhanced adsorption of calcium carbonate particles. As would be predicted, the deposition tendency decreased with increasing salt content of the aqueous solution. Hubbe et al. (2007a) employed an alphachloro trimethylammonium chloride compound to modify microcrystalline cellulose (MCC); the resulting positively charged MCC particles could be used to probe the charge character of the outer surfaces of cellulosic materials.

Alternatively, cellulosic surfaces can be rendered hydrophobic by derivatization (Bletzinger 1943; Pothan et al. 2002; Andresen and Stenius 2007). Acetylation is an especially interesting and flexible approach, and the results depend both on the extent and the location of treatment. Hydrophobic modifications of cellulosic fibers and nanofibers are of particular interest in relation to the development of cellulose-based composite materials. Relevant work was cited in an earlier review article (Hubbe et al. 2008).

\section{COLLOIDAL PROPERTIES vs. APPLICATIONS OF CELLULOSICS}

\section{Papermaking Applications of Colloid Science}

Papermaking technologists can seem schizophrenic with respect to their attitude towards colloidal stability (see Rojas and Hubbe 2004). On the one hand, many additives to the papermaking process are delivered as emulsions or dispersions. When storing and handling such additive formulations it can be very important to avoid premature coagulation, creaming, or settling. But later on in the process, soon before the sheet of paper is formed, papermakers employ a variety of additives to destabilize the system, causing fine particles to be retained with adequate efficiency in the wet web of paper as it is being formed (Sieber 1922; Kenaga et al. 1967; Melzer 1972; Strazdins 1972, 1977, 1980, 1989, 1995; Britt 1973; McKague et al. 1974; Lindström et al. 1974; Lindström and Söremark 1975; Horn and Melzer 1975; Davison and Cates 1975; Unbehend 1976; Eisenlauer et al. 1987; Stark and Eichinger 1989; Allen and Yaraskavitch 1991; Poppel 1992; Lindström 1992, 1996; Patton and Lee 1993; Sanders and Schaeffer 1994; Vanderhoek 1994; Jaycock and Swales 1994; Stana-Kleinschek et al. 1995; Miyanishi 1995a,b; Andersson and Lindgren 1996; Laine and Stenius 1997; Swerin et al. 1997a,b; Isogai et al. 1997; Tanaka 1998; Winters 1998; Rojas and Neuman 1999; Przybysz et al. 2002; Wang 2002; Whipple and Maltesh 2002; Rice and Roeraade 2003; Bhardwaj et al. 2005; Hubbe and Heitmann 2007; Yoon 2007). Successful papermaking therefore requires sequencing and control of dosages of additives, with careful attention to the levels of hydrodynamic shear at different points of the papermaking process (Rojas and Hubbe 2004; Hubbe 2007). Recently, related colloid-chemical principles have been used to gain a better understanding of de-inking technologies, which are employed during the recycling of wastepaper (Bloom and Heindl 1997; Forsström et al. 2005; Theander et al. 2005).

Hubbe and Rojas (2008). "Colloidal stability of cellulosics," BioResources 3(4), 1419-1491. 1462 


\section{Textile Applications of Colloid Science}

Though many steps in conventional textile manufacturing processes are carried out in the absence of water, there are some exceptions, including the "sizing" treatments of threads. Various advances related to the colloid chemistry of textile applications have been reported (Iyer and Jayaram 1971; Madan et al. 1973; Madan and Shrivastava 1975, 1976; Lokhande and Salvi 1976, 1978; Espinosa-Jimenez and Gonzalez-Caballero 1991; Stana-Kleinschek and Ribitsch 1998; Pusic et al. 1999; Poppel et al. 2001; Ribitsch et al. 2001; Stana-Kleinschek et al. 1999, 2001, 2002; Grancaric et al. 1997, 2005; Reischl et al. 2006). For instance, the charge characteristics of cotton and other cellulose fabrics is a key variable in terms of dye adsorption and fastness. Detergency is yet another central concern, related to textiles use, which benefits from advances in colloid science (Paria et al. 2004, 2005).

\section{Microcrystalline Cellulose and Pharmaceutical Applications}

Perhaps because of its non-toxic nature and relatively low cost, microcrystalline cellulose (MCC) has become a material of choice for the compounding of pills for pharmaceutical and nutritional applications. A review article in the previous issue of this journal summarized the technology behind isolation of crystalline regions from cellulosic fibers and explained how the strong sulfuric acid treatment used during that process can give rise to a strongly negative surface charge (Hubbe et al. 2008). As was noted in that article, the spray-drying process commonly used for preparation of MCC causes many individual crystals of cellulose to fuse together, forming hydrogen-bonded agglomerates (Bondeson et al. 2006). Properties of MCC, relative to various pharmaceutical applications, are known to depend on charge characteristics of the dry powders (RamirezDorronsoro et al. 2006). Because triboelectric charge bears a complicated relationship to the colloidal charge of particles in aqueous suspension (Baur et al. 1999; Manouchehri et al 2001), it would make sense for future research to focus more attention on the electrokinetic properties of pharmaceutical-grade MCC.

\section{Cellulosic Particles as Stabilizers}

Cellulosic nanoparticles and fibrillar structures (such as micro or nano fibrillar cellulose), also can be used as stabilizers of foams and emulsions. As reported by Andresen and Stenius (2007), water-in oil emulsions could be stabilized by partially treating the nanofibrillar cellulose to achieve an optimum degree of hydrophobicity. The emulsions showed high stability against coalescence and settling. Wege et al. (2008) also used partially hydrophobized cellulose to achieve highly stable foams and oil-in water emulsions. Essential elements in their preparations were the fibrillar cellulose, hydrodynamic shear, and either air or a water-immiscible oil. The effects were attributed to elongated shape and intermediate hydrophobicity of the cellulosic particles, allowing them to stay at the interfaces, forming a shell. 


\section{IN SUMMARY}

As shown in this review, literature related to the colloidal aspects of cellulosic material is quite diverse. However, some common themes are evident. One of these themes is to contrast hydrophilic vs. hydrophobic character. Contributions to hydrophilic character include the hydroxyl groups on the polysaccharide components of cellulosic material. On the other hand, many of the $\mathrm{OH}$ groups participate in intra- or intermolecular hydrogen bonding, which, especially in the case of crystalline regions of the cellulose, makes the $\mathrm{OH}$ groups unavailable for interaction with free water. Further hydrophobicity can be contributed by the phenol propane building blocks of lignin, as well as various wood resins, especially the triglycerides, fatty acids, and resin acids. In various experiments and practical applications the fibers are intentionally made yet more hydrophobic by chemical derivatization of the surfaces in various ways.

A second theme, and one that seems to offer particular promise for further development, is the charged character of cellulosic surfaces. For the most part, investigators have made themselves content with the charged nature of the material, in the form that they received it. But the gains in various performance factors achieved by different charge-modifying or enhancing procedures provide motivation for further research and manufacturing innovations along such lines. In principle, the properties of cellulose can be modified in such a way to achieve a wide gamut of colloidal properties, ranging from highly stable suspensions to strongly flocculated mixtures, suitable for various applications.

\section{REFERENCES CITED}

Ahola, S., Salmi, J., Johansson, L. S., Laine, J., and Österberg, M. (2008a). "Model films from native cellulose nanofibrils. Preparation, swelling, and surface interactions," Biomacromolecules 9(4), 1273-1282.

Ahola, S., Myllytie, P., Österberg, M., Teerinen, T., and Laine, J. (2008b). "Effect of polymer adsorption on cellulose nanofibril water binding capacity and aggregation," BioResources 3(4), 1315-1328.

Ahrens, F., Alaimo, N., Nanko, H., and Patterson, T. (1999). "Initial development of an improved water retention value test and its application to the investigation of water removal potential," TAPPI 1999 Proc., 37.

Alfano, J. C., Carter, P. W., Dunham, A. J., Nowak, M. J., and Tubergen, K. R. (2000). "Polyelectrolyte-induced aggregation of microcrystalline cellulose: Reversibility and shear effects," J. Colloid Interface Sci. 223(2), 244-254.

Alila, S., Aloulou, F., Beneventi, D., and Boufi, S. (2007). "Self-aggregation of cationic surfactants onto oxidized cellulose fibers and coadsorption of organic compounds," Langmuir 23(7), 3723-3731.

Alila, S., Boufi, S., Belgacem, M. N., and Beneventi, D. (2005). “Adsorption of a cationic surfactant onto cellulosic fibers - I. Surface charge effects," Langmuir 21(18), 8106-8113.

Hubbe and Rojas (2008). "Colloidal stability of cellulosics," BioResources 3(4), 1419-1491. 1464 
Alince, B. (1975). "Development of paper tensile strength by periodate oxidation," Svensk Papperstidning 78(7), 253-257.

Alince, B. (2002). "Porosity of swollen pulp fibers revisited," Nordic Pulp Paper Res. J. 17(1), 71-73.

Alince, B., Petlicki, J., and van de Ven, T. G. M. (1991). "Kinetics of colloidal particle deposition on pulp fibers. 1. Deposition of clay on fibers of opposite charge," Colloids Surf. 59, 265-277.

Alince, B., and van de Ven, T. G. M. (1993). "Kinetics of colloidal particle depsoition on pulp fibers. 2. Deposition of clay on fibers in the presence of poly(ethyleneimine)," Colloids Surf. A 71(1), 105-114.

Alince, B., and Robertson, A. A. (1974). "Aggregation of microcrystalline cellulose with polyethylenimine," Colloid Polymer Sci. 252(11), 920-927.

Alince, B., and van de Ven, T. G. M. (1997). "Porosity of swollen pulp fibers evaluated by polymer adsorption," in C. F. Baker, ed., The Fundamentals of Papermaking Materials, Pira Intl., Leatherhead, Surrey, UK, 771-788.

Allan, G. G., and Reif, W. M. (1971). "Fiber surface modification - Stereochemistry of ionic bonding in paper," Svensk Papperstidning 74(18), 563-570.

Allen, L. H., and Yaraskavitch, I. M. (1991). "Effects of retention and drainage aids on paper machine drainage: A review," Tappi J. 74 (7), 79-84.

Amelina, E. A., Shchukin, E. D., Parfenova, A. M., Pelekh, V. V., Vidensky, I. V., Bessonov, A. I., Aranovich, G., and Donohue, M. (2000). "Effect of cationic polyelectrolyte and surfactant on cohesion and friction in contacts between cellulose fibers," Colloids Surf. A 167(3), 215-227.

Andersson, K., and Lindgren, E. (1996). "Important properties of colloidal silica in microparticulate systems," Nordic Pulp Paper Res. J. 11(1), 15-21, 57.

Andreasson, B., Forsström, J., and Wågberg, L. (2003). "The porous structure of pulp fibers with different yields and its influence on paper strength," Cellulose 10, 111123.

Andresen, M., and Stenius, P. (2007). "Water-in-oil emulsions stabilized by hydrophobized microfibrillated cellulose," J. Dispersion Sci. Technol. 28(6), 837-844.

Anon. (1981). "Water retention value," TAPPI Useful Method UM 256.

Arnson, T. R., and Stratton, R. A. (1983). "The adsorption of complex aluminum species by cellulosic fibers," Tappi J. 66(12), 72-75.

Athley, K., Ulmgren, P., and Ohman, L. O. (2001). "Acid-base properties of oxygendelignified kraft pulps,” Nordic Pulp Paper Res. J. 16(3), 195-203.

Back, E. L., and Allen, L. H. (2000). Pitch Control, Wood Resin and Deresination, TAPPI Press, Atlanta, 392 pp.

Back, E. L., and Salmén, N. L. (1982). "Glass transition of wood components hold implications for molding and pulping processes," Tappi 65(7), 107-110.

Baker, C. F. (1995). "Good practice for refining the types of fiber found in modern paper furnishes," Tappi J. 78(2), 147-153.

Baltazar-Y-Jimenez, A., and Bismarck, A. (2007). "Wetting behaviour, moisture up-take and electrokinetic properties of lignocellulosic fibres," Cellulose 14(2), 115-127. 
Baltazar-Y-Jimenez, A., Bistritz, M., Schulz, E., and Bismarck, A. (2008). “Atmospheric air pressure plasma treatment of lignocellulosic fibres: Impact on mechanical properties," Composites Sci. Technol. 68(1), 215-227.

Barzyk, D., Page, D. H., and Ragauskas, A. (1997). "Acidic group topochemistry and fiber-to-fiber specific bond strength,” J. Pulp Paper Sci. 23(2), J59-J61.

Bastidas, J. C., Pawlak, J. J., Venditti, R. A., Heitmann, J. A., Hubbe, M. A., and Kadla, J. F. (2008). "A colloidal probe microscopy study of cellulose/gypsum interactions," Materials Characterization 59(2), 144-150.

Baumgartner, H., and Bley, L. (1994). "Practical experiences with online charge titration on a paper machine," Wochbl. Papierfabr. 122(22), 894-898.

Baur, R., Macholdt, H. T., and Michel, E. (1999). "Streaming current charge versus tribo charge," Electrostatics 1999, Inst. Phys. Conf. Ser. 163, 285-288.

Beck, U., Müller, F., Rohloff, E., and Tretter, H. (1987). "Ladungsmessungen in Papierstoff-Systemen - Methoden und Möglichkeiten," Papier 41(10A), V44-V51.

Beck-Candanedo, S., Roman, M., and Gray, D. G. (2005). "Effect of reaction conditions on the properties and behavior of wood cellulose nanocrystal suspensions," Biomacromolecules 6(2), 1048-1054.

Bednar, F., Perin-Levasseur, Z., van de Ven, T. G. M., and Paris, J. (2004). "Polyethylene oxide disentanglement," J. Pulp Paper Sci. 30(2), 49-52.

Beghello, L., and Lindström, T. (1998). "The influence of carboxymethylation on the fiber flocculation process," Nordic Pulp Paper Res. J. 13(4), 269-273.

Bellissent-Funel, M.-C. (2002). "Water near hydrophilic surfaces," J. Molecular Liquids 96-97, 287-304.

Bennington, C. P. J., Kerekes, R. J., and Grace, J. R. (1990). "The yield stress of fiber suspensions," Can. J. Chem. Eng. 68, 746-757.

Bergenstrahle, M., Wohlert, J., Larsson, P. T., Mazeau, K., and Berglund, L. A. (2008). "Dynamics of cellulose-water interfaces: NMR spin-lattice relaxation times calculated from atomistic computer simulations," J. Phys. Chem. B 112(9), 25902595.

Bergström, L., Stemme, S., Dahlfors, T., Arwin, H., and Ödberg, L. (1999).

"Spectroscopic ellipsometry characterization and estimation of the Hamaker constant of cellulose," Cellulose 6, 1-13.

Berthold, J., and Salmén, L. (1997). "Effects of mechanical and chemical treatments on the pore-size distribution in wood pulps examined by inverse size-exclusion chromatography (ISEC)," J. Pulp Paper Sci. 23(6), J245-253.

Bhardwaj, N. K., Kumar, S., and Bajpai, P. K. (2005). "Effect of zeta potential on retention and drainage of secondary fibers," Colloids Surf. A. 260(1-3), 245-250.

Bi, S., Wang, C., Cao, Q., and Zhang, C. (2004). "Studies on the mechanism of hydrolysis and polymerization of aluminum salts in aqueous solution: Correlations between the "Core-links" model and "Cage-like" Keggin- $\mathrm{Al}_{13}$ model," Coordination Chem. Rev. 248, 441-455.

Biefer, G. J., and Mason, S. G. (1954). "Electroosmosis and streaming in natural and synthetic fibers," J. Colloid Sci. 9, 20-35. 
Biermann, O., Hadicke, E., Koltzenburg, S., and Muller-Plathe, F. (2001).

"Hydrophilicity and lipophilicity of cellulose crystal surfaces," Angew. Chemie-Intl. Ed. 40(20), 3822-3825.

Bischof, P., "Relationship of zeta-potential and particle charge detection in colloidal system relating to paper manufacturing," Proc. TAPPI 1997 Nonwovens Conf., 115.

Biswas, S. C., and Chattoraj, D. K. (1997). "Polysaccharide-surfactant interaction. 1. Adsorption of cationic surfactants at the cellulose-water interface," Langmuir 13(17), 4505-4511.

Bleier, A., and Matijević, E. (1976). "Heterocoagulation. I. Interactions of monodispersed chromium hydroxide with polyvinyl chloride latex," J. Colloid Interface Sci. 55(3), 510-524.

Bletzinger, J. C. (1943). "Effect of acetylation on water-binding properties of cellulose," Ind. Eng. Chem. 35(4), 474-480.

Bley, L. (1992). "Measuring the concentration of anionic trash - the PCD," Paper Technol. 33(4), 32-37.

Bley, L., and Kästner, M., "On-line process charge control in papermaking," in The Chemistry of Papermaking, Proc. PIRA Conf., Jan. 28-29, 1992, paper 17.

Bloom, F., and Heindel, T. (1997). "Theoretical model of flotation deinking efficiency," J. Colloid Interface Sci. 190(1), 182-197.

Bobacka, V., Näsman, J., and Eklund, D. (1998). "Interactions between cationic starch and anionic trash of a peroxide-bleached TMP at different salt concentrations," $J$. Pulp Paper Sci. 24(3), 78-81.

Bondeson, D., Mathew, A., and Oksman, K. (2006). "Optimization of the isolation of nanocrystals from microcrystalline cellulose by acid hydrolysis," Cellulose 13(2), 171-180.

Bordel, D., Putaux, J. L., and Heux, L. (2006). "Orientation of native cellulose in an electric field," Langmuir 22(11), 4899-4901.

Bottéro, J.-Y., and Fiessinger, F. (1989). "Aluminum chemistry in aqueous solution," Nordic Pulp Paper Res. J. 4(2), 81-89.

Bottéro, J. Y., Poirier, J. E., and Fiessinger, F. (1980). "Study of partially neutralized aqueous aluminum chloride solutions: Identification of aluminum species and relation between the composition of the solutions and their efficiency as a coagulant," Prog. Water Tech. 13(1), 601-612.

Bowen, W. R., and Jenner, F. (1995). "The calculation of dispersion forces for engineering applications," Adv. Colloid Interface Sci. 56, 201-243.

Brace, R., and Matijević, E. (1973). "Aluminum hydrous oxide sols. I. Spherical particles of narrow size distribution," J. Inorg. Nucl. Chem. 35, 3691-3705.

Briggs, D. R. (1928). "The determination of the zeta potential on cellulose - A Method," J. Phys. Chem. 33(5), 641-675.

Britt, K. W. (1973). "Mechanisms of retention during paper formation," Tappi 56(10), 4650.

Britt, K. W., and Unbehend, J. E. (1974). "Electrophoresis in paper stock suspensions as measured by mass transport analysis," Tappi 57(12), 81-84. 
Buchhammer, H.-M., Petzold, G., and Lunkwitz, K. (1993). "The interaction between oppositely charge polyelectrolytes in the presence of solid surfaces," Colloids Surf. A 76, 81-85.

Buchhammer, H.-M., Kramer, G., and Lunkwitz, K. (1994). "Interaction of colloidal dispersions of non-stoichiometric polyelectrolyte complexes and silica particles," Colloids Surf. A 95, 299-304.

Budd, J., and Herrington, T. M. (1989). "Surface charge and surface area of cellulose fibers," Colloids Surf. 36(3), 273-288.

Bygrave, G., and Englezos, P. (1998). "Fiber charge from potentiometric titration of kraft pulp and Donnan equilibrium theory," Nordic Pulp Paper Res. J. 13(3), 220-224.

Carambassis, A., and Rutland, M. W. (1999). "Interactions between cellulose surfaces: Effect of electrolyte," Langmuir 9, 5584-5590.

Carr, M. E., Hamerstrand, G. E., Hofreiter, B. T., and Russell, C. R. (1977). “A polysalt complex for wet-end addition," Tappi 60(12), 148-149.

Carrasco, F., Mutje, P., and Pelach, M. A. (1996). "Refining of bleached cellulosic pulps: Characterization by application of the colloidal titration technique," Wood Sci. Technol. 30(4), 227-236.

Cathala, B., Saake, B., Faix, O., and Monties, B. (2003). “Association behaviour of lignins and lignin model compounds studied by multidetector size-exclusion chromatography," J. Chromatography A 1020(2), 229-239.

Chan, D., Perram, J., White, L., and Healy, T. W. (1976). "Regulation of surface potential at amphoteric surfaces during particle-particle interactions," J. Chem. Soc., Faraday Trans. I 71(5), 1046-1057.

Chang, M. Y., and Robertson, A. A. (1967a). "Flocculation studies of fiber suspensions: Influence of zeta potential," Pulp Paper Mag. Can. 68(9), T438-T444.

Chang, M. Y. and Robertson, A. A. (1967b). "Zeta potential measurements of fibers. DC streaming current method," Can. J. Chem. Eng. 45(2), 66-71.

Chen, J., Hubbe, M. A., and Heitmann, J. A. (2001). "Measurement of colloidal charge in the paper mill by streaming current," TAPPI 2001 Papermakers Conf., electronic document, TAPPI Press, Atlanta.

Chen, S.-L., Wang, S., and Lucia, L. A. (2004). "New insights into the fundamental nature of lignocellulosic fiber surface charge," J. Colloid Interface Sci. 275(2), 392397.

Claesson, P. M., Dedinaite, A., and Rojas, O. J. (2003). "Polyelectrolytes as adhesion modifiers," Advances in Colloid and Interface Science 104, 53-74.

Claesson, P. M., Poptoshev, E., Blomberg, E., and Dedinaite, A. (2005). "Polyelectrolytemediated surface interactions," Adv. Colloid Interface Sci. 114, 173-187.

Claesson, P. M., and Rutland, M. W. (2001). "Measuring interactions between surfaces," in Holmberg, K. (ed.), Handbook of Applied Surface and Colloid Chem., Wiley, New York, Ch. 20, 383-414.

Clark, J. d'A. (1985). "Fibrillation and fiber bonding," in Pulp Technology and Treatment for Paper, $2^{\text {nd }}$ Ed., Miller Freeman, San Francisco, Ch. 8, pp. 160-180.

Dahlgren, M. A. G., and Leermakers, F. A. M. (1995). "Depletion zones in polyelectrolyte systems - polydispersity effects and colloidal stability," Langmuir 11(8), 2996-3006. 
Danovich, T. A., and Hsieh, Y.-L. (2007). "Surface modification of cellulose with plant triglycerides for hydrophobicity," Cellulose 14, 469-480.

Das, B. S., and Lomas, H. (1973). "Flocculation of paper fines. I. Adsorption of and flocculation by polyelectrolytes. II. Study of the nature of the solid surface and soluble impurities," Pulp Paper Mag. Can. 74(8), 95-100.

Davison, R. W., and Cates, R. E. (1975). "Electrokinetic effects in papermaking systems: Theory and practice," Paper Technol. Ind. 16(2), 107-114.

de Gennes, P. G. (1987). "Polymers at an interface; A simplified view," Advances in Colloid and Interface Science 27(3-4), 189-209.

Deodhar, S., and Luner, P. (1980). "Measurement of bound (nonfreezing) water by differential scanning calorimetry," ACS Symp. Ser. 127, Water in Polymers, S. P. Rowland (ed.), Ch. 16, 273-286.

Derjaguin, B. V., and Landau, L. D. (1941). "Theory of the stability of strongly charged lyophobic sols and the adhesion of strongly charged particles in solution of electrolytes," Acta Pysicochim. URSS 14, 633-662.

de Souza Lima, M. M. D., and Borsali, R. (2002). "Static and dynamic light scattering from polyelectrolyte microcrystal cellulose,” Langmuir 18(4), 992-996.

Dong, D., Fricke, A. L., Moudgil, B. M., and Johnson, H. (1996). "Electrokinetic study of kraft lignin," Tappi J. 79(7), 191-197.

Donnan, M. B., Healy, T. W., and Nelson, P. F. (1981). “An electrokinetic study of alum coagulation and polymer flocculantion of cellulose pulp fines," Colloids Surf. 2(2), 133-143.

Duchesne, I., Daniel, G., Van Leerdam, G. C., and Basta, J. (2003). "Surface chemical composition and morphology of ITC kraft fibers as determined by XPS and FESEM,” J. Pulp Paper Sci. 29(3), 71-76.

Dugal, H. S., and Swanson, J. W. (1972). "Effect of polymer mannan content on the effectiveness of modified guar gum as a beater adhesive," Tappi 55(9), 1362-1367.

Dzyaloshinskii, I. E., Lifshitz, E. M., and Pitaevskii, L. P. (1961). "The general theory of van der Waals forces," Advances in Physics 10(38), 165-209.

Edgar, C. D., and Gray, D. G. (2003). "Smooth model cellulose I surfaces from nanocrystal suspensions," Cellulose 10, 299-309.

Ehrnrooth, E., Htun, M., and de Ruvo, A. (1977). "Esterification as a means of improving the properties of once-dried fibers," Trans. Symp. Fiber-Water Interactions in Papermaking, Oxford, British Paper and Board Industry Federation, 899-915.

Eisenlauer, J., Horn, D., Linhart, F., and Hemel, R. (1987). "Fiber-optic flocculation sensor for on-line control of retention and drainage aids efficiency," Nordic Pulp Paper Res. J. 4(4), 132-138.

Eriksson, M., Notley, S. M., and Wågberg, L. (2005a). “The influence on paper strength properties when building multilayers of weak polyelectrolytes onto wood fibers," $J$. Colloid Interface Sci. 292(1), 38-45.

Eriksson, M., Pettersson, G., and Wågberg, L. (2005b). "Application of polymeric multilayers of starch onto wood fibers to enhance strength properties of paper," Nordic Pulp Paper Res. J. 20(3), 270-276. 
Espinosa-Jimenez, M., and Gonzalez-Caballero, F. (1991). "The electrokinetic properties of cellulose fabrics and their significance in dyeing processes," Cellulose Chem. Technol. 25(1-2), 65-77.

Exall, K. N., and vanLoon, G. W. (2003). "Effects of raw water conditions on solutionstate aluminum speciation during coagulant dilution," Water Res. 37(4), 3341-3350.

Fält, S., and Wågberg, L. (2003). "Influence of electrolytes on the swelling and strength of kraft-liner pulps," Nordic Pulp Paper Res. J. 18(1), 69-73.

Fardim, P., and Duran, N. (2005). "Effects of kraft pulping on the interfacial properties of eucalyptus pulp fibres," J. Brazilian Chem. Soc. 16(5), 915-921.

Fardim, P. and Holmbom, B. (2003). "Fast determination of anionic groups in different pulp fibers by methylene blue sorption," Tappi J. 2(10), 28-32.

Fardim, P. and Holmbom, B. (2005). "Origin and surface distribution of anionic groups in different papermaking fibers," Colloids Surf. A 252, 237-242.

Fardim, P., Hullten, A. H., Boisvert, J. P., Johansson, L. S., Ernstsson, M., Campbell, J. M., Lejeune, A., Holmbom, B., Laine, J., and Gray, D. (2006). "Critical comparison of methods for surface coverage by extractives and lignin in pulps by X-ray photoelectron spectroscopy (XPS)," Holtzforschung 60(2), 149-155.

Farley, C. E. (1997). "Factors influencing the rate of charge decay," Tappi J. 80(10), 177183.

Farnood, R. R., Loewen, S. R., and Dodson, C. T. J. (1994). "Estimation of intra-floc forces," Appita 47(5), 391-396.

Feng, X. H., Pelton, R., Leduc, M., and Champ, S. (2007a). "Colloidal complexes from poly(vinyl amine) and carboxymethyl cellulose mixtures," Langmuir 23(6), 29702976.

Feng, X., Pouw, K., Leung, V., and Pelton, R. (2007b). "Adhesion of colloidal polyelectrolyte complexes to wet cellulose," Biomacromol. 8(7), 2161-2166.

Fernandez Diniz, J. M. B. (1995). "Distribution of Charge in Wood Pulps,” Langmuir 11(10), 3617-3619.

Fleer, G. J., Cohen-Stuart, M. A., Scheutjens, J. M. H. M., Cosgrove, T., and Vincent, B. (eds.), (1993). Polymers at Interfaces, Chapman and Hall, London, see 343-375.

Forsström, J., Eriksson, M., and Wågberg, L. (2005). "A new technique for evaluating ink-cellulose interactions: Initial studies of the influence of surface energy and surface roughness," J. Adhesion Sci. Technol. 19(9), 783-798.

Freudenberg, U., Zimmermann, R., Schmidt, K., Behrens, S. H., and Werner, C. (2007). "Charging and swelling of cellulose films," J. Colloid Interface Sci. 309(2), 360-365.

Fröberg, J. C., Rojas, O. J., and Claesson, P. M. (1999). "Surface forces and measuring techniques," Int. J. Miner. Process. 56, 1-30.

Fujita, M., and Harada, H. (2000). "Ultrastructure and formation of wood cell wall," in Wood and Cellulosic Chemistry, $2^{\text {nd }}$ Ed., D. N.-S. Hon and N. Shiraishi (eds.), Dekker, New York, Ch. 1, 1-49.

Gärdlund, L., Forsström, J., Andreasson, B., and Wågberg, L. (2005). "Influence of polyelectrolyte complexes on the strength properties of papers from unbleached kraft pulps with different yields," Nordic Pulp Paper Res. J. 20(1), 71-77. 
Gärdlund, L., Wågbberg, L., and Gernandt, R. (2003). "Polyelectrolyte complexes for surface modification of wood fibers. 2. Influence of complexes on wet and dry strength of paper," Colloids Surf. A 218(1-3), 137-149.

Gerdes, W. F. (1966). "A new instrument - The streaming current detector," $12^{\text {th }}$ Natl. ISA Analysis Inst. Symp., Houston, TX, 181-198.

Gernandt, R., Wågberg, L., Gärdlund, L., and Dauzenberg, H. (2003). "Polyelectrolyte complexes for surface modification of wood fibers. 1. Preparation and characterization of complexes for dry and wet strength improvement of paper," Colloids Surf. A 213(1), 15-25.

Gert, E. V. (1996). "Possibilities of nitric acid preparation of powder cellulose forms," Cellulose 3(4), 217-228.

Ghosh, B. N., and Pal, P. K. (1961). "Evaluation of zeta potential with correction of cell constant and surface conductance," Trans. Faraday Soc. 57, 116-122.

Giri, M., Simonsen, J., and Rochefort, W. E. (2000). "Dispersion of pulp slurries using carboxymethylcellulose," Tappi J. 83(10), 58 [electronic document].

Goossens, J. W. S., and Luner, P. (1976). "Flocculation of microcrystalline cellulose suspensions with cationic polymers - Effect of agitation," Tappi 59(2), 89-94.

Goring, D. A. I., and Mason, S. G. (1950a). "Electrokinetic properties of cellulose fibers. 1. Stream potential and electro-osmosis," Can. J. Res. B 28(6), 307-322.

Goring, D. A. I., and Mason, S. G. (1950b). "Electrokinetic properties of cellulose fibers. 2. Zeta-potential measurements by the stream-compression method," Can. J. Res.Sec. B 28(6), 323-338.

Goulet, M. T. and Stratton, R. A. (1990). "The effect of pulping, bleaching, and refining operations on the electrokinetic properties of wood fines," Nordic Pulp Paper Res. J. 5(3), 118-125.

Grancaric, A. M., Pusic, T., Soljacic, I., and Ribitsch, V. (1997). "Influence of electrokinetic potential on adsorption of cationic surfactants," Textile Chemist Colorist 29(12), 33-35.

Grancaric, A. M., Tarbuk, A., and Pusic, T. (2005). "Electrokinetic properties of textile fabrics," Coloration Technol. 121(4), 221-227.

Grignon, J., and Scallan, A. M. (1980). "Effect of pH and neutral salts upon the swelling of cellulose gels," J. Appl. Polymer Sci. 25(12), 2829-2843.

Gruber, E., Grossmann, K., and Schempp, W. (1996). "Interactions of synthetic cationic polymers with fibers and fillers; Influence on adsorption," Wochenbl. Papierfabr. 124(1), 4-11.

Habibi, Y., Chanzy, H., and Vignon, M. R. (2006). “TEMPO-mediated surface oxidation of cellulose whiskers," Cellulose 13(6), 679-687.

Habibi, Y., Foulon, L., Aguie-Beghin, V., Molinari, M., and Douillard, R. (2007). "Langmuir-Blodgett films of cellulose nanocrystals: Preparation and characterization," J. Colloid Interface Sci. 316(2), 388-397.

Halab-Kessira, L., and Ricard, A. (1996). "Adsorption of $\mathrm{CaCO}_{3}$ particles on cationic cellulose graft copolymers .2. Effect of physical parameters," J. Colloid Interface Sci. 184(2), 437-442.

Halabisky, D. D. (1977). "Wet-end control for the effective use of cationic starch," Tappi 60(12), 125-127. 
Hamaker, H. C. (1937). "The London-van der Waals attraction between spherical particles," Physica 4, 1058-1072.

Hand, V., Koethe, J., Kuchibhotla, S., and Scott, W. (1993). "An evaluation of two padforming paper stock charge analyzers," Papermakers Conf. Proc., TAPPI Press, Atlanta, 591-598.

Hannuksela, T., and Holmbom, B. (2004). "Sorption of mannans to different fiber surfaces: An evolution of understanding," Hemicelluloses: Sci. Technol., ACS Symp. Ser. 864, 222-235.

Hannuksela, T., Tenkanen, M., and Holmbom, B. (2002). "Sorption of dissolved galactoglucomannans and galactomannans to bleached kraft pulp," Cellulose 9(3-4), 251-261.

Haslam, J. H., and Steele, F. A. (1936). "The retention of pigments in paper," Tech. Assoc. Papers 19, 249-252.

Heiner, A. P., Kuutti, L., and Teleman, O. (1998). "Comparison of the interface between water and four surfaces of native crystalline cellulose by molecular dynamics simulations," Carbohydrate Res. 306(1-2), 205-220.

Heiner, A. P., and Teleman, O. (1997). "Interface between monoclinic crystalline cellulose and water: Breakdown of the odd/even duplicity," Langmuir 13(11), 511 518; (26), 7305 (erratum).

Herrington, T. M., and Midmore, B. R. (1984a). "Adsorption of ions at the cellulose aqueous-electrolyte interface. 1. Charge pH isotherms," J. Chem. Soc. - Faraday Trans. I 80(6), 1525-1537.

Herrington, T. M., and Midmore, B. R. (1984b). "Adsorption of ions at the cellulose aqueous-electrolyte interface. 2. Determination of the surface-area of cellulose fibers," J. Chem. Soc. - Faraday Trans. I 80(6), 1539-1552.

Herrington, T. M., and Midmore, B. R. (1984c). "Adsorption of ions at the cellulose aqueous-electrolyte interface. 3. Calculation of the potential at the surface of cellulose fibers," J. Chem. Soc. - Faraday Trans. I 80(6), 1539-1552.

Herrington, T. M., and Petzold, J. C. (1992). "An investigation into the nature of charge on the surface of papermaking woodpulps. 2. Analysis of potentiometric titration data," Colloids Surf. 64(2), 109-118.

Hesselink, F. T. (1977). "Theory of polyelectrolyte adsorption - Effect on adsorption behavior of electrostatic contribution to adsorption free-energy," J. Colloid Interface Sci. 60, 448-466.

Hiemenz, P. C., and Rajagopalan, R. (1997). Principles of Colloid and Surface Science, $3^{\text {rd }}$ Ed., Dekker, New York.

Hoffmann, F., Müller, R., Rohloff, E., and Tretter, H. (1975). "Erfahrungen mit der Strömungspotentialmethode bei Retentions- und Naßfestigkeitsproblemen," Papier 29(12), 529-534.

Hogg, R., Healy, T. W., and Fuerstenau, D. W. (1966). "Mutual coagulation of colloidal dispersions," Trans. Faraday Soc. 62(6), 1638-1651.

Holmberg, M., Berg, J., Stemme, S., Ödberg, L., Rasmusson, J., and Claesson, P. (1997a). "Surface force studies of Langmuir-Blodgett cellulose films," J. Colloid Interface Sci. 186(2), 369-381. 
Holmberg, M., Wigren, R., Erlandsson, R., and Claesson, P. M. (1997b). "Interactions between cellulose and colloidal silica in the presence of polyelectrolytes," Colloids Surf. A 129-130, 175-183.

Horn, D. (2001). "Exploring the nanoworld of interfaces and their functions during paper manufacturing and upgrading," Wochenbl. Papierfabr. 129(23/24), 1589-1596.

Horn, D., and Melzer, J. (1975). "The effect of high molecular cationic dewatering aids on the electrokinetic properties of pulp," Papier 29(12), 534-541.

Horn, D., and Melzer, J. (1977). "Electrostatic and steric effects of cationic polymers adsorbed on cellulose," Trans BPBIF Symp. Fiber-Water Interactions in Papermaking (Oxford), 135-150.

Horvath, A. E., Lindström, T., and Laine, J. (2006). "On the indirect polyelectrolyte titration of cellulosic fibers. Conditions for charge stoichiometry and comparison with ESCA," Langmuir 22(2), 824-830.

Hostetler, R. E.., and Swanson, J. W. (1974). "Diffusion into and adsorption of polyethylenimine on porous silica gel," J. Polymer Sci. 12(1), 29-43.

Hubbe, M. A. (1979). "A modified reporting procedure for polyelectrolyte titrations," Tappi 62(8), 120-121.

Hubbe, M. A. (1984). "Theory of detachment of colloidal particles from flat surfaces exposed to flow," Colloids Surf. 12, 151-178.

Hubbe, M. A. (1985). "Detachment of colloidal hydrous oxide spheres from flat solids exposed to flow. 2. Mechanism of release," Colloids Surf. 16(3-4), 249-270.

Hubbe, M. A. (1987a). "Detachment of colloidal hydrous oxide spheres from flat solids exposed to flow. 3. Forces of adhesion," Colloids Surf. 25(2-4), 311-324.

Hubbe, M. A. (1987b). "Detachment of colloidal hydrous oxide spheres from flat solids exposed to flow. 4. Effects of polyelectrolytes," Colloids Surf. 25, 325-339.

Hubbe, M. A. (1999). "Method and apparatus for measuring an electrical property of papermaking furnish," U.S. Patent 5,936,151, Aug. 10.

Hubbe, M. A. (2000a). "Selecting and interpreting colloidal charge measurements," Proc. Scientific and Technical Advances in Wet End Chemistry, PIRA, Barcelona, June 1920.

Hubbe, M. A. (2000b). "Reversibility of polymer-induced fiber flocculation by shear. 1," Nordic Pulp and Paper Res. J. 15(5), 545-553; 16(4), 375.

Hubbe, M. A. (2001b). "Method for determining electrokinetic properties of papermaking furnish," U.S. Patent 6,176,974, Jan. 23.

Hubbe, M. A. (2005). "Microparticle programs for drainage and retention," in Rodriguez, J. M. (ed.), Micro and Nanoparticles in Papermaking, TAPPI Press, Atlanta, Chapter $1,1-36$.

Hubbe, M. A. (2007). "Flocculation and redispersion of cellulosic fiber suspensions: A review of effects of hydrodynamic shear and polyelectrolytes," BioRes. 2(2), 296331.

Hubbe, M. A., and Chen, J. (2004). "Charge-related measurements - A reappraisal. Part 1. Streaming current," Paper Technol. 45(8), 17-23.

Hubbe, M. A., and Heitmann, J. A. (2007). "Review of factors affecting the release of water from cellulosic fibers during paper manufacture," BioRes. 2(3), 500-533.

Hubbe and Rojas (2008). "Colloidal stability of cellulosics," BioResources 3(4), 1419-1491. 1473 
Hubbe, M. A., Moore, S. M., and Lee, S. Y. (2005). "Effects of charge ratios and cationic polymer nature on polyelectrolyte complex deposition onto cellulose," Ind. Eng. Chem. Res. 44(9), 3068-3074.

Hubbe, M. A., Rojas, O. J., Argyropoulos, D. S., Wang, Y., Song, J., Sulić, N., and Sezaki, T. (2007c). "Charge and the dry-strength performance of polyampholytes. Part 2. Colloidal effects," Colloids Surf. A 301(1), 23-32.

Hubbe, M. A., Rojas, O. J., Lee, S. Y., Park, S., and Wang, Y. (2007b). "Distinctive electrokinetic behavior of nanoporous silica particles treated with cationic polyelectrolyte," Colloids Surf. A 292(2), 271-278.

Hubbe, M. A., Rojas, O. J., Lucia, L. A., and Jung, T. M. (2007a). "Consequences of the nanoporosity of cellulosic fibers on their streaming potential and their interactions with cationic polyelectrolytes," Cellulose 14(6), 655-671.

Hubbe, M. A., Rojas, O. J., and Venditti, R. A. (2006). "Control of tacky deposits on paper machines - A review," Nordic Pulp Paper Res. J. 21(2), 154-171.

Hubbe, M. A., Rojas, O. J., Lucia, L., A., and Sain, M. (2008). "Cellulosic nanocomposites: A review," BioRes. 3(3), 929-980.

Hubbe, M. A., Wagle, D. G., and Ruckel, E. R. (1999). "Method for increasing the strength of a paper or paperboard product," U.S. Patent 5,956,180.

Hubbe, M. A., and Wang, F. (2002). "Where to add retention aid: Issues of time and shear," Tappi J. 1(1), 28-33.

Hubbe, M. A. and Wang, F. (2004). "Charge-related measurements - A reappraisal. Part 2: Fiber-pad streaming potential," Paper Technol. 45(9), 27-34.

Hunter, R. J. (1981). Zeta Potential in Colloid Science, Academic Press, London.

Hunter, R. J. (2001). Foundations of Colloid Science, $2^{\text {nd }}$ Ed., Oxford Univ. Press, Oxford.

Iamazaki, E. T., and Atvars, T. D. Z. (2007). "Sorption of a fluorescent whitening agent (Tinopal CBS) onto modified cellulose fibers in the presence of surfactants and salt," Langmuir 23(26), 12886-12892.

Ibrahim, T. H., Burk, T. R., Etzler, F. M., and Neuman, R. D. (2000). "Direct adhesion measurements of pharmaceutical particles to gelatin capsule surfaces," Journal of Adhesion Science and Technology 14(10), 1225-1242.

Isogai, A., Kitaoka, C., and Onabe, F. (1997). "Effects of carboxyl groups in pulp on retention of alkylketene dimer," J. Pulp Paper Sci. 23(5), J215-J219.

Israelachvili, J. N. (1992). Intermolecular and Surface Forces, Academic Press, London.

Israelachvili, J. N., and McGuiggan, P. M. (1990). "Adhesion and short-range forces between surfaces. 1. New apparatus for surface force measurements," J. Mater. Res. 5(10), 2223-2231.

Iyer, S. R. S., and Jayaram, R. (1971). "Zeta-potential studies in cellulose fibre-aqueous electrolyte solution systems," J. Soc. Dyers Colourists 87(10), 338-342.

Jacob, P. N., and Berg, J. C. (1993). "Contact-angle titrations of pulp fiber furnishes," TAPPI J. 76(5), 133-137.

Jacobasch, H. J., Grundke, K., and Werner, C. (1995). "Surface characterization of cellulose materials," Papier 49(12), 740-745. 
Jacquelin, G., and Bourlas, H. (1964). "Measurement of the zeta potential of papermaking fibers. Effects of preliminary treatments," Techniques et Recherches Papeteries 3, 49-58.

Jaycock, M. J. (1995). "Assumptions made in the measurement of zeta-potential by streaming current/potential detectors," Paper Technol. 36(3), 35-38.

Jaycock, M. J., and Pearson, J. L. (1975). "Colloidal aspects of paper formation .1. Factors affecting electrokinetic properties of cellulose fibers," Svensk Papperstidn. 78(5), 167-171.

Jaycock, M. J., and Pearson, J. L. (1976a). "A study of the retention of pigment during paper formation," J. Colloid Interface Sci. 55(1), 181-190.

Jaycock, M. J., Pearson, J. L., Counter, R., and Husband, F. W. (1976b). "Effect of cellulose fiber fines on the retention of fillers," J. Appl. Chem. Biotechnol. 26(7), 370-374.

Jaycock, M. J., and Swales, D. K. (1994). “The theory of retention,” Paper Technol. 35(8), 26-33.

Jayme, G. and Büttel, H. (1968). "The determination and meaning of water retention value (WRV) of various bleached and unbleached cellulosic pulps," Wochenbl. Papierfabr. 96(6), 180-187.

Johnsen, I. A., Stenius, P., Tammelin, T., Österberg, M., Johansson, L. S., and Laine. J. (2006). "The influence of dissolved substances on resin adsorption to TMP fine material,” Nordic Pulp Paper Res. J. 21(5), 629-637.

Joubert, J. M., Kirge, G. J. R., and Borgin, K. (1959). "Evidence for a hydrate of cellulose from studies of its surface properties," Nature 184(4698), 1561-1562.

Kadla, J. F., and Gilbert, R. D. (2000). "Cellulose structure: A review," Cellulose Chem. Technol. 34(3-4), 197-216.

Kamiti, M., and van de Ven, T. G. M. (1995). "Impinging jet studies of the kinetics of deposition and dissolution of calcium-carbonate particles," Colloids Surf. A 100, 117 129.

Kang, T., and Paulapuro, H. (2006). “Characterization of chemical pulp fines,” Tappi J. $5(2), 25-28$.

Katz, K., Beatson, R. P., and Scallan, A. M. (1984). "The determination of strong and weak acidic groups in sulfite pulps," Svensk Papperstidning 87(6), R48-R53.

Kenaga, D. L., Kindler, W. A., and Meyer, F. J. (1967). "Studies of adsorption of cationic polyelectrolytes on pulp using streaming current detection," Tappi 50(7), 381-387.

King, C. A., and Williams, D. G. (1975). "Cellulose fiber-to-fiber and fines-in-fiber flocculation: A dynamic comparison," IPC Tech Paper Ser. 3, Inst. Paper Sci.

Technol. at Georgia Inst. Technol., Atlanta, available at http://smartech.gatech.edu/dspace/handle/1853/2896? mode=full.

Kleen, M., Kangas, H., and Laine, C. (2003). "Chemical characterization of mechanical pulp fines and fiber surface layers," Nordic Pulp Paper Res. J. 18(4), 361-368.

Kleimann, J., Lecoultre, G., Papastavrou, G., Jeanneret, S., Galletto, P., Koper, G. J. M., and Borkovec, M. (2006). "Deposition of nanosized latex particles onto silica and cellulose surfaces studied by optical reflectometry," J. Colloid Interface Sci. 303(2), 460-471. 
Kline, J. E. (1967). "The application of the Verwey-Overbeek theory to the relative sediment volume of kaolin-water dispersions," Tappi 50(12), 590-596.

Kocherbitov, V., Ulvenlund, S., Kober, M., Jarring, K., and Arnebrant, T. (2008). "Hydration of microcrystalline cellulose and milled cellulose studied by sorption calorimetry," J. Phys. Chem. B 112(12), 3728-3734.

Koethe, J. L., and Scott, W. E. (1993). "Polyelectrolyte interactions with papermaking fibers: The mechanism of surface-charge decay," Tappi J. 76(12), 123-133.

Koljonen, K., Mustaranta, A., and Stenius, P. (2004). "Surface characterization of mechanical pulps by polyelectrolyte adsorption," Nordic Pulp Paper Res. J. 19(4), 495-505.

Kontturi, E., Tammelin, T., and Österberg, M. (2006). "Cellulose - Model films and the fundamental approach," Chem. Soc. Rev. 35(12), 1287-1304.

Kotz, J., Bogen, I., Heinze, U., Heinze, T., Klemm, D., Lange, S., and Kulicke, W. M. (1998). "Colloidal properties of statistic, blocklike and regioselective substituted carboxymethylcelluloses," Papier 52(12), 704-712.

Kratochvil, D., Alince, B., and van de Ven, T. G. M. (1999). "Flocculation of clay particles with poorly and well-dissolved polyethylene oxide," J. Pulp Paper Sci. 25(9), 331-335.

Kratohvil, S., Janauer, G. E., and Matijević, E. (1969). "Coagulation of microcrystalline cellulose dispersions," J. Colloid Interface Sci. 29(2), 187-193.

Kumar, A. R., and Teli, M. (2007). "Electrokinetic studies of modified cellulosic fibres," Colloids Surf. A. 301(1-3), 462-468.

Lafaye, J. F., and Jacquelin, G. (1968). "The zeta potential and its application in paper making," Paperi Puu 50(4a), 155-162.

Laine, J. (1997). "Effect of ECF and TCF bleaching on the charge properties of kraft pulp," Paperi Puu 79(8), 551-559.

Laine, J., Buchert, J., Viikari, L., and Stenius, P. (1996). "Characterization of unbleached kraft pulps by enzymatic treatment, potentiometric titration and polyelectrolyte adsorption," Holzforschung 50(3), 208-214.

Laine, J., and Lindström, T. (2001). "Topochemical modification of cellulosic fibres with bipolar activators - An overview of some technical applications," Int. Papierwirtsch. $1,40-45$.

Laine, J., Lindström, T., Glad Nordmark, G., and Risinger, G. (2000). "Studies on topochemical modification of cellulosic fibers. Part 1. Chemical conditions for the attachment of carboxymethyl cellulose onto fibers," Nordic Pulp Paper Res. J. 15(5), $520-526$.

Laine, J., Lindström, T., Glad Nordmark, G., and Risinger, G. (2002). "Studies on topochemical modification of cellulosic fibers. Part 2. The effect of carboxymethyl cellulose attachment on fibre swelling and paper strength," Nordic Pulp Paper Res. J. 15(5), 520-526.

Laine, J., Lindström, T., Bremberg, C., and Glad Nordmark, G. (2003a). "Studies on topochemical modification of cellulosic fibers. Part 4. Toposelectivity of carboxymethylation and its effects on the swelling of fibres," Nordic Pulp Paper Res. J. 18(3), 316-324.

Hubbe and Rojas (2008). "Colloidal stability of cellulosics," BioResources 3(4), 1419-1491. 1476 
Laine, J., Lindström, T., Bremberg, C., and Glad Nordmark, G. (2003b). "Studies on topochemical modification of cellulosic fibers. Part 5. Comparison of the effects of surface and bulk chemical modification and beating of pulp on paper properties," Nordic Pulp Paper Res. J. 18(3), 325-332.

Laine, J., Lovgren, L., Stenius, P., and Sjöberg, S. (1994). "Potentiometric titration of unbleached kraft cellulose fiber surfaces," Colloids Surf. A 88(2-3), 277-287.

Laine, J., Mattsson, R., and Swerin, A. (2004), "The effect of bleached pulp type on AKD internal sizing - An EuroFEX experimetnal paper machine study," Paperi Puu 86(3), 325-332.

Laine, J., and Stenius, P. (1997). "Effect of charge on the fiber and paper properties of bleached industrial kraft pulps," Paperi Puu 79(4), 257-266.

La Mer, V. K., and Healy, T. W. (1963). "Adsorption-flocculation reactions of macromolecules at the solid-liquid interface," Rev. Pure Appl. Chem. 13(Sept.), 112-133.

Leiviskä, T., Rämö, J., Sillanpää, M., and Vuorenpalo, V.-M. (2005). "Multimodal zeta potential distributions in chemical pulp bleaching filtrates," J. Pulp Paper Sci. 31(4), 167-174.

Leporatti, S., Sczech, R., Riegler, H., Bruzzano, S., Storsberg, J., Loth, F., Jaeger, W., Laschewsky, A., Eichhorn, S., and Donath, E. (2005). "Interaction forces between cellulose microspheres and ultrathin cellulose films monitored by colloidal probe microscopy - Effect of wet strength agents," J. Colloid Interface Sci. 281(1), 101-111.

Li, S., and Dai, H. (2004). "The influence of inorganic salts on WRV of papermaking stock," Proc. $2^{\text {nd }}$ International Symposium on Technologies of Pulping, Papermaking and Biotechnology on Fiber Plants, Oct. 13-14, Nanjing Forestry Univ., 434-437.

Li, T. Q., Henriksson, U., Eriksson, J. C., and Ödberg, L. (1992). "Water cellulose interaction in wood pulp fiber suspensions studied by O-17 and H-2 NMR relaxation - The effect of beating," Langmuir 8(2), 680-686.

Lima, M. M. D., and Borsali, R. (2004). "Rodlike cellulose microcrystals: Structure, properties, and applications," Macromol. Rapid Comm. 25(7), 771-787.

Lindgren, H., Öhman, L.-O., Gunnars, S., and Wågberg, L. (2002). "Charge determinations of cellulose fibers of different origin - Comparison between different methods," Nordic Pulp Paper Res. J. 17(1), 89-96.

Lindgren, H., and Öhman, L.-O. (2000). "Characterization of acid/base properties for bleached softwood fibers as influenced by ionic salt medium," Nordic Pulp Paper Res. J. 15(1), 18-23.

Lindgren, L., Persson, P., and Öhman, L. O. (2001). "Interactions of calcium(II), copper(II) and aluminium(III) ions with two chemically modified wood fibres," Nordic Pulp Paper Res. J. 16(3), 225-234.

Lindström, T., (1991). "Electrokinetics of the papermaking industry," in Paper Chemistry, J. C. Roberts (ed.), Blackie, London, Ch. 3, 25-43.

Lindström, T. (1992). "Chemical factors affecting the behavior of fibers during papermaking.” Nordic Pulp Paper Res. J. 7(4), 181-192.

Lindström, T. (1996). "Electrokinetics of the papermaking industry," in Roberts, J. C. (ed.), Paper Chemistry, $2^{\text {nd }}$ Ed., Blackie Academic, New York, Ch. 3, 25-43. 
Lindström, T., and Carlsson, G. (1982). "The effect of carboxyl groups and their ionic form during drying on the hornification of cellulose fibers," Svensk Papperstidn. 85(15), R146-R151.

Lindström, T., and Glad-Nordmark, G. (1984). "Network flocculation and fractionation of latex particles by means of a polyethyleneoxide-phenolformaldehyde resin complex," J. Colloid Interface Sci. 97(1), 62-67.

Lindström, T., and Söremark, C. (1975). "Zeta potential measurement in the manufacture of paper," Papier 29(12), 519-525.

Lindström, T., and Söremark, C. (1976). "Adsorption of cationic polyacrylamides on cellulose," J. Colloid Interface Sci. 55(2), 305-312.

Lindström, T. , Söremark, C., Heinegård, C., and Martin-Löf, S. (1974). "The importance of electrokinetic properties of wood fiber for papermaking," Tappi 57(12), 94-96.

Lloyd, J. A., and Horne, C. W. (1993). "The determination of fiber charge and acidic groups of radiata pine pulps," Nordic Pulp Paper Res. J. 8(1), 48-52.

Lokhande, H. T., and Salvi, A. S. (1976). "Electrokinetic studies of cellulosic fibers. 1. Zeta-potential of fibers dyed with reactive dyes," Colloid Polymer Sci. 254(11), 10301041.

Lokhande, H. T., and Salvi, A. S. (1978). "Electrokinetic studies of cellulosic fibers. 2. Surface charge density of fibers dyed with reactive dyes," Colloid Polymer Sci. 256(10), 1021-1028.

Lofton, M. C., Moore, S. M., Hubbe, M. A., and Lee, S. Y. (2005). "Polyelectrolyte complex desposition as a mechanism of paper dry-strength development," Tappi $J$. 4(9), 3-7.

Lvov, Y. M., Grozdits, G. A., Eadula, S., Zheng, Z. G., and Lu, Z. H. (2006). "Dry and wet strength of paper - Layer-by-layer nanocoating of mill broken fibers for improved paper," Nordic Pulp and Paper Research Journal 21(5), 552-557.

Madan, G. L., Shirvastava, S. K., and Baddi, N. T. (1973). "Electrokinetic studies of cotton. Part 1: Streaming potential measurements of dimethylol ethyelene urea treated cotton," Kolloid Z. Z. Polymere 251(7), 483-489.

Madan, G. L., and Shrivastava, S. K. (1975). "Electrokinetic studies of cotton. 2. Measurement of surface potential at interface between cellulose and solution of crosslinking agents," Colloid Polymer Sci. 253(11), 969-973.

Mahanty, J., and Ninham, B. W. (1975). "Self-energy in adsorption," Faraday Discussions 59, 13-21.

Maloney, T. C., Laine, J. E., and Paulapuro, H. (1999). “Comments on the measurement of cell wall water," Tappi J. 82(9), 125-127.

Mann, J., and Marrinan, H. J. (1958). "Polarized infrared spectra of cellulose-1," J. Polymer Sci. 27(115), 595-596.

Manouchehri, H. R., Rao, K. H., and Forssberg, K. S. E. (2001). "Triboelectric charge characteristics and donor-acceptor, acid-based properties of minerals - Are they related?" Particulate Sci. Technol. 19(1), 23-43.

Marton, J. (1980a). "The role of surface chemistry in fines - alum interactions," Tappi 63(2), 121-125. 
Marton, J. (1980b). "The role of surface chemistry in fines - cationic starch nteractions," Tappi 63(4), 87-91.

Marton, J., and Marton T. (1976). "Wet end starch: Adsorption of starch on cellulosic fibers," Tappi 59(12), 121-124.

Mathews, J., Gustafson, R. and Hodgson, K. (2004). "A method to determine the charge demand of single pulp fibers," Nordic Pulp Paper Res. J. 19(4), 453-459.

Matijević, E., Shulz, K., Mirnik, M., Herak, J., Vouk, V. B., Sjunjski, M., Babic, S., Kratohvil, J., and Palarm, T. (1953). "The mechanism of coagulation of lyophobic sols as revealed through investigations of silver halide solids in statu-nascendi," $J$. Phys. Chem. 57(3), 301-307.

Maximova, N., Laine, J., and Stenius, P. (2005). "Adsorption of lignin-cationic starch complexes on cellulose fibres and their effect on sheet properties," Paperi Puu 87(3), 176-182.

Maximova, N., Stenius, P., and Salmi, J. (2004). "Lignin uptake by cellulose fibres from aqueous solutions," Nordic Pulp Paper Res. J. 19(2), 135-145.

McKague, J. F., Etter, D. O., Pilgrim, J. O., and Griggs, W. H. (1974). "Practical applications of the electrokinetics of papermaking," Tappi 57(12), 101-103.

McKenzie, A. W. (1968). "Structure and properties of paper. XVIII. The retention of wetend additives," Appita 21(4), 104-116.

McKenzie, A. W., Balodis, W., and Milgrom, A. (1969). "Influence of alum and pH on the zeta potential of fibers and additives," Appita 23(1), 40-44.

McNeal, M. R., Nanko, H., and Hubbe, M. A. (2005). "Imaging of macromolecular events occurring during the manufacture of paper," Proc. XIII Fundamental Research Symposium, Cambridge, 1225-1267.

Melzer, J. (1972). "Zeta potential and its importance in the manufacture of paper," Papier 26(7), 305-332.

Micic, M., Radotic, K., Jeremic, M., and Leblanc, R. M. (2003). "Study of self-assembly of the lignin model compound on cellulose model substrate," Macromol. Biosci. 3(2), 100-106.

Miyanishi, T. (1995a). "On-line zeta potential analyses of a fine paper machine and a newsprint paper machine," Tappi J. 78(3), 85-91.

Miyanishi, T. (1995b). "Effects of zeta potential on flocculation measurement in microparticle systems," Tappi J. 78(11), 135-150.

Miyanishi, T., and Montegi, S. (1996). "Optimization of flocculation and drainage for microparticle systems by zeta potential control," Proc. 1996 Papermakers Conf., TAPPI Press, Atlanta, 73-82.

Miyanishi, T., and Shigeru, M. (1997). "Optimizing flocculation and drainage for microparticle systems by controlling zeta potential," Tappi J. 80(1), 262-270.

Mocchiutti, P., and Zanuttini, M. A. (2005). "A useful equation for estimating the surface charge of pulp fibers," Tappi J. 4(5), 18-22.

Montanari, S., Rountani, M., Heux, L., and Vignon, M. R. (2005). "Topochemistry of carboxylated cellulose nanocrystals resulting from TEMPO-mediated oxidation," Macromol. 38(5), 1665-1671. 
Mosbye, J., Foss, M. H., Laine, J., and Moe, S. (2003a). "Interaction between model colloidal wood resin, fillers and dissolved substances," Nordic Pulp Paper Research Journal 18(2), 194-199.

Mosbye, J., Harstad, B., and Fiksdahl, A. (2000). "Solid-phase extraction (SPE) of hydrophobic components from a model white water," Nordic Pulp \& Paper Research Journal 15(2), 101-105.

Mosbye, J., Laine, J., and Moe, S. (2003b). "The effect of dissolved substances on the adsorption of colloidal extractives to fines in mechanical pulp," Nordic Pulp Paper Research Journal 18(1), 63-68.

Mosbye, J., Moe, S., and Laine, J. (2002). "The charge and chemical composition of fines in mechanical pulp," Nordic Pulp Paper Res. J. 17(3), 352-356.

Mutje, P., Vilaseca, F., Gou, M., and Pelach, M. A. (2001). "Interactions between a cationic polyelectrolyte and cellulose fibres bleached for paper manufacture," AFINIDAD 57(491), 29-38.

Nanko, H., and Pan, S. (2003a). "Visualization of polymer adsorption on pulp fiber. 1: Polyacrylamide," TAPPI Spring Technical Conf.,

Nako, H., and Pan, S. (2003b). "Visualization of polymer adsorption on pulp fiber. 1: Polyacrylamide, Part 2," International Paper Coating Chemistry Symposium, Proceedings, $5^{\text {th }}$, Montreal, TAPPI Press, Atlanta, 245-251.

Neale, S. M. (1946). "The electrical double layer, the electrokinetic potential, and the streaming current," Trans. Faraday Soc. 42, 473-478.

Nelson, P. F., and Kalkipsakis, C. G. (1964). "Carboxymethylation of eucalypt kraft pulp," Tappi 47(2), 107-110.

Neuman, R. D., Berg, J. M., and Claesson, P. M. (1993). "Direct measurement of surface forces in papermaking and paper coating systems," Nordic Pulp Paper Res. J. 8(1), 96-104.

Newman, R. H., and Davidson, T. C. (2004). "Molecular conformations at the cellulosewater interface," Cellulose 11(1), 23-32.

Northrop, J. H., and Kunitz, M. (1926). "The swelling and osmotic pressure of gelatin in salt solutions," J. Gen Physiol. 8(4), 317-337.

Notley, S. M. (2008). "Effect of introduced charge in cellulose gels on surface interactions and the adsorption of highly charged cationic polyelectrolytes," Phys. Chem. Chem. Phys. 10(13), 1819-1825.

Notley, S. M., Eriksson, M., Wågberg, L., Beck, S., and Gray, D. G. (2006). "Surface forces measurements of spin-coated cellulose thin films with different crystallinity," Langmuir 22(7), 3154-3160.

Notley, S. M., and Norgren, M. (2006). "Measurement of interaction forces between lignin and cellulose as a function of aqueous electrolyte solution conditions," Langmuir 22(26), 11199-11204.

Nurmi, M., Wallin, S., and Eklund, D. (2003). "Interactions between cationic polyacryl amide and TMP," Wochenbl. Papierfabr. 131(11-12), 678-682.

Ödberg, L., Barla, P., and Glad-Nordmark, G. (1995). "Transfer of adsorbed alum from cellulosic fibers to clay particles," J. Pulp Paper Sci. 21(7), J250-J254. 
Oertel, J., Petzold, G., Buchhammer, H., Geyer, S., Schwarz, S., Muller, U., and Ratzsch, M. (1991). "Introduction of surface-charge into polymers by polyelectrolyte complexes," Colloids Surf. 57(3-4), 375-381.

Oh, E., and Luner, P. E. (1999). "Surface free energy of ethylcellulose films and the influence of plasticizers," Intl. J. Pharmaceutics 188(2), 203-219.

Öhman, L. O., Wågberg, L., Malmgren, K., and Tjernström, A. (1997). “Adsorption of aluminum(III) on cellulosic fibres in neutral to alkaline solutions - Influence of charge and size of the particles formed," J. Pulp Paper Sci. 23(10), J467-J474.

Ojala, T. (1993). "Charge measurements of different furnishes using polyelectrolyte titration with a streaming current detector," Proc. TAPPI 1993 Papermakers Conf., 613-626.

Österberg, M. (2000). "The effect of a cationic polyelectrolyte on the forces between two cellulose surfaces and between one cellulose and one mineral surface," J. Colloid Interface Sci. 229(2), 620-627.

Paananen, A., Österberg, M., Rutland, M., Tammelin, T., Saarinen, T., Tappura, K., and Stenius, P. (2004). "Interaction between cellulose and xylan: An atomic force microscope and quartz crystal microbalance study," Hemicelluloses: Sci. Technol., ACS Symp. Ser. 864, 269-290.

Pang, L., and Gray, D. G., "Heterogeneous fibrillation of kraft pulp fiber surfaces observed by atomic force microscopy," J. Pulp Paper Sci. 24(11), 369-372 (1998).

Paria, S., Manohar, C., and Khilar, K. C. (2004). "Effect of cationic surfactant on the adsorption characteristics of anionic surfactant on cellulose surface," Colloids Surf. A 232(2-3), 139-142.

Paria, S., Manohar, C., and Khilar, K. C. (2005). "Adsorption of anionic and non-ionic surfactants on a cellulosic surface," Colloids Surf. A 252(2-3), 221-229.

Park, S., Venditti, R. A., Jameel, H., and Pawlak, J. J. (2006). "Changes in pore size distribution during the drying of cellulose fibers as measured by differential scanning calorimetry," Carbohydrate Polymers 66(1), 97-103.

Parks, G. A. (1965). "The isoelectric points of solid oxides, solid hydroxides, and aqueous hydroxo complex systems," Chem. Rev. 65(2), 177-198.

Patton, P. A., and Lee, D. T. (1993). "Charge analyses: Powerful tools in wet-end optimization," Tappi J. 76(8), 107-115.

Pearson, R. G. (1969). Modern Theory of Acids and Bases, American Chemical Society, Washington.

Pelton, R. (1993). "A model of the external surface of wood pulp fibers," Nordic Pulp Paper Res. J. 8(1), 113-119.

Pelton, R. H. (1999). "Polymer-colloid interactions in pulp and paper manufacture," in Farinato, R. S., and Dubin, P. L. (eds.), Colloid-Polymer Interactions: From Fundamentals to Practice, Wiley-Interscience, New York, Ch. 2, 51-82.

Pelton, R. H., and Allen, L. H. (1984). "Factors influencing the adhesion of polystyrene spheres attached to Pyrex by polyethyleneimine in aqueous solution," J. Colloid Interface Sci. 99(2), 387-398.

Penfold, J., Tucker, I., Petkov, J., and Thomas, R. K. (2007). "Surfactant adsorption onto cellulose surfaces," Langmuir 23(16), 8357-8364.

Hubbe and Rojas (2008). "Colloidal stability of cellulosics," BioResources 3(4), 1419-1491. 1481 
Penniman, J. G. (1992). “Comparison of pulp pad streaming potential measurement and mobility measurement," TAPPI J. 75(8), 111-115.

Petersson, L., Kvien, I., and Oksman, K. (2007). "Structure and thermal properties of poly(lactic acid)/cellulose whiskers nanocomposite materials," Composites Sci. Technol. 67(11-12), 2535-2544.

Petlicki, J., and van de Ven, T. G. M. (1994). "Adsorption of polyethylenimine onto cellulose fibers," Colloids Surf. A 83(1), 9-23.

Petzold, G., Schwarz, S., Buchhammer, H. M., and Lunkwitz, K. (1997). “A very effective method for the cationic modification of cellulose," Angew. Makromol. Chemie 253, 1-15.

Petzold, G., Nevel, A., Buchhammer, H.-M., and Lunkwitz, K. (1998). "Preparation and characterization of different polyelectrolyte complexes and their application as flocculants," Colloid Polymer Sci. 276(1), 125-130.

Pfau, A., Schrepp, W., and Horn, D. (1999). "Detection of a single molecule adsorption structure of poly(ethylenimine) macromolecules by AFM," Langmuir 15(9), 32193225 (1999).

Phipps, J. S. (1999). "Some mechanistic insights for using the streaming current detector to measure wet-end charge," Tappi J. 82(8), 157-165.

Poppel, E. (1992). "The meaning of zeta potential in the wet end of paper manufacture and the possibilities for optimization by means of electrokinetic control," Wochenbl. Papierfabr. 120(14), 565-571.

Poppel, E., Muresan, R., and Muresan, A. (2001). "The zeta potential of some cellulosic ant man-made fibers during operations of softening and antistatization," Cellulose Chem. Technol. 35(1-2), 45-57.

Poptoshev, E., Rutland, M. W., and Claesson, P. M. (2000). "Surface forces in aqueous polyvinylamine solutions. 2. Interactions between glass and cellulose," Langmuir 16, 1987-1992.

Porubska, J., Alince, B., and van de Ven, T. G. M. (2002). "Homo- and heteroflocculation of papermaking fines and fillers," Colloids Surf. A 210(2-3), 223-230.

Pothan, L. A., Bellman, C., Kailas, L., and Thomas, S. (2002). "Influence of chemical treatments on the electrokinetic properties of cellulose fibres," J. Adhesion Sci. Technol. 16(2), 157-178.

Pruszynski, P., and Jakubowksi, R. (2002). "Impact of conductivity and cationic demand on drainage of TMP-based newsprint furnish," APPITA Annual General Conf., 323331.

Przybysz, K., Rybicki, E., and Czechowski, J. (2002). "Electrokinetic potential studies of dissolved substances washed out in the paper-making process," Fibres \& Textiles in Eastern Europe 10(2), 65-68.

Pusic, T., Grancaric, A. M., Soljacic, I., and Ribitsch, V. (1999). "The effect of mercerisation on the electrokinetic potential of cotton," J. Soc. Dyers Colourists 115(4), 121-124.

Radtchenko, I. L., Papastavrou, G., and Borkovec, M. (2005). "Direct force measurements between cellulose surfaces and colloidal silica particles," Biomacromol. 6(6), 3057-3066. 
Ramirez-Dorronsoro, J. C., Jacko, R. B., and Kildsig, D. O. (2006). “Chargeability measurements of selected pharmaceutical dry powders to assess their electrostatic charge control capabilities," AAPS Pharmscitech 7(4), Article no. 103.

Räsänen, E., and Stenius, P. (1997). "The sorption of $\mathrm{Na}^{+}, \mathrm{Ca}^{++}, \mathrm{Mg}^{++}$, and $\mathrm{Mn}^{++}$on cellulose fibers: Prediction and analysis of sorption equilibrium with electrostatic models," Proc. ISWPC, Paper 94, 1-5.

Räsänen, E., Stenius, P., and Tervola, P. (2001). "Model describing Donnan equilibrium, $\mathrm{pH}$ and complexation equilibria in fiber suspensions," Nordic Pulp Paper Res. J. 16(2), 130-139.

Ravnjak, D., Plazl, I., and Moze, A. (2007). "Kinetics of colloidal alkylketene dimer particles deposition on pulp fibers," Colloid Polymer Sci. 285(8), 907-914.

Reischl, M., Stana-Kleinschek, K., and Ribitsch, V. (2006). "Adsorption of surfactants on polymer surfaces investigated with a novel zeta-potential measurement system," Adv. Materials Forum III, 514-516(Pts. 1-2), 1374-1378.

Ribitsch, V., Stana-Kleinschek, K., Kreze, T., and Strnad, S. (2001). "The significance of surface charge and structure on the accessibility of cellulose fibres," Macromol. Mater. Eng. 286(10), 648-654.

Rice, M., and Roeraade, J. (2003). "Continuous filtration and titration apparatus for real time monitoring of polyelectrolyte concentration and cationic demand of a paper furnish," Nordic Pulp Paper Res. J. 18(1), 95-107.

Roberts, J. C., and Tatham, J. (1992). "Succinylation of pulps," in The Chemistry of Papermaking, paper 08, Pira Int'1., Leatherhead, Surrey, UK.

Roberts, K., Kowalews, J., and Friberg, S. (1974). "Influence of aluminum salts on colloidal properties of abietic acid suspensions, and on co-flocculation with cellulose fines," Svensk Papperstidn. 77(7), 239-246.

Rohloff, E., and Höschle, O. (1993). "Zeta potential experiences with laboratory and online measurements," Wochenbl. Papierfabr. 121(23-24), 990-994.

Rohrsetzer, S., Kovacs, P., Kabaifaix, M., Papp, J., and Volgyi, P. (1995). "Investigation of the inside and outside surfaces of pulp fibers by adsorption of molecular, colloidal and coarse size particles," Cellulose Chem. Technol. 29(1), 65-75.

Rojas, O. J., Claesson, P. M., Muller, D., and Neuman, R. D. (1998). "The effect of salt concentration on adsorption of low-charge-density polyelectrolytes and interactions between polyelectrolyte-coated surfaces," J. Colloid Interface Sci. 205(1), 77-88.

Rojas, O. J., Dedinaite, A., Byrd, M. V., Hubbe, M. A., and Claesson, P.M. (2005). "On the origins of adhesion in papermaking systems," Proc. XIII Fundamental Research Symposium, Cambridge, S. J. I'Anson, (ed.), Vol. 2, p. 1351-1378, Digital Books Logistics Ltd, Peterborough, UK, 2005.

Rojas, O. J., Ernstsson, M., Neuman, R. D., and Claesson, P. M. (2000). "X-ray photoelectric spectroscopy in the study of polyelectrolyte adsorption on mica and cellulose," J. Phys. Chem. B 104, 10032-10042.

Rojas, O. J., and Hubbe, M. A. (2004). "The dispersion science of papermaking," J. Dispersion Sci. Technol. 25(6), 713-732.

Rojas, O. J., and Neuman, R. D. (1999). "Adsorption of polysaccharide wet-end additives in papermaking systems," Colloids Surf. A 155(2-3), 419-432.

Hubbe and Rojas (2008). "Colloidal stability of cellulosics," BioResources 3(4), 1419-1491. 1483 
Rojas, O. J., Neuman, R. D., and Claesson, P. M. (2001). "Desorption of low-chargedensity polyelectrolyte adlayers in aqueous sodium n-dodecyl sulfate solution," Journal of Colloid and Interface Science 237(1), 104-111.

Roman, M., and Gray, D. G. (2005). "Parabolic focal conics in self-assembled solid films of cellulose nanocrystals," Langmuir 21(12), 5555-5561.

Rundlöf, M., Htun, M., Höglund, H., and Wågberg, L. (2000). "Mechanical pulp fines of poor quality - Characteristics and influence of white water," J. Pulp Paper Sci. 26(9), 308-316.

Rutland, M. W., Carambassis, A., Willing, G. A., and Neuman, R. D. (1997). "Surface force measurements between cellulose surfaces using scanning probe microscopy," Colloids and Surfaces A 123, 369-374.

Sack, W. (1976). "Continuous streaming potential measurements on a paper machine," Papier 30(10A), V42-V46.

Sack, W., Storbeck, W., and Winiker, R. (1993). "Ten years experience with continuous zeta potential measurements for paper machine process control," Wochenbl. Papierfabr. 121(19), 803-805.

Saito, T., and Isogai, A. (2007). "Wet strength improvement of TEMPO-oxidized cellulose sheets prepared with cationic polymers," Indust. Eng. Chem. Res. 46(3), 773-780.

Saito, T., Yanagisawa, M., and Isogai, A. (2005). "TEMPO-mediated oxidation of native cellulose: SEC-MALLS analysis of water-soluble and -insoluble fractions in the oxidized products," Cellulose 12(3), 305-315.

Salmén, L., and Berthold, J. (1997). "The swelling ability of pulp fibers," in The Fundamentals of Papermaking Materials, Trans. $11^{\text {th }}$ Fundamental Res. Symp., Cambridge, Sept. 1997, Baker, C. F. (ed.), Pira Intl., Leatherhead, Surrey, UK, Vol. 2, 683-701.

Salmén, L., Kolselth, P., and de Ruvo, A. (1985). "Modeling the softening behavior of wood fibers," J. Pulp Paper Sci. 11(4), J102-J107.

Salmi, J., Österberg, M., and Laine, J. (2007b). "The effect of cationic polyelectrolyte complexes on interactions between cellulose surfaces," Colloids Surf. A 297(1-3), 122-130.

Salmi, J., Österberg, M., Stenius, P., and Laine, J. (2007a). "Surface forces between cellulose surfaces in cationic polyelectrolyte solutions: The effect of polymer molecular weight and charge density," Nordic Pulp Paper Res. J. 22(2), 249-257.

Sandell, L. S., and Luner, P. (1974). "Flocculation of microcrystalline cellulose with cationic ionene polymers," J. Appl. Polymer Sci. 18(7), 2075-2083.

Sanders, N. D. (1994). "The occurrence and importance of polymodal electrophoretic mobility distributions," Dispersion Aggregation, Proc. Eng. Found. Conf. 1992 (Pub. 1994), B. M. Moudgil and P. Somasundaran, Eds., 183-190.

Sanders, N. D., and Schaefer, J. H. (1989). "Zeta potential distributions in pulp/PCC mixtures," Proc. TAPPI 1989 Papermakers Conf., p. 69-74.

Sanders, N. D., and Schaefer, J. H. (1992). "A comparison of zeta potential distributions and colloid titration of papermaking materials: Particle surface charge vs. polyelectrolyte adsorption," Proc. TAPPI 1992 Papermakers Conf., 463-472. 
Sanders, N. D., and Schaefer, J. H. (1994). "Comparison of electrophoretic mobility distributions in synthetic papermaking furnishes with streaming potential and polyelectrolyte titration data," Proc. TAPPI 1994 Papermakers Conf., 629-638.

Sanders, N. D., and Schaefer, J. H. (1995). "Comparing papermaking wet-end chargemeasuring techniques in kraft and groundwood systems," Tappi J. 78(11), 142-150.

Scallan, A. M. (1983). "The effect of acidic groups on the swelling of pulps: A review," Tappi J. 66(11), 73-75.

Scallan, A. M. (1989). “The electrical conductance of pulp suspensions,” Tappi J. 72(11), 157-162.

Scallan, A. M., and Carles, J. E. (1972). "The correlation of the water retention value with the fiber saturation point," Svensk Papperstidn. 75(7), 699-703.

Scallan, A. M., and Tigerström, A. C. (1992). "Swelling and elasticity of the cell walls of pulp fibers,” J. Pulp Paper Sci. 18(5), J188-J193.

Schempp, W. (1988). "Polyelectrolyte titration - zeta potention, a critical comparison," Wochenbl. Papierfabr. 116(20), 869-872.

Sczech, R., and Riegler, H. (2006). "Molecularly smooth cellulose surfaces for adhesion studies," J. Colloid Interface Sci. 301(2), 376-385.

Sennett, P., and Olivier, J. P. (1965). "Colloidal dispersion, electrokinetic effects and the concept of zeta potential," Indus. Eng. Chem. 57(8), 33-50.

Seth, R. S. (2003). "The measurement and significance of fines," Pulp Paper Can. 104(2), 41-44.

Shen, W., and Parker, I. H. (1999). "Surface composition and surface energetics of various eucalypt pulps," Cellulose 6(1), 41-55.

Shirazi, M., van de Ven, T. G. M., and Garnier, G. (2003). “Adsorption of modified starches on pulp fibers," Langmuir 19(26), 10835-10842.

Sieber, R. (1922). "Colloidal chemistry problems of the paper and cellulose industry," Kolloid-Zeitschrift 31(5), 308-310.

Siffert, B., and Metzger, J. M. (1991). "Study of the interaction of titanium-dioxide with cellulose fibers in an aqueous-medium," Colloids Surf. 53(1-2), 79-99.

Sikora, M. D., and Stratton, R. A. (1981). "The shear stability of flocculated colloids," Tappi 64(11), 97-101.

Simončič, B., Černe, L., Tomšič, B., and Orel, B. (2008). "Surface properties of cellulose modified by imidazolidinone," Cellulose 15(1), 47-58.

Sjöberg. J., Kleen, M., Dahlman, O., Agnemo, R., and Sundvall, H. (2004). "Fiber surface composition and its relations to papermaking properties of sodaanthraquinone and kraft pulps," Nordic Pulp Paper Res. J. 19(3), 392-396.

Sjöström, E. (1993). Wood Chemistry. Fundamentals and Applications, $2^{\text {nd }}$ Ed., Academic Press, San Diego.

Smook, G. A. (1992). Handbook for Pulp \& Paper Technologists, $2^{\text {nd }}$ Ed., Angus Wilde Publ., Vancouver.

Solberg, D., and Wågberg, L. (2003a). "On the mechanism of cationic-polyacrylamideinduced flocculation and re-dispersion of a pulp fiber dispersion," Nordic Pulp Paper Res. J. 18(1), 51-55.

Solberg, D., and Wagberg, L. (2003b). "Adsorption and flocculation behavior of cationic polyacrylamide and colloidal silica," Colloids Surf. A 219(1-3), 161-172.

Hubbe and Rojas (2008). "Colloidal stability of cellulosics," BioResources 3(4), 1419-1491. 1485 
Song, J. (2008). "Adsorption of amphoteric and nonionic polymers on model thin films," Ph.D. Thesis, North Carolina State University.

Springer, A. M., and Taggart, T. E. (1986). "Quantitative evaluation of alternative methods of determining total charge," Tappi J. 69(5), 116-121.

St. John, M. R., and Gallagher, T. M. (1992). "Evaluation of the charge state of papermachine systems using the charge titration method," Proc. 1992 TAPPI Papermakers Conf., TAPPI Press, Atlanta, 479-502.

Stana-Kleinschek, K., Kreze, T., Ribitsch, V., and Strnad, S. (2001). "Reactivity and electrokinetical properties of different types of regenerated cellulose fibres," Colloids Surf. A 195(1-3), 275-284.

Stana-Kleinschek, K., Pohar, C., and Ribitsch, V. (1995). "Adsorption of whitening agents on cellulose fibers - Monitored by streaming potential measurements, calorimetry and fluorescence," Colloid Polymer Sci. 273(12), 1174-1178.

Stana-Kleinschek, K., and Ribitsch, V. (1998). "Electrokinetic properties of processed cellulose fibers," Colloids Surf. A 140(1-3), 127-138.

Stana-Kleinschek, K., Ribitsch, V., Kreze, T., and Fras, L. (2002). "Determination of the adsorption character of cellulose fibres using surface tension and surface charge," Mater. Res. Innov. 6(1), 13-18.

Stana-Kleinschek, K., Strnad, S., and Ribitsch, V. (1999). "Surface characterization and adsorption abilities of cellulose fibers," Polymer Eng. Sci. 39(8), 1412-1424.

Stark, H., and Eichinger, R. (1989). "Effect of zeta potential on the adsorption tendency and degree of organization of fiber suspensions," Wochenbl. Papeirfabr. 117(11/12), 521-524.

Stenius, P., and Laine, J. (1994). "Studies of cellulose surfaces by titration and ESCA," Appl. Surf. Sci. 75, 213-219.

Stiernstedt, J., Brumer, H., Zhou, Q., Teeri, T. T., and Rutland, M. W. (2006a). "Friction between cellulose surfaces and effect of xyloglucan adsorption," Biomacromol. 7(7), 2147-2153.

Stiernstedt, J., Nordgren, N., Wågberg, L., Brumer, H, Gray, D. G., and Rutland, M. W. (2006b). "Friction and forces between cellulose model surfaces: A comparison," J. Colloid Interface Sci. 303(1), 117-123.

Stone, J. E., and Scallan, A. M. (1968). "A structural model for the cell wall of waterswollen wood pulp fibers based on their accessibility to macromolecules," Cellulose Chem. Technol. 2(3), 343-358.

Stratton, R. A. (1983). "Effect of agitation on polymer additives," Tappi J. 66(3), 141144.

Strazdins, E. (1972). "Factors affecting the electrokinetic properties of cellulose fibers," Tappi 55(12), 1691-1695.

Strazdins, E. (1977). "Optimization of the papermaking process by electrophoresis," Tappi 60(7), 113-114.

Strazdins, E. (1980). "New approaches towards optimizing dry strength of waste paper containing stock furnishes," Papier 34(10A), V49-V55.

Strazdins, E. (1989). "Theoretical and practical aspects of alum use in papermaking," Nordic Pulp Paper Res. J. 4(2), 128-134. 
Strazdins, E. (1994). "Application of electrokinetics in optimization of wet-end chemistry," in Wet-Strength Resins and the Application, L L. Chan, ed., TAPPI Press, Atlanta, 63-83.

Strazdins, E. (1995). "Critical issues in applying electrokinetics to papermaking," Tappi J. 78(8), 115-119.

Ström, G., and Kunnas, A. (1991). "The effect of cationic polymers on the water retention value of various pulps,” Nordic Pulp Paper Res. J. 6(1), 12-19.

Sundberg, K., and Holmbom, B. (1997). "Destabilization of colloidal wood resin caused by cellulosic fibers in thermomechanical pulp suspensions," Paperi Puu 79(1), 50-54.

Sundberg, K. E., Sundberg, A. C., Thornton, J. W., and Holmbom, B. R. (1998). "Pectic acids in the production of wood-containing paper," Tappi J. 81(7), 131-136.

Suurnäkki, A., Heijnesson, A., Buchert, J., Viikari, L., and Westemark, U. (1996). "Chemical characterization of the surface layers of unbleached pine and birch kraft pulp fibers," J. Pulp Paper Sci. 22(2), J43-J47.

Swerin, A., Glad-Nordmark, G., and Ödberg, L. (1997b). "Adsorption and flocculation in suspensions by two cationic polymers - Simultaneous and sequential addition," $J$. Pulp Paper Sci. 23(8), J389-J393.

Swerin, A., and Ödberg, L. (1993). "Flocculation and floc strength in suspensions flocculated by retention aids," Nordic Pulp Paper Res. J. 8(1), 141-147.

Swerin, A., and Ödberg, L. (1997). "Some aspects of retention aids," in The Fundamentals of Papermaking Materials, C. F. Baker (ed.), Pira Intl., Leatherhead, UK, 265-350.

Swerin, A., Ödberg, L., and Lindström, T. (1990). "Deswelling of hardwood kraft pulp fibers by cationic polymers. The effect on wet pressing and sheet properties," Nordic Pulp Paper Res. J. 5(4), 188-196.

Swerin, A., Ödberg, L., and Wågberg, L. (1996b). "An extended model for the estimation of flocculation efficiency factors in multicomponent flocculation systems," Colloids Surf. 113(1-2), 25-38.

Swerin, A., Powell, R. L., and Ödberg, L. (1992). "Linear and nonlinear dynamic viscosity of pulp suspensions,” Nordic Pulp Paper Res. J. 7(3), 126-132.

Swerin, A., Risinger, G., and Odberg, L. (1997a). "Flocculation in suspensions of microcrystalline cellulose by microparticle retention aid systems," J. Pulp Paper Sci. 23(8), J374-J381.

Tam Doo, P. A., Kerekes, R. J., and Pelton, R. H. (1984). "Estimates of maximum hydrodynamic shear stresses on fiber surfaces in papermaking," J. Pulp Paper Sci. 10(7), J80-J88.

Tammelin, T., Johnsen, I. A., Österberg, M., Stenius, P., and Laine, J. (2007). “Adsorption of colloidal extractives and dissolved hemicelluloses on thermomechanical pulp fiber components studied by QCM-D," Nordic Pulp Paper Res. J. 22(1), 93-101.

Tammelin, T., Österberg, M., Johansson, L-S., and Laine, J. (2006). "Preparation of lignin and extractive model surfaces using spincoating technique - Application for QCM-D studies," Nordic Pulp Paper Research Journal 21(4), 444-450.

Tammelin, T., Saarinen, T., Österberg, M., and Laine, J. (2005). "Preparation of Langmuir/Blodgett cellulose surfaces by using horizontal dipping procedure. 
Application for polyelectrolyte adsorption studies performed with QCM-D," Cellulose 13(5), 519-535.

Tanaka, H. (1998). "Zeta potential: Paper," in Ohshima, H., and Furusawa, K. (eds.), Electrical Phenomena at Interfaces: Fundamentals, Measurements, and Applications, $2^{\text {nd }}$ Ed., Surfactant Science Ser. 76, Marcel Dekker, New York, Ch. 19, 389-404.

Tanaka, H., Swerin, A., and Ödberg, L. (1993). "Transfer of cationic retention aid from fibers to fine particles and cleavage of polymer chains under wet-end papermaking conditions," Tappi J. 76(5), 157-163.

Tanaka, H., Ueda, I., Ichiura, H., and Kitaoka, T. (2000). "Determining cationic demand of suspensions using chromo-PDADMAC," Proc. Intl. Symp. Environ. Friendly Emerging Technol. Sustainable Pulp Paper Ind., TFRI Extension Ser. 115, 68-71.

Terayama, H. (1952). "Method of colloid titration (A new titration between polymer ions)," J. Polym. Sci. 8(2), 243-253.

Theander, K., Pugh, R. J., and Rutland, M. W. (2005). "Friction force measurements relevant to de-inking by means of atomic force microscope," J. Colloid Interface Sci. 291(2), 361-368.

Thiele, B., and Kopp, J. W. (1997). "Ladundsbilanzen von Papiermachinen-Systemen ein Weg zur Prozeßoptimierung," Wochbl. Papierfabr. 125(11/12), 542-556.

Thode, E., and Ingmanson, W. L. (1959). "Factors contributing to the strength of a sheet of paper. I. External specific surface and swollen specific volume," Tappi 42(1), 7483.

Tiberg, F., Daicic, J., and Fröberg, J. (2001). "Surface chemistry of paper," in Holmberg, K. (ed.), Handbook of Applied Surface and Colloid Chemistry, Wiley, New York, Ch. 7, 123-173.

Torn, L. H., Koopal, L. K., de Keizer, A., and Lyklema, J. (2005). “Adsorption of nonionic surfactants on cellulose surfaces: Adsorbed amounts and kinetics," Langmuir 21(17), 7768-7775.

Touchette, R. V., and Jenness, L. C. (1960). "Effect of surface active agents on drainage and physical strength properties of sulfite pulp," Tappi 43(5), 484-489.

Tripattharanan, T., Hubbe, M.A., Venditti, R.A., and Heitmann, J.A. (2004a). "Effect of idealized flow conditions on retention aid performance. 1. Cationic acrylamide copolymer," Appita J. 57(5), 404-410.

Tripattharanan, T., Hubbe, M. A., Heitmann, J. A., and Venditti, R. A. (2004b). "Effect of idealized flow conditions on retention aid performance. Part 2: Polymer bridging, charged patches, and charge neutralization," Appita J. 57(6), 448-454.

Turon, X., Rojas, O. J., and Deinhammer, R. S. (2008). "Enzymatic kinetics of cellulose hydrolysis: A QCM-D study," Langmuir 24(8), 3880-3887.

Tze, W. T. Y., Gardner, D. J., Tripp, C. P., and O'Neill, S. C. (2006). “Cellulose fiber/polymer adhesion: Effects of fiber/matrix interfacial chemistry on the micromechanics of the interphase," J. Adhesion Sci. Technol. 20(15), 1649-1668.

Unbehend, J. E. (1976). "Mechanisms of 'soft' and 'hard' floc formation in dynamic retention measurement," Tappi 59(10), 74-77.

van de Steeg, T. G. M., Cohen Stuart, M. A., de Keizer, A., and Bijsterbosch, B. H. (1992). "Polyelectrolyte adsorption: A subtle balance of forces," Langmuir 8(10), 2538-2546. 
van de Steeg, H. G. M., de Keizer, A., Cohen Stuart, M. A., and Bijsterbosch, B. H. (1993a). "Adsorption of cationic amylopectin on microcrystalline cellulose," Colloids Surf. A 70(1), 77-89.

van de Steeg, H. G. M., de Keizer, A., Cohen Stuart, M. A., and Bijsterbosch, B. H. (1993b). "Adsorption of cationic potato starch on microcrystalline cellulose," Colloids Surf. A 70(1), 91-103.

van de Steeg, H. G. M., de Keizer, A., Cohen Stuart, M. A., and Bijsterbosch, B. H. (1993c). "Adsorption of cationic starches on microcrystalline cellulose," Nordic Pulp Paper Res. J. 8(1), 34-40.

van de Ven, T. G. M. (1999). "Effect of fibre conductivity on zeta potential measurements of pulp fibres," J. Pulp Paper Sci. 25(7), 243-245.

van de Ven, T. G. M. (2000). "A model for the adsorption of polyelectrolytes on pulp fibers: Relation between fiber structure and polyelectrolyte properties," Nordic Pulp Paper Res. J. 15(5), 494-501.

van de Ven, T. G. M., and Alince, B. (1996). "Association-induced polymer bridging: New insights into the reteniton of fillers with PEO," J. Pulp Paper Sci. 22(7), J257J263.

van de Ven, T. G. M., and Mason, S. G. (1981). "Comparison of hydrodynamic and colloidal forces in paper machine headboxes," Tappi 64(9), 171-175.

van de Ven, T. G. M., Saint-Cry, K., and Allix, M. (2007). "Adsorption of toluidine blue on pulp fibers," Colloids Surf. A. 294(1-3), 1-7.

Vanderhoek, N. (1994). "Optimizing paper machine performance through electrokinetic measurement," Appita J. 47(5), 397-401.

van der Waals, J. D. (1910). "The equation of state for gases and liquids," Nobel Lecture, December 12.

Vanerek, A., and van de Ven, T. G. M. (2006). "Coacervate complex formation between cationic polyacrylamide and anionic sulfonated kraft lignin," Colloids Surf. A 273(12), 55-62.

Varoqui, R. (1982). "Effect of polymer adsorption on the electrophoretic mobility of cellulose," Nouv. J. Chimie 6(4), 187-189.

Verwey, E. J. W., and Overbeek, J. Th. G. (1948). Theory of the Stability of Lyophobic Colloids, Elsevier, New York.

Visser, J. (1972). "On Hamaker constants: A comparison between Hamaker constants and Lifshitz-van der Waals constants," Adv. Colloid Interface Sci. 3(4), 331-364.

Visser, J. (1995). "Particle adhesion and removal: A review," Particulate Sci. Technol. 13(3-4), 169-196.

Wågberg, L. (2000). "Polyelectrolyte adsorption onto cellulose fibers - A review," Nordic Pulp Paper Res. J. 15(5), 586-597.

Wågberg, L., and Åsell, I. (1995). "The action of cationic polymers in the fixation of dissolved and colloidal substances. 2," Colloids Surf. A 104(2-3), 169-184.

Wågberg, L., Forsberg, S., Johansson, A., and Juntti, P. (2002). "Engineering of fiber surface properties by application of polyelectrolyte multilayer concept. Part 1. Modification of paper strength," J. Pulp Paper Sci. 28(7), 222-228. 
Wågberg, L., and Kolar, K. (1996). "Adsorption of cationic starch on fibres from mechanical pulps,” Berichte Bunsen-Geselsch. Phys. Chem. Chem. Phys. 100(6), 984993.

Wågberg, L., and Ödberg, L. (1989). "Polymer adsorption on cellulosic fibers," Nordic Pulp Paper Res. J. 4(2), 135-140.

Wågberg, L., Ödberg, L., and Glad-Nordmark, G. (1989). "Charge determination of porous substrates by polyelectrolyte adsorption. Part 1. Carboxymethylated, bleached cellulosic fibers," Nordic Pulp Paper Res. J. 4(2), 71-76.

Walkush, J. C., and Williams, D. G. (1974). "The coagulation of cellulose pulp fibers and fines as a mechanism of retention," Tappi 57(1), 112-116.

Wang, F., and Hubbe, M. A. (2001). "Development and evaluation of an automated streaming potential measurement device," Colloids Surf. A 194(1-3), 221-232.

Wang, F., and Hubbe, M. A. (2002). "Charge properties of fibers in the paper mill environment. Part 1: Effect of electrical conductivity,” J. Pulp Paper Sci. 28(10), 347-353.

Wang, W., and Chase, G. G. (2004). "Effects of $\mathrm{pH}$ and alum concentrations on $\mathrm{TiO}_{2}$ capture on cellulose during co-filtration," J. Chinese Inst. Chem. Eng. 35(1), 5-16.

Wang, X. H. (2002). "Surface and colloid chemistry of papermaking," Encyc. Surface Colloid Sci. 4, 4936-4961.

Watanabe, A., Morita, S., and Ozaki, Y. (2006). "A study on water adsorption onto microcrystalline cellulose by near-infrared spectroscopy with two-dimensional correlation spectroscopy and principal component analysis," Applied Spectroscopy 60(9), 1054-1061.

Wege, H. A., Kim, S., Paunov, V. N., Zhong, Q., and Velev, O. D. (2008). "Long-term stabilization of foams and emulsions with in-situ formed microparticles from hydrophobic cellulose," Langmuir 24(17), 9245-9253.

Weise, U., Maloney, T., and Paulapuro, H. (1996). "Quantification of water in different states of interaction with wood pulp fibers," Cellulose 3(4), 189-202.

Werner, C., and Jacobasch, H. J. (1996). "Surface characterization of hemodialysis membranes based on electrokinetic measurements," Macromol. Symp. 103, 43-54.

Werner, C., Konig, U., Augsburg, A., Arnhold, C., Korber, H., Zimmermann, R., and Jacobasch, H. J. (1999). "Electrokinetic surface characterization of biomedical polymers - A survey," Colloids Surf. A 159(2-3), 519-529.

Whipple, W. L., and Maltesh, C. (2002). "Adsorption of cationic flocculants to paper slurries," J. Colloid Interface Sci. 256(1), 33-40.

Wiegel, F. W. (1977). "Adsorption of a macromolecules to a charged surface," J. Phys. A., Math. Gen. 10, 299-303.

Wiese, G., and Healy, T. W. (1970). "Effect of particle size on colloid stability," Trans. Faraday Soc. 566, 490-499.

Willing, G. A., Ibrahim, T. H., Etzler, F. M., and Neuman, R. D. (2000). "New approach to the study of particle-surface adhesion using atomic force microscopy," Journal Colloid Interface Science 226(1), 185-188.

Willing, G. A., and Neuman, R. D. (2002). "Analysis of asperity-asperity adhesion forces utilizing statistical analysis techniques and the force selectivity of the scanning probe microscope," Langmuir 18(22), 8370-8374. 
Winters, J. C. (1998). "Introduction to the electrokinetics of papermaking," in J. M. Gess (ed.), Retention of Fines and Fillers during Papermaking, TAPPI Press, Atlanta, Ch. 3, 29-50.

Wu, M. R., Paris, J., and van de Ven, T. G. M. (2007). "Flocculation of papermaking fines by poly(ethylene oxide) and various cofactors: Effects of PEO entanglement, salt and fines properties," Colloids Surf. A 303(3), 211-218.

Xiao, H., Pelton, R., and Hamielec, A. (1996). "Retention mechanisms for twocomponent systems based on phenolic resins and PEO or new PEO-copolymer retention aids," J. Pulp Paper Sci. 22(12), J475-J485.

Yaginuma, Y., and Kijima, T. (2006). "Effect of $\mathrm{pH}$ on rheological properties of microcrystalline cellulose dispersions," J. Dispersion Sci. Technol. 27(3), 365-370.

Yoon, S. H. (2007). "Analysis on adsorption equilibrium of polyamide-epichlorhydrin in aqueous fibrous suspension by colloid titration," J. Industrial Eng. Chem. 13(3), 345351.

Yoon, D.-H., and Park, J.-M. (2005). "Fibers flocculation and physical property changes of paper depending on cationic polymer addition," Palpu Chongi Gisul 37(1), 10-16.

Zauscher, S., and Klingenberg, D. J. (2000a). "Normal forces between cellulose surfaces measured with colloidal probe microscopy," J. Colloid Interface Sci. 229(2), 497510.

Zauscher, S., and Klingenberg, D. J. (2000b). "Surface and friction forces between cellulose surfaces measured with colloidal probe microscopy," Nordic Pulp Paper Res. J. 15(5), 459-468.

Zauscher, S., and Klingenberg, D. J. (2001). "Friction between cellulose surfaces measured with colloidal probe microscopy," Colloids Surf. A 178(1-3), 213-229.

Zemljic, L. F., Persin, Z., Stenius, P., and Kleinschek, K. S. (2008). "Carboxyl groups in pre-treated regenerated cellulose fibres," Cellulose 15(5), 681-690.

Zhang, J., Pelton, R. H., Wågberg, L., and Rundlöf, M. (2000). "The effect of charge density and hydrophobic modification on dextran-based paper strength enhancing polymers," Nordic Pulp Paper Res. J. 15(5), 440-445.

Zheng, Z., McDonald, J., Khillan, R., Shutava, T., Grozdits, G., and Lvov, Y. (2006). "Layer-by-layer nanocoating of lignocellulose fibers for enhanced paper properties," J. Nanoscience Nanotechnology 6, 624-632.

Zhou, Q., Rutland, M. W., Teeri, T. T., and Brumer, H. (2007). "Xyloglucan in cellulose modification," Cellulose 14(6), 625-641. 